University of Louisville

ThinkIR: The University of Louisville's Institutional Repository

Electronic Theses and Dissertations

$12-2020$

\title{
Fostering African American female students' sense of belonging: a digital storytelling participatory action research approach.
}

Rajwinder Kaur

University of Louisville

Follow this and additional works at: https://ir.library.louisville.edu/etd

Part of the Junior High, Intermediate, Middle School Education and Teaching Commons, and the Urban Education Commons

\section{Recommended Citation}

Kaur, Rajwinder, "Fostering African American female students' sense of belonging: a digital storytelling participatory action research approach." (2020). Electronic Theses and Dissertations. Paper 3548.

https://doi.org/10.18297/etd/3548

This Doctoral Dissertation is brought to you for free and open access by ThinkIR: The University of Louisville's Institutional Repository. It has been accepted for inclusion in Electronic Theses and Dissertations by an authorized administrator of ThinkIR: The University of Louisville's Institutional Repository. This title appears here courtesy of the author, who has retained all other copyrights. For more information, please contact thinkir@louisville.edu. 


\title{
FOSTERING AFRICAN AMERICAN FEMALE STUDENTS' SENSE OF BELONGING: A DIGITAL STORYTELLING PARTICIPATORY ACTION RESEARCH APPROACH
}

\author{
By \\ Rajwinder Kaur \\ B.A., Middlebury College, 2011 \\ M.A.T., University of Louisville, 2013 \\ Ed.S. Bellarmine University, 2015
}

\begin{abstract}
A Dissertation
Submitted to the Faculty of the

College of Education and Human Development of the University of Louisville In Partial Fulfillment of the Requirements

for the Degree of

Doctor of Education

In Educational Leadership and Organizational Development
\end{abstract}

Department of Educational Leadership, Evaluation and Organizational Development University of Louisville

Louisville, Kentucky

December 2020 
Copyright 2020 by Rajwinder Kaur

All Rights Reserved 

FOSTERING AFRICAN AMERICAN FEMALE STUDENTS' SENSE OF BELONGING: A DIGITAL STORYTELLING PARTICIPATORY ACTION RESEARCH APPROACH

\author{
By \\ Rajwinder Kaur \\ B.A., Middlebury College, 2011 \\ M.A.T., University of Louisville, 2013 \\ Ed.S. Bellarmine University, 2015 \\ A Dissertation Approved on
}

November 9, 2020

By the following Dissertation Committee:

Dr. Mary Brydon-Miller, Dissertation (Chair)

Harrie Buecker

Tomarra Adams

Ishwanzya Rivers 


\section{ACKNOWLEDGEMENTS}

First and foremost, I would like to acknowledge each of the girls in this study: Diana, Iris, Rhea, Athena, Minerva, and Selene. Thank you for sharing part of your summer with me and for your stories. You are so brilliant and beautiful. I promise to continue to work to create schools that are fitting of your brilliance and beauty.

I would like to thank my dissertation committee for their belief in me and this dissertation study. My committee chair, Dr. Mary Brydon-Miller, thank you for allowing me the space to pursue my passion and for pushing me. You have been with me every step of this journey and words cannot express my appreciation. Your guidance has truly changed me. Thank you, Dr. Rivers, for introducing me to the literature and research on Black girls. Dr. Adams, for making sure I grounded this research into what middle school students want. Dr. Buecker, thank you for your constant support throughout this program. I have enjoyed learning from you so much over these three years on leading schools effectively and conducting research. Thank you all for your faith in me.

I would like to thank other people who have been integral in this research and my life. I want to give a big shout out to my dear friends I began teaching with in 2011 and Block 20. You are all so fabulous and fun. I know you will continue to do amazing things in schools and school districts. Keep fighting for our kids. I want to acknowledge my Johnson Family and Dr. April Brooks, our school's principal. Thank you for your unwavering love, faith, and trust in me. Let us continue to do work that honors the legacy of our school's namesake, Lyman T. Johnson. With a team like ours, there is nothing we cannot accomplish. \#JohnsonOnTheRise. I want to acknowledge my family and husband for leaving their homes to come to a country that was and still is so unfamiliar, unkind, 
and foreign at times. Let us continue to create a space here for our future generations to find love, warmth, and live in Chardi Kala.

Finally, this dissertation was written in the spirit of Sarbat Da Bhala. In Sikh philosophy, Sarbat Da Bhala asks for the well-being and prosperity of everyone. As an educator, I believe it is my duty to create an environment that promotes each student's success - every single one. Though I do not share the racial identity and experiences of the girls in this study, I will continue to listen and learn so that I can support my students. With that, this research has only begun. Let us structure our schools and classrooms in the essence of Sarbat Da Bhala, where all students prosper. 


\begin{abstract}
FOSTERING AFRICAN AMERICAN FEMALE STUDENTS' SENSE OF BELONGING: A DIGITAL STORYTELLING PARTICIPATORY ACTION RESEARCH APPROACH
\end{abstract}

\author{
Rajwinder Kaur
}

November 9, 2020

This Participatory Action Research dissertation discovers what fosters or diminishes school sense of belonging for African American female students. This is achieved by foregrounding the voices of the individual participants and the collective voice of those within this study. Both Critical Race Theory and Black Feminist Thought guide this dissertation study to ensure the intersectionality between race and gender is addressed. Data for this study was collected during five workshop sessions, where participants created digital stories on their sense of belonging. The findings revealed the importance of students' racial identity, family, peer relationships, fitting in, safety, and being seen/heard by teachers for fostering belonging. Acts such as misrepresentation of one's identity or ignoring students diminish sense of belonging. This dissertation study addresses the lack of scholarly research around African American female students and their sense of belonging in schools. Future research must continue to counter African American females' invisibility and conduct research alongside them to truly impact outcomes. 


\section{TABLE OF CONTENTS}

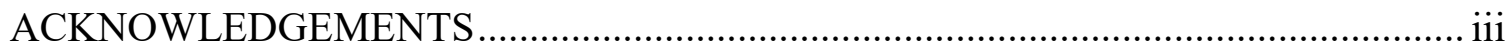

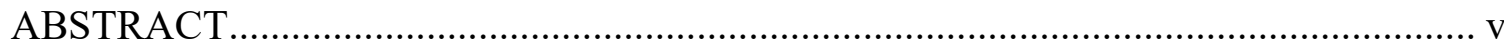

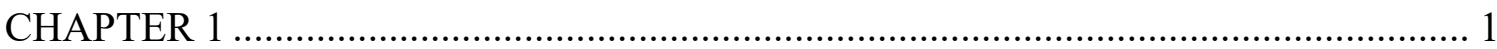

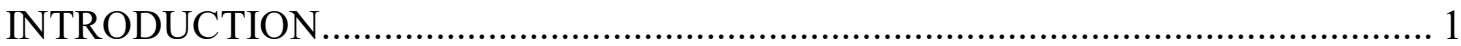

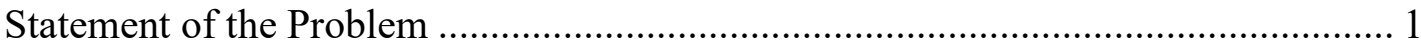

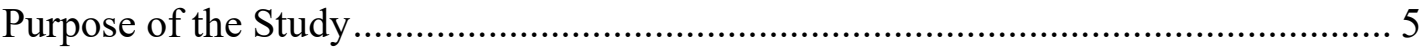

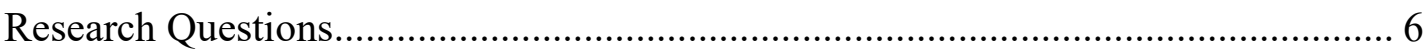

Theoretical Frameworks: Critical Race Theory and Black Feminist Thought............. 6

Methodological Rationale.............................................................................. 7

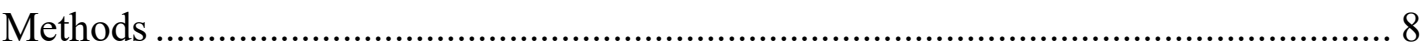

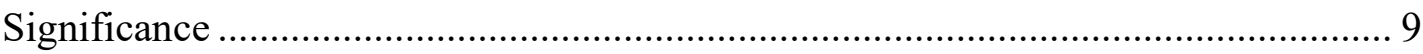

Definition of Key Terms....................................................................................... 10

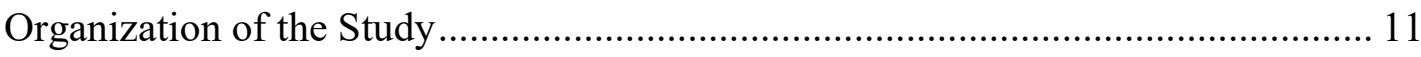

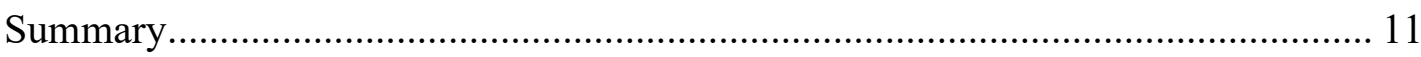

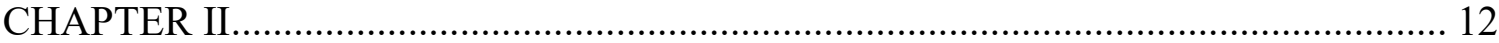

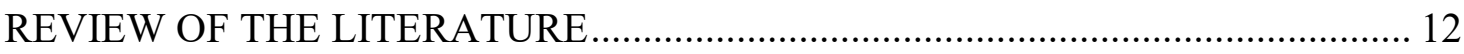

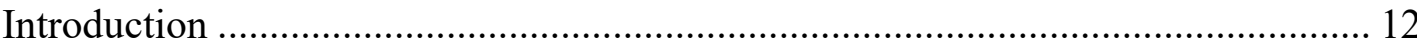

Sense of Belonging and African American Female Students..................................... 16

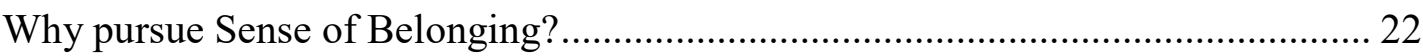

Getting There: How Can We Foster Sense of Belonging? ....................................... 27

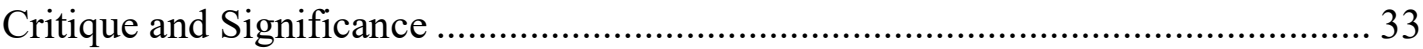

Critical Race Theory, Black Feminist Thought, and Sense of Belonging.................. 36

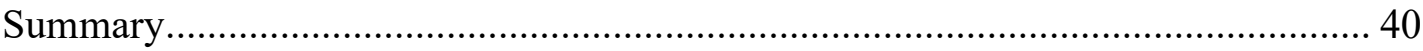

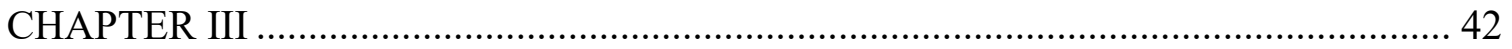




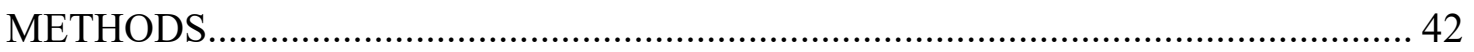

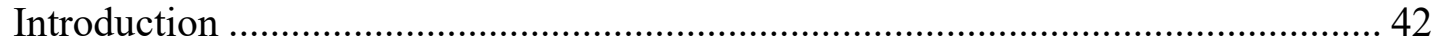

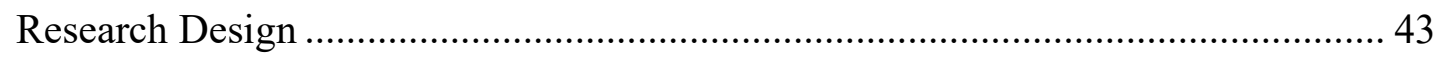

Data Collection and Instrumentation Procedures ...................................................... 48

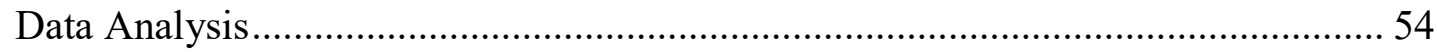

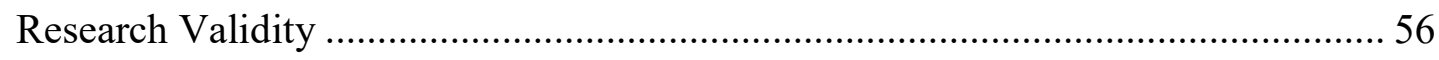

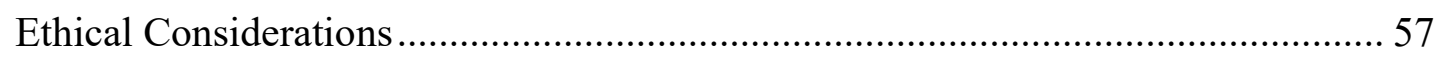

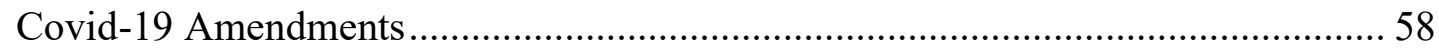

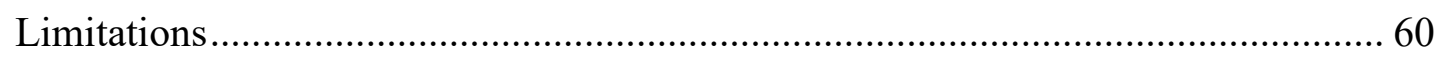

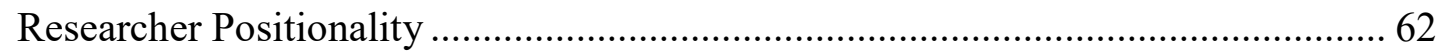

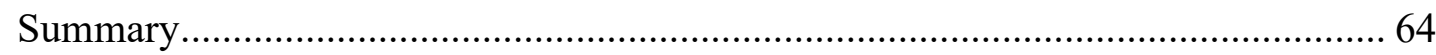

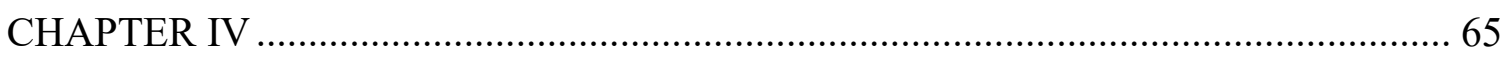

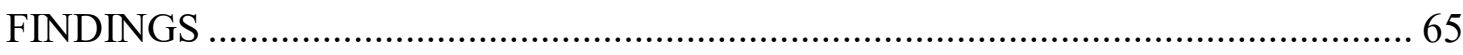

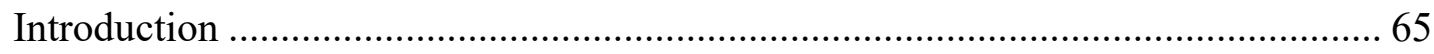

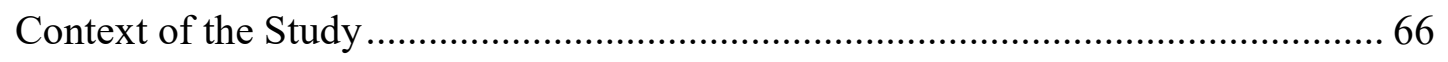

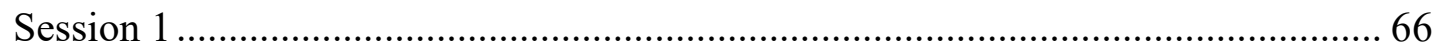

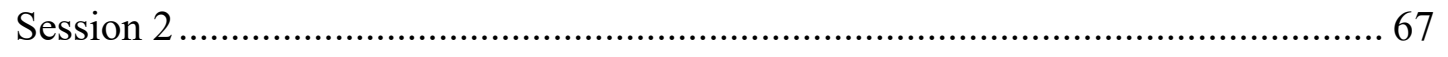

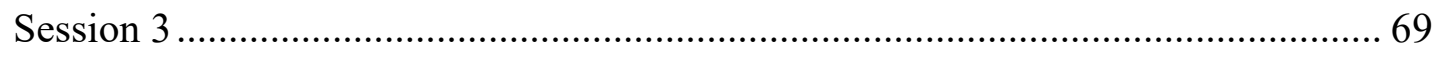

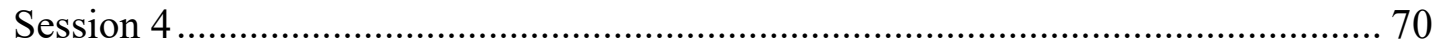

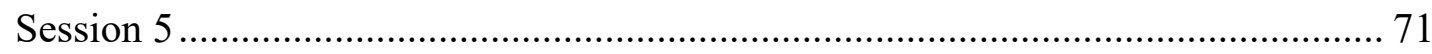

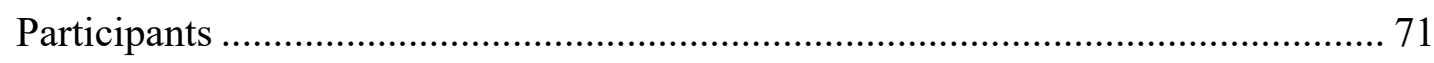

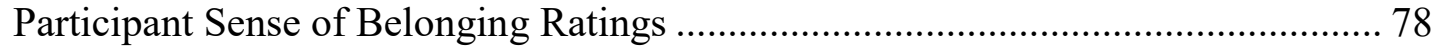

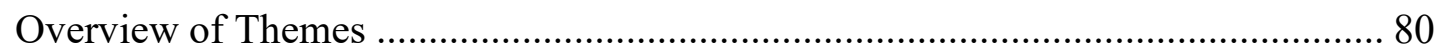

Theme 1 Honoring Lived Experiences................................................................... 80

Theme 2 Peer Relationships ................................................................................ 84

Theme 3 Fitting In, But Embracing Differences .................................................... 88

Theme 4 Being Seen and Heard by Teachers ......................................................... 91

Participant Input on Themes ............................................................................... 94

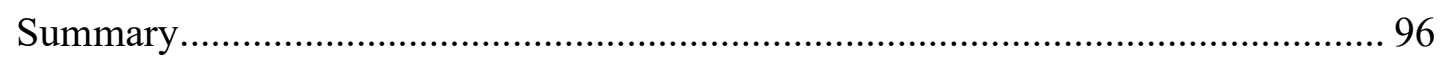

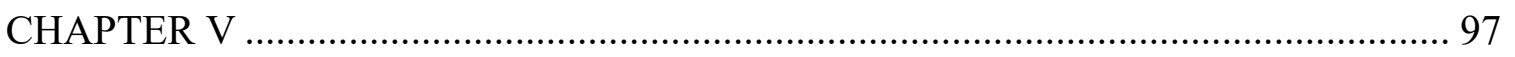




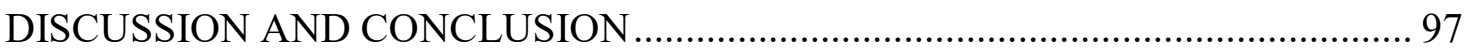

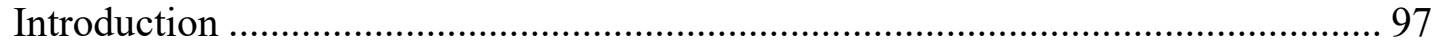

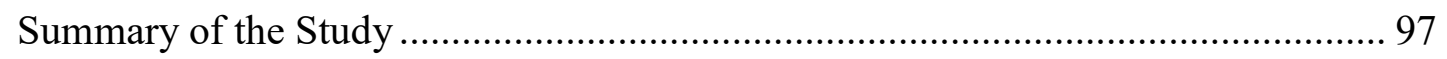

Discussion of Findings ........................................................................................ 98

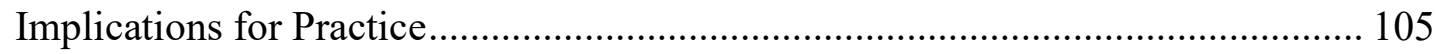

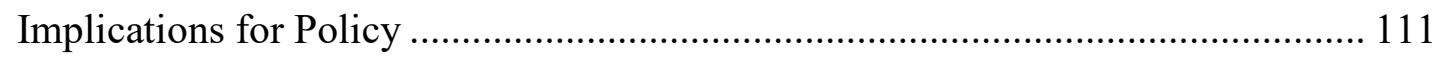

Recommendations for Future Research............................................................... 115

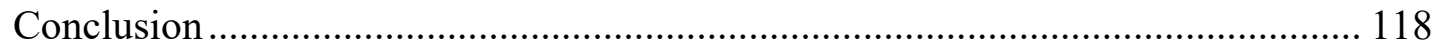

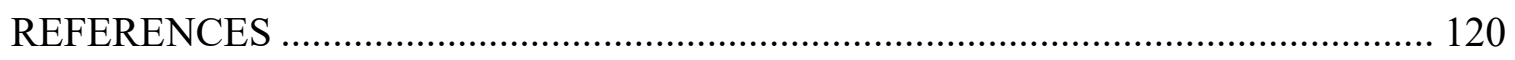

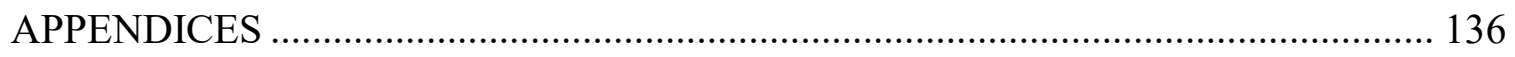

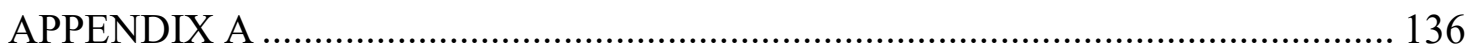

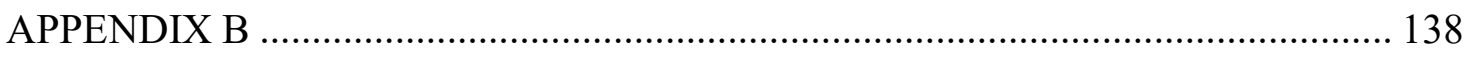

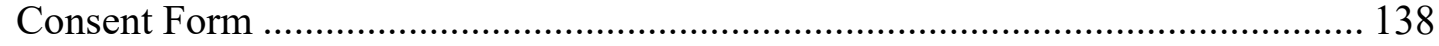

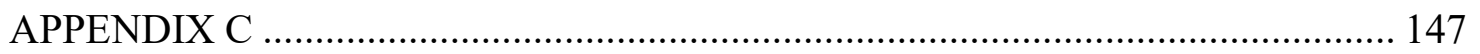

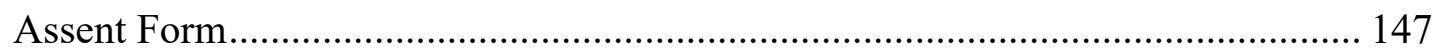

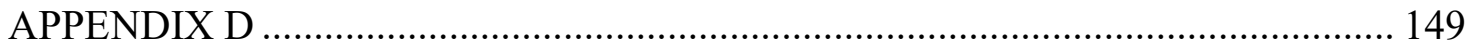

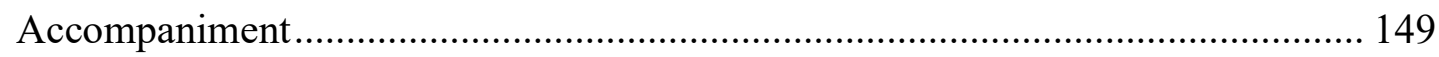

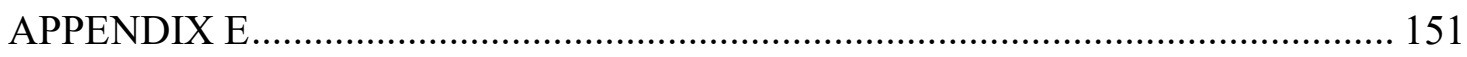

Recruitment Flyer …………………………………....................................... 151

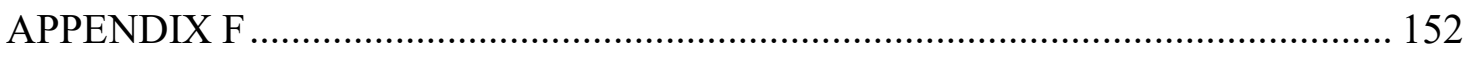

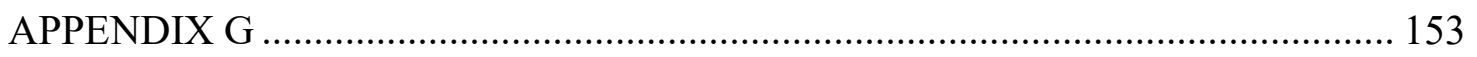

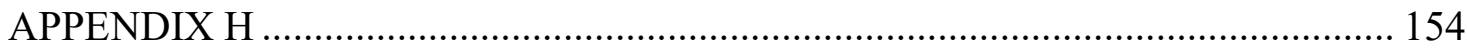

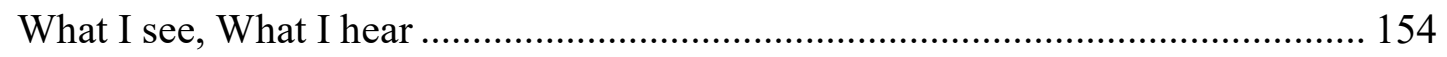

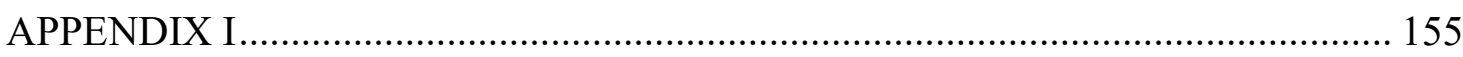

Semi-Structured Reflective Questions................................................................. 155

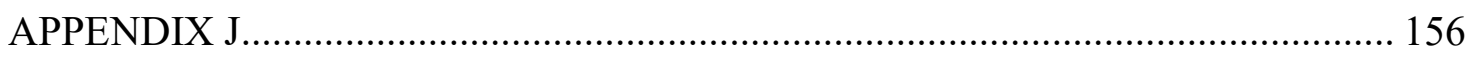

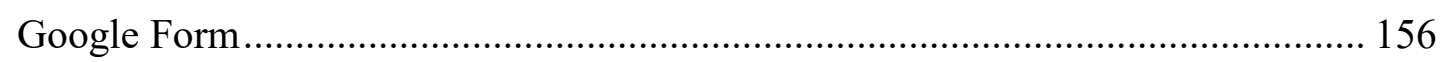

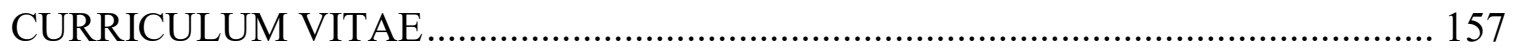




\section{CHAPTER 1}

\section{INTRODUCTION}

\section{Statement of the Problem}

The need to educate all students has been reiterated in educational policies and reforms over the years. No Child Left Behind's (NCLB, 2001) Statement of Purpose reads, "The purpose of this title is to ensure that all children have a fair, equal, and significant opportunity to obtain a high-quality education and reach, at a minimum, proficiency on challenging state academic achievement standards and state academic assessments" ("Sec. 1001.," para. 1). Later in the policy, there are references to closing the achievement gap between minority and non-minority students, high and low performing students, and between advantaged and disadvantaged students. Similarly, the succeeding policy, Every Student Succeeds Act (2015), addressed equitable access to effective teachers, equitable funding, and the disparities between minority, low-income students when compared to their non-minority and economically advantaged peers.

Despite these efforts, many students are still not provided with equal opportunities and treatment in our schools. Jefferson County Public Schools (JCPS) established a Racial Equity Plan to formulate a systematic approach to ensure, "that Students of Color have equitable learning opportunities, experiences, and outcomes," (JCPS, 2018c, p.1). The very necessity and creation of this plan informs us that there are inequities within 
schools across the district and that every child is not provided with equitable opportunities. Serving all students in theory, policies, and reforms has not translated to all students in practice.

As early as preschool, educational disparities are prevalent between African American students and their peers. According to the U.S. Department of Education, Office of Civil Rights (2014), African American students account for $18 \%$ of the preschool population, but $48 \%$ of the preschool students who receive more than one outof-school suspension. Kindergarten through grade 12 data shows African American students are three times more likely to be expelled or suspended than their White peer (OCR, 2014) Similar disparities exist within academic results. Hussar et al. (2020) report assessment indicators of student performance at fourth, eighth, and 12th-grade levels. These indicators show that African American students are among the lowest-performing demographic groups in 2015 and 2019 in both reading and math. Additionally, African American students are more likely to attend schools with limited access to resources and certified teachers (National Association of the Advancement of Colored People [NAACP] Legal Defense and Education Fund \& National Women's Law Center [NWLC], 2014).

Still, within data, reports, and briefs on African American students, there is a lack of awareness around African American female students (Andrews, Brown, Castro, \& IdDeen, 2019). Ricks (2014) notes a substantial focus on Black males, their dropout rates, overall achievement, and graduation rates, but Black girls and their experiences are ignored. When examining African American female students' experiences in schools, it is evident there is a lack of equal opportunity. African American girls face "gendered 
racism" (Ricks, 2014, p.11), where both race and gender impact their educational outcomes. According to NAACP and NWLC (2014), African American girls are stereotyped as aggressive or angry, leading to lower academic expectations and greater disciplining. African American female students are less likely to be recommended for advanced placement courses. Chavous and Cogburn (2007) argue that African American girls are "at-risk" (p. 24) due to their historical and social oppression, but continue to show resilience. Finally, African American girls are the least likely demographic group to feel like they belong in school (Crenshaw, Nanda, \& Ocen, 2015).

Goodenow (1993) argues that belonging, feeling personally valued and welcomed, is critical for at-risk students. After all, Goodenow connects a lack of belonging to both lower interest and lower engagement to school and vice versa. Consider how one could be interested and engaged when they are not respected, valued, or welcomed. Student sense of belonging to school is a facet of education in which the discrepancy between African American girls and their peers is also visible. Each year, JCPS (2018a) measures sense of belonging through sense of belonging statements on the district's Comprehensive Student Survey (CSS). African American female students' sense of belonging in kindergarten to 12th-grade settings deserves more attention in research and among education practitioners. Jefferson County Public Schools (JCPS, 2018b) district-level sense of belonging data shows African American female students have the lowest sense of belonging in elementary, middle, and high school when compared to other race and gender subgroups.

Table 1

JCPS Student Sense of Belonging 2018-2019 


\begin{tabular}{lccccccc}
\hline \multicolumn{2}{c}{} & \multicolumn{2}{c}{ Black } & \multicolumn{2}{c}{ White } & \multicolumn{2}{c}{ Hispanic } \\
\hline \multicolumn{1}{c}{ Grade Level } & Female & Male & Female & Male & Female & Male \\
Elementary & $86.6 \%$ & $87 \%$ & $91.2 \%$ & $90.6 \%$ & $92.4 \% *$ & $91.4 \% *$ \\
Middle & $73.9 \% *$ & $80 \% *$ & $75.2 \%$ & $79.8 \% *$ & $79.2 \%$ & $80.7 \% *$ \\
High & $68.7 \% *$ & $74.9 \% *$ & $71.7 \% *$ & $76 \% *$ & $73.8 \%$ & $74.6 \% *$ \\
\hline
\end{tabular}

Note. Adapted from "School Culture and Climate: Student Voice," by Jefferson County Public Schools, 2018b, Envision Equity Report.

*Indicates an increase in percentages from the previous year, 2018-2019.

The asterisk indicates where sense of belonging percentages increased from the previous year's results. While this data shows that sense of belonging for African American females at the middle and high school level has increased from the previous year, African American female students still maintain the lowest belonging at each level. At each level, African American female students show the most significant gap between their belonging and the belonging of male students of the same race. The JCPS (2018b) African American female sense of belonging data counters previous research on gender-based sense of belonging that indicates female students have a greater sense of belonging than male students (Furrer \& Skinner, 2003; Goodenow \& Grady, 1993; Huyge, Van Maele, \& Van Houtte, 2015; Nichols, 2006), indicating that further research is necessary. The district-level data also counters previous research that shows African American females have a greater sense of belonging than male students of the same race (Dotterer, McHale, \& Crouter, 2009; Goodenow \& Grady, 1993; Voelk1, 1997). By targeting sense of belonging, we may be able to enhance African American female students' educational experiences and change the trajectory of outcomes. 


\section{Purpose of the Study}

Present and historical research on female student sense of belonging shows that female students have a greater sense of belonging than their male peers (Huyge et al., 2015, Nichols, 2006; Voelkl, 1997). Even past research on African American students shows that female students have a greater sense of belonging than their male counterparts (Goodenow \& Grady, 1993). Yet, African American female students in JCPS show the lowest sense of belonging in elementary, middle, and high school (JCPS, 2018b). Researchers note that there is a lack of research on Black girls and their experiences (Chavous \& Cogburn, 2007; Ricks, 2014), minority students and their sense of belonging (Capps, 2004; Singh, Chang, \& Dika, 2010), specifically African American students (Boston \& Warren, 2017), and gender-based differences in sense of belonging to school (Sanchez, Colon, \& Esparza, 2005; Shochet, Smith, Furlong, \& Homel, 2011). Lastly, researchers suggest focusing on middle school since at this level, sense of belonging decreases due to greater vulnerability, alienation, and need for approval, as well as, issues with self-esteem (Anderman, 2003; Faust, Ennis, \& Hodge, 2014).

Within scholarly research and schools, African American female students are silenced or made invisible (Andrews et al., 2019; Patton, Crenshaw, \& Haynes, 2016). This dissertation study addresses these gaps by discovering what fosters sense of belonging to school according to African American female students themselves. An understanding of sense of belonging is achieved by listening to African American female students' individual and collective voices. Finally, the purpose of this dissertation is to change practices within schools and classrooms so that, truly, all students feel as though they belong. 


\section{Research Questions}

This dissertation study addresses the following research questions:

- According to students, what contributes to a positive African American female sense of belonging in school?

- According to students, what diminishes African American female sense of belonging in school?

\section{Theoretical Frameworks: Critical Race Theory and Black Feminist Thought}

To increase voice and make African American female students visible Critical Race Theory (CRT) and Black Feminist Thought (BFT) were used to guide this dissertation study. Simply, CRT and BFT both emphasize voice. In CRT, voice is used with storytelling. Storytelling is viewed as a way for people of color to express their experiences. Delgado and Stefancic (2001) state that stories are a cure for the silencing of minority voices:

Stories also serve a powerful psychic function for minority communities. Many victims of racial discrimination suffer in silence, or blame themselves for their predicament. Stories can give them voice and reveal that others have similar experiences. Stories can name a type of discrimination; once named, it can be combated. (p. 43)

Similarly, in BFT, dialogue is vital to assessing knowledge claims and knowledge is constructed in collaboration with others. Collins (2009) writes, "For Black women, new knowledge claims are rarely worked out in isolation from other individuals and are usually developed through dialogues with other members of a community" (p. 279). Here, there is an emphasis on collaboration, making meaning with one another, and 
knowledge as interdependent. This dissertation study centers on African American female students, creates a space for collaboration and dialogue, and utilizes storytelling to discover what fosters or diminishes sense of belonging.

\section{Methodological Rationale}

The current research on K-12 student sense of belonging in schools is heavily quantitative in nature. Surveys have been used extensively to gather student perspectives. These quantitative measures limit understanding around sense of belonging in that details on barriers that impact sense of belonging are not included (Gray, Hope, \& Matthews, 2018). In fact, Faust et al., (2014) argue for more qualitative research to support quantitative data, "qualitative data from students and teachers would strengthen the quantitative data and supplement the analysis of students' responses" (p. 53). However, within the qualitative data on student sense of belonging, there is limited research that utilizes student voices and experiences to learn more about student sense of belonging (Booker, 2007; Doda \& Knowles, 2008; Kester, 1994).

Both quantitative and qualitative measures may not fully address the research gaps and pedagogical concerns surrounding African American girls and their sense of belonging. Evans-Winter and Esposito (2010) suggest research that, "empirically validates the experiences of girls of African descent" (p. 15) but also changes classroom practices. Therefore, participatory action research (PAR) is the optimal choice for addressing the methodological gaps within the research. According to Hall (1992), PAR focuses on empowering participants within a study and on knowledge construction. Hall explains that in PAR, attention to race, gender, and ethnicity is central. This methodology foregrounds marginalized voices. PAR, "combines three activities: research, education 
and action" (p. 16). The emphasis in PAR on marginalized voices and perspective lends itself to the selected theoretical frameworks, CRT and BFT. This dissertation study, influenced by PAR, uses a co-learning environment between myself and the participants to construct knowledge. The goal of this study is to influence both school practices and policy.

\section{Methods}

To address this dissertation study's research questions, selected theoretical frameworks, and methodology, digital storytelling was utilized. Digital storytelling is a combination of text, images, sound, or narration to create short videos that emphasize participants' voice and personal experiences (Stewart \& Ivala, 2017). Used in PAR research studies, digital storytelling allows participants to guide how the research is conducted (de Jager, Fogarty, Tewson, Lennette \& Boydell, 2017). Other researchers support this methodological choice. Rolon-Dow (2011) asserts that the, "digital storymaking process, and its ensuing engagement of multimodal literacy practices, offers great potential to CRT scholars seeking to document and understand the complex experiential knowledge of youth in authentic and engaging ways" (p. 162). Digital storytelling allows for voice, self-direction, and self-authorship, as well as, serves to counter predominant narratives (de Jager et al., 2017; Rossiter \& Garcia, 2010). These tenets align with key components of CRT and BFT. The digital stories are created by the participants in this study to better understand what fosters or diminishes sense of belonging in schools from the participants' perspective. These stories provide the participants ability to express their voice in a multimodal way, through images, words, narration, etc. Data was coded using In Vivo and focused coding to determine salient themes. According to Saldaña (2016), In 
Vivo coding uses the participant's own words and phrases. This coding method was selected because In Vivo coding, like CRT and BFT, also honors participants' voices and foregrounds their voice within the research. After In Vivo coding, focused coding allows for the categorization of codes based on thematic similarities.

\section{Significance}

This study's policy significance includes the potential to impact Jefferson County Public Schools Racial Equity Policy (JCPS, 2018c). The policy addresses the discrepancy in sense of belonging, achievement, and opportunity gaps between students of color and their White peers. Moving from policy to practice, the study results will provide support for practitioners working for students in schools. The results of this study will reveal classroom and school-level tangible strategies for increasing student sense of belonging, particularly for African American female students. These strategies can be used by practitioners to increase students' sense of belonging, and in turn, increase student achievement (Boston \& Warren, 2017; Faircloth \& Hamm, 2005; Goodenow, 1993b; Harborg, 1998) and well-being for students in our schools (Albanesi, Cicognani, \& Prati, 2018; Faust et al., 2014).

Finally, this dissertation study will contribute to the scholarly literature on sense of belonging in schools. This study will address the "superinvisible" (Chavous \& Cogburn, 2007, p. 28) and limited presence of African American females in research. The need for sense of belonging research that centers African American students will be addressed (Bostan \& Warren, 2017). Within the methodological design is an emphasis on participants' voice, thus addressing the lack of African American females in research on students of color. 


\section{Definition of Key Terms}

The basic terms used in this study are defined below:

African American: This study uses terminology similar to that used by The National Association of the Advancement of Colored People Legal Defense and Education Fund \& National Women's Law Center (2014). “The term 'African American' is used to refer to those of African origin living in the United States (no distinction is made between descendants of those who were brought against their will and more recent immigrants)" (p. 46). While within-group variations exist and there is a difference between American born, immigrant, or foreign-born African Americans, this is beyond this dissertation's scope.

Digital Stories. Digital stories are narrative vignettes that tell stories using images, sounds, music, narration, video, etc. (Stewart \& Ivala, 2017).

Peer Relationships. Relationships, quality of friendships, interactions, and relatedness to other students within a school building (Bouchard \& Berg, 2017).

Sense of Belonging. Sense of belonging is defined in this research using Goodenow's (1993a) definition: “belonging is defined here as students' sense of being accepted, valued, included, and encouraged by others (teachers and peers) in the academic classroom setting and of feeling oneself to be an important part of the life and activity of the class" (p. 25). In this dissertation, this definition will extend to the overall school setting, not just the classroom setting.

School Staff Practices and Interactions. This includes teacher and school staff interactions with students, classroom practices, pedagogical and curricular choices, and adult behaviors. 


\section{Organization of the Study}

Chapter 1 is organized as follows: a statement of the problem, the purpose of the study, research questions, theoretical frameworks, methodological rationale, methods, significance, definitions of key terms, and a preview of the remainder of the dissertation. Chapter 2 spotlights African American female students and reviews prior research on student sense of belonging. The literature review will also discuss the theoretical frameworks used in this study. In Chapter 3, the research design is described. This chapter also includes data collection, recruitment, and analysis procedures. The validity procedures, ethical considerations, amendments made to the study due to a pandemic, limitations, and the researcher's positionality are detailed. Chapter 4 consists of an analysis of the data. Lastly, Chapter 5 discusses the major findings and recommendations of policy, practice, and future research. A reference list and appendices are also included.

\section{Summary}

Chapter 1 provides the context for this PAR digital storytelling dissertation study. This research study seeks to address not only the general lack of research on African American females, but also the conflicting results within district data on sense of belonging and prior research. Accordingly, this study has an emphasis on foregrounding individual and collective voices. In the next chapter, a review of literature will spotlight African American female students, present details on prior sense of belonging research, and show that further research is needed to address the lack of scholarly work around and with African American females and their sense of belong. 


\section{CHAPTER II}

\section{REVIEW OF THE LITERATURE}

\section{Introduction}

This literature review will begin with a spotlight on African American female students in our educational system and provide evidence on how African American females' academic and personal development needs are not addressed in schools. Next, sense of belonging will be presented as a worthy pursuit in and of itself, but also one that can further academic achievement and well-being. Sense of belonging research specific to African American students and female students will be presented, as well as, the gaps within current research on these subgroups. The literature review will include relevant research on fostering sense of belonging in schools through teacher practices and peer relationships. Finally, details on how adopting Black Feminist Thought and Critical Race Theory can foreground African American female voices and experiences and why these frameworks are suited for sense of belonging research will be presented.

\section{Spotlighting African American Female Students}

In 2009, President Barack Obama created The White House Council on Women and Girls to address the inequities women and girls face, including but not limited to lower pay, underrepresentation in particular fields, violence, a lack of adequate health care, and unequal educational opportunities (Executive Order 13506, 2009). This 
Executive Order mentions the need to concentrate on the concerns of women and girls of color. Over a decade later, African American girls' concerns are still not fully addressed in our education system. In fact, African American female student needs are sidelined in the discourse on African American students, foregrounding African American males and their needs (Patton, Crenshaw, Haynes, \& Watson, 2016). For example, Obama's 2014 \$200 million dollar initiative called “My Brother’s Keeper" focused exclusively on supporting male students of color through providing summer jobs, mentorships, and other programs (Crenshaw, 2014). This initiative has a concrete strategy for meeting the needs of males of color, while within The White House Council on Women and Girls, the same intentionality is lacking.

Often, African American female needs are overlooked because they are considered better off than their male counterparts (Crenshaw, 2014). In actuality, African American females experience gendered racism. Critical Race scholar Philomena Essed (1991) defines gendered racism as the, "converging systems of race, class, and gender oppression" (p. 5). This shapes Black women's experiences, and specific to this dissertation study, African American female student experiences. Essed (1991) argues that race and gender cannot be analyzed independently. To consider only one facet of identity will not fully speak to African American girls' experience. Simply stated, their experiences differ from male students and non-Black female students (Evan-Winters \& Esposito, 2010). Thus, initiatives and programs that successfully support African American male students may not be suitable for girls (Green, Walker, \& Shapiro, 2020). A lack of awareness, planning, and urgency around African American female students' gendered and racial experiences has perpetuated inequities within schools. 
Within schools, Nunn (2016) writes, "Black girls are often trapped in environments that do not fully support their personal and academic development" ( $p$. 244). Concerning African American female students' academic development, achievement data paints a complex picture. For example, the African American female college enrollment rate had increased from $35 \%$ in 2000 to $41 \%$ in 2018 . Their college enrollment rate is greater than that of White and Black males, but still second to White females (Hussar et al., 2020). Simultaneously, African American female students are less likely to be recommended for Advanced Placement classes and are retained a grade at a far greater rate than other girls. African American females make up only $5 \%$ of math and science Advanced Placement class population. The retention rate is $21 \%$ for African American female students in Kindergarten through ninth grade, more than twice that of their White female peers (National Association of the Advancement of Colored People [NAACP] Legal Defense and Education Fund \& National Women's Law Center [NWLC], 2014). Additionally, African American girls experience a curriculum that does not speak to their gendered and racial experiences (Evan-Winters \& Esposito, 2010).

Concerning personal support, African American female students may be facing trauma related, but not limited to, poverty, violence, and the impact of stereotypes labeling girls as defiant or deviant without addressing underlying causes (Morris 2016; NAACP \& NWLC, 2014). Other scholars add to these stereotypes: Black girls are often seen as loud, masculine, hypersexual, or aggressive (Evan-Winters \& Esposito, 2010; Fordham, 1993; Morris, 2016). As girls and as girls of color, African American female students face school and district policies that may be racist, classist, and sexist (EvanWinters \& Esposito, 2010). These stereotypes have dire consequences for African 
American girls. The U.S. Department of Education, Office for Civil Rights (2014) reports that African American females are suspended from school more frequently than other female students and most male students. For example, African American female students are suspended at a rate of $12 \%$, while White males and female students are suspended at a rate of $6 \%$ and $2 \%$, respectively.

Another factor in personal development is school sense of belonging. According to Goodenow (1993a), sense of belonging is:

Belonging is defined here as students' sense of being accepted, valued, included, and encouraged by others (teachers and peers) in the academic classroom setting and of feeling oneself to be an important part of the life and activity of the class. (p. 25)

Sense of belonging extends beyond the classroom because it is a multidimensional construct (Shochet, Smith, Furlong, \& Homel, 2011) that develops in academic and social contexts, as well as, within the school's structure (Anderman, 2003). This notion that sense of belonging extends beyond the classroom is seen in other research (Bouchard \& Berg, 2017; Kester, 1994). Sense of belonging is a fundamental need for all human beings and is prevalent across all cultures (Baumeister \& Leary, 1995; Wegmann, 2017). Still, according to Crenshaw, Nanda, and Ocen (2015), African American female students' belonging is undermined, overlooked, or undervalued. This means schools are assigning little importance to African American female students' feelings of support, acceptance, and encouragement. Even within research on sense of belonging, African American girls are not foregrounded. Similarly, to the discourse on African American 
females where gender and race are not looked at in tandem, sense of belonging research focuses on African American students generally or female students (Patton et al., 2016).

\section{Sense of Belonging and African American Female Students}

When considering the sense of belonging for African American female students, the intersectionality of race and gender must be analyzed. Delgado and Stefancic (1995) define intersectionality as, "the examination of race, sex, class, national origin, and sexual orientation, and how their combination plays out in various settings" (p. 51). The authors later provide an example that can serve to illuminate the experiences of African American female students. Delgado and Stefancic (1995) argue, "Imagine a black woman. She may be oppressed because of her race. She may also be so because of her gender" (p. 52). Simply stated, African American female sense of belonging in schools cannot be analyzed without considering both race and gender.

\section{African American Students and Sense of Belonging}

To understand African American student sense of belonging, stereotype threat, disciplinary measures, and discrimination must be examined. Wegmann (2017) argues that African American students face stereotype threat, or the psychological phenomenon of conforming to stereotypes applied to a group. Stereotype threat can negatively impact students' academic performance and achievement. Wegmann (2017) notes stereotype threat exists along race, gender, and socioeconomic class lines, and when groups face negative stereotypes, their academic task performance is affected. The author suggests that students with a greater sense of belonging are protected against stereotype threat effects. Similarly, Uwah, McMahon, and Furlow (2008) believe that the stereotype threat 
and the fear of being perceived negatively keep African American students, specifically male students, from engaging with the school community and in school activities.

As mentioned in the previous section, African American girls are susceptible to many negative stereotypes and, as a result, are subject to unfair disciplinary practices. According to the NAACP and NWLC (2014), African American girls are disciplined for subjective reasons like perceived disruption or disobedience. This is due to teacher perceptions of what is acceptable behavior for girls. African American girls are disciplined for failure to conform to behaviors typically attributed to White middle-class girls. Disciplinary practices do not exist in isolation. In fact, discipline practices within a school can contribute or diminish student sense of belonging. Bottiani, Bradshaw, and Mendelson (2017) sampled almost 20,000 suburban and rural students. Bottiani et al. (2017) found a relationship between how equitable and inclusive African American students saw their schools and how disproportionately African American students were suspended from school. Bottiani et al. (2017) hold that African American student sense of belonging can decrease with an increase of out-of-school suspensions.

In addition to the fear of being stereotyped and undervalued, African American students have historically experienced discrimination in schools (Boston \& Warren, 2017). Discrimination has a negative impact on sense of belonging. Dotterer, McHale, and Crouter (2009) study of African American middle and high school students from working and middle-class families found that even low levels of discrimination were related to decreased school engagement and attachment. Dotterer et al. (2009) used the term school bonding to determine belonging levels and measured this with adapting five items from previous research (Voelkl, 1997). The researchers also examined ethnic 
identity and how it relates to sense of belonging and discrimination. High levels of ethnic identity measures, such as pride and connection to other African Americans, increased sense of belonging. They also found that girls who had a weaker ethnic identity, or sense of ethnic pride, experienced more discrimination, and had a lower sense of belonging.

These studies indicate that sense of belonging for African American students is impacted negatively by stereotype threat, discipline practices, and discrimination in schools. Yet, strong same-ethnic bonds positively impact sense of belonging for African American students. In another study (Booker, 2007), with 13 African American students in a school where the student population was majority White, $85 \%$ of the African American students interviewed felt comfortable being themselves at school. The students felt the school accepted and appreciated them, rather than stereotyped or discriminated against them. Booker's (2007) study shows high African American comfort at a majority White school, but this was due to strong same-ethnic group relationships. Booker (2007) noticed students mostly associated with their own racial demographic. Faircloth and Hamm (2011) support the importance of same-ethnic bonds in their qualitative study using survey items they developed. The study was conducted in classrooms where African American students were in the majority and found that peer experiences can mitigate the decline of sense of belonging and increase belonging for African American students.

\section{Female students and sense of belonging}

Female student sense of belonging is a topic less researched than overall student sense of belonging. The research reviewed here indicates that female students have a greater sense of belonging than male students, but face marginalization in particular 
areas. Furrer and Skinner (2003) conducted a longitudinal study of majority White third to sixth graders. They found that female students reported a greater sense of relatedness or feelings of belonging to their teachers than male participants. McGraw, Moore, Fuller, and Bates (2008) found that female students show stronger peer connectedness than male students, but both groups are moderately connected to their school. McGraw et al. (2008) argued that school belonging overlaps with peer connectedness due to experiences students may have with school friends. Likewise, Huyge, Van Maele, and Van Houtte (2015) conducted a study in Flemish schools and found in their multilevel analysis results similar to other researchers (Goodenow \& Grady, 1993; Nichols, 2006). In Huyge et al.'s (2015) study of 6,380 students, male students showed less sense of belonging to their schools than female students. Both male and female students had a greater sense of belonging when around students of the same gender. Meanwhile, teacher gender did not impact sense of belonging. They also found that greater student participation and identification also correlated to greater achievement.

There has been a historical trend of female students reporting greater sense of belonging than male students within research that includes African American students. In Goodenow and Grady's (1993) study, the researchers looked at an equal sample of male and female students, a majority of whom were African American. The results show that female students were more likely to express a sense of belonging and motivation than male students. Female students also noted that their friends believed doing well in school was important. In another study, Voelkl (1997) conducted research on 1,335 African American and White eighth-graders in urban, rural, and inner-city schools. Voelkl (1997) found that African American students had a greater identification with school than their 
White peers. Within these results, female students had higher classroom participation levels and identification with the school than male students. A possible explanation for these results can be found within Uwah et al.'s (2008) study. The researchers speculate that female students may place greater importance on sense of belonging because they are more interpersonally oriented than male students.

Another explanation for the variance between male and female students' sense of belonging can be attributed to the marginalization of male students of color. Dotterer et al. (2009), report that African American male participants faced more personal racial discrimination from teachers and peers than African American female students, resulting in a greater likelihood of school detachment for male students. Hernandez, Robins, Widaman, and Conger (2017) found that male Chicano students had lower sense of belonging than their female peers. However, sense of belonging for both groups declined as they matriculated from elementary, middle, and high school. When comparing male and female students, the researchers found a stronger positive correlation between ethnic pride and sense of belonging amongst the male participants. Hernandez et al. (2017) postulate that this difference may be due to the greater number of challenging experiences, like discrimination, that male students may face compared to female students.

At the same time, there is research that conflicts with the notion that female students have a greater sense of belonging than male students. In fact, female students encounter marginalization as well. According to Murphy and Whitelegg (2006), teachers spend more time working and interacting with male students and male students are given more opportunities to participate. The researchers assert that students' prior achievement 
may impact teachers' treatment of female and male students, leading to different academic outcomes. Murphy and Whitelegg (2006) explain girls are more likely to face marginalization. Their research, conducted in the United Kingdom, reveals teachers believe in female incompetence in math and science when compared to male students. Simply, teacher perceptions of students impact their sense of belonging.

While the research reviewed here shows that male students experience marginalization, the marginalization of African American female students is not emphasized. The results of a survey conducted by Epstein, Blake, and Gonzalez (2017) show that African American females feel they are seen as less likely to need nurturing, protection, and support, and more likely to be seen as independent and able to talk about adult topics than White females. These racialized perceptions may impact sense of belonging. Researchers, too, are noting the lack of African American female student experiences and perspectives in studies. Uwah et al. (2008) suggest that there is a limitation to their research on sense of belonging in that while they focus on African American students, they do not specifically address female students.

In summary, the reviewed research shows that female students tend to have a consistently greater sense of belonging in schools than male students. The research reviewed here does not correspond to JCPS (2018b) data in that district-level data shows female sense of belonging for African American students is less than all other demographic groups, regardless of race and gender at the elementary, middle, and high school level. At the elementary level, the difference between African American female and male students is only $1 \%$, but at the middle and high school level, the difference is over $6 \%$. When comparing all gender-based results for students of the same ethnicity, the 
difference between African American female and male sense of belonging is the greatest. The conflict between district-level data and previous research can be attributed to the lack of research devoted solely to African American female student sense of belonging or practices specific to Jefferson County Public Schools that disproportionately impact African American female sense of belonging. Still, the discrepancy shows the need for further gender and race-specific research around sense of belonging that concentrates on African American female students.

\section{Why pursue Sense of Belonging?}

\section{Academic Success}

Academic indicators for African American female students show an achievement gap when compared to female students of other races. The NAACP and NWLC's (2014) report shows that African American and Native American girls had the greatest number of scores at the basic achievement level in both reading and mathematics when compared to other female students. African American females are held back at a rate of $21 \%$, more than twice that of their White female peers. Moreover, African American girls are less likely to complete high school within four years and have a lower graduation rate than all female groups, except American Indians. Sense of belonging may be a way to reverse these trends and further African American female student success.

Researchers are largely consistent in finding a positive correlation between sense of belonging and academic achievement. Numerous studies have reinforced this positive correlation throughout the years. In Goodenow's work (1993b) the results indicate that school belonging is associated with academic achievement and grades for urban youth. Harborg's (1998) study of 30 White middle school students used the often-referenced 
Psychological Sense of School Membership (PSSM) questionnaire (Goodenow, 1993b).

In Harborg's (1998) study, students that scored high on the questionnaire, indicating a greater sense of belonging, also reported stronger grades, more time spent on homework, and greater school motivation. There was also a statistically significant $(\mathrm{p}>.05)$ correlation between school membership and post-middle school educational aspirations. Smerdon (2002) conducted a longitudinal study using the National Education Longitudinal Study of 1988 data of over 11,000 high school sophomores enrolled in public, Catholic, and elite private schools. Smerdon (2002) found that students who entered high school with low grades, negative academic behaviors, and low perceptions of middle school also reported low perceptions of high school membership. Likewise, Abdollahi and Noltemeyer (2018) suggest that sense of belonging and achievement may have a direct causal relationship. Simply, a greater sense of belonging may prompt students to engage with challenging tasks and thus increase their achievement. Conversely, lower sense of belonging may prompt students to disengage from academic tasks and result in lower academic achievement.

The positive relationship between sense of belonging and academic achievement is reiterated by other researchers but show, for students of color, sense of belonging is complex. Faircloth and Hamm (2005) conducted a study on diverse high school students. They found sense of belonging, described as a relationship with teachers, peers, and participation in extracurricular activities, had a statistically significant relationship to motivation and academic success. They found that discrimination, defined as how unfairly school staff and students treated participants based on their ethnicity, decreased sense of belonging. The researchers suggest a need for further research on identifying 
aspects of belonging for members of specific cultures and ethnic groups, as well as the practices within schools and classrooms that will develop and sustain belonging. More recently, Singh, Chang, and Dika (2010) explored research on ethnicity-based differences, finding a positive correlation between sense of belonging and achievement. Singh et al. (2010) also found student sense of belonging to be a predictor for grades and engagement for African American students. Singh et al. (2010) state that, "In contrast to self-concept, school belonging was a significant predictor of both school engagement and grades for African-American students" (p. 171). At the same time, Singh et al. (2010) found that African American students felt disengagement with school because of the stereotype threat. This mirrors the research results presented previously (Wegmann, 2017). Boston and Warren (2017), in a quantitative study using a state-developed instrument on African American high school students, found a positive relationship between sense of belonging and grades for African American students. Likewise, in a study conducted with over 300 African American students, Byrd and Chavous (2011) found that African American students who are valued will have more intrinsic motivation in school. Being valued was defined in the study as valuing racial identity. These studies show the positive correlations between sense of belonging and achievement among students, regardless of ethnicity, but for African American students, discrimination and stereotype threat impact sense of belonging.

\section{Student Well-Being}

Understanding African American sense of belonging is vital due to the negative stereotyping, microaggressions, mistreatment, and historic discrimination this subpopulation has and continues to face (Boston \& Warren, 2017; Ogbu, 2004; Ricks, 
2014). When schools engage in such practices, lower self-esteem and disidentification with academics may occur. Morris (2016) notes African American females experience trauma, which can affect mental and physical health. Specifically for African American girls, NAACP and NWLC's (2014) report explains that African American females experience greater sexual and partner violence rates than White females. In schools, $12 \%$ of African American female students reported dating violence (NAACP \& NWLC, 2014). African American female students also face vulnerabilities, such as a lack of mental health services and other school supports. Moreover, Morris (2016) reports that two of the leading causes of death amongst African American females ages 15-19 are unintentional injuries and homicide. Considering these disheartening figures, a focus on sense of belonging may support student well-being for African American female students as sense of belonging has shown a positive impact on other sub-groups' well-being.

Research supports the correlation between sense of belonging and well-being. Faust, Ennis, and Hodge (2014) discuss peer group acceptance, an indicator of sense of belonging, noting that low acceptance leads to stress and difficulty concentrating. The opposite is true where sense of belonging is present. In a study undertaken in Italy, Albanesi, Cicognani, and Prati (2017) surveyed over 1,000 middle and high school students. They found that a strong school-level community, or attachment to the school, positively correlated with students' well-being. Well-being is defined in this study as positive feelings and functioning. These studies show that by fostering sense of belonging, schools may be able to counter the impact of trauma, stereotype threat, and the effects of discrimination. 
More specifically, within well-being and sense of belonging research, greater sense of belonging can, in some instances, protect against stress, anxiety, and depression symptoms. Huynh and Gillen-O'Neel (2016) focused on Latinx and Asian American students and found that discrimination effects, like worse sleep, were weaker among students with greater belonging. Shochet et al. (2011) sampled 504 seventh and eighthgraders in New South Wales and Tasmania using Goodenow's PSSM scale (Goodenow, 1993b) and a host of questionnaires to assess mental health conducted by school guidance counselors. Shochet et al. (2011) discovered that lower levels of acceptance were associated with higher negative affect levels, defined as depression and anxiety symptoms. However, they also suggest that caring teachers and staff members may only have a limited effect on these negative effects due to weak predictability. Roche and Kuperminc (2012) used the PSSM scale (Goodenow, 1993b) among other surveys on mostly Chicano/a and other-Latinx participants. They found that discrimination stress, but not immigration stress, was negatively correlated to school belonging. The authors defined immigration stress as the tension faced by new immigrants to the country. Watts, Province, and Toohy (2019) found that school attachment was significantly associated with depressive symptoms. Likewise, McGraw et al. (2008) found school sense of belonging was correlated with lower levels of depression, anxiety, and stress for final year students in Australia. Finally, students with a greater sense of belonging are more likely to reach out for support. Shi and Goings (2018) found that African American students with a higher sense of belonging were more likely to talk to an adult and see school-based counselors about college and discuss personal issues. These studies are not specific to African American female students. From the research reviewed for this 
literature review, there is a lack of scholarly work on African American female students, sense of belonging, and well-being. Nonetheless, a presumption can be made that if sense of belonging is correlated to positive well-being for various demographic groups, results may be similar for African American female students. If this trend is consistent across demographics, fostering sense of belonging may serve as a way to address the academic outcomes and socio-emotional needs of African American female students.

\section{Getting There: How Can We Foster Sense of Belonging?}

\section{School Staff Practices and Interactions}

Some researchers have explicitly sought to discover what staff interactions, practices, pedagogical and curricular choices, and behaviors further student sense of belonging. Research shows that classroom pedagogical choices can further student sense of belonging. Osterman's (2010) synthesis of research provides common teacher practices such as emphasizing high expectations, focusing on mastery, delivering engaging instruction, checking for understanding, encouraging students, providing feedback and opportunities to relearn content, allowing for cooperative learning and dialogue amongst students as practices that increased belonging. Additionally, Anderman (2003) conducted a longitudinal study of both urban and rural middle schools to inform what would create sense of belonging. The majority of the sample of students who completed the survey for the study were White and received free and reduced lunch. Anderman's (2003) results show that classrooms that were goal-oriented, focused on effort, improvement, and mastery strengthened student sense of belonging. Anderman (2003) also discovered that assignments that were interesting and considered important correlated to a stronger sense of belonging, regardless of the students' level of 
achievement. Assignment importance was defined as useful, interesting, and relevant to student concerns. Similarly to Osterman (2010), Anderman (2003) suggests teachers should tap into student thinking and provide cooperative learning opportunities to develop a sense of community in the classroom. Faust et al. (2014) note that student voice in classroom/school decision-making and policies can develop a strong student sense of belonging by increasing student satisfaction within the learning environment. Doda and Knowles (2008) conducted a study asking teachers in 30 middle schools, ranging from rural to urban, to gather student perspectives on what students wanted from school. Two themes emerge from the student responses: quality learning and relationships. Concerning the latter, students desire, "compassion, respect, personalization, fellowship, and friendship" (p. 27) and wanted positive relationships with their teachers. Students also preferred quality learning, defined as neither underestimating nor overestimating student capabilities, as well as real-world engagement opportunities.

Teacher curricular choices also impact sense of belonging for students of color. Covarrubias and Fryberg (2015) conducted a study analyzing school sense of belonging among Native American students. The quantitative study adapted a school attachment scale by Walton and Goden (2007) into student-friendly language. Students reviewed images and biographies of role models that shared their ethnicity. The results indicate that having exposure to role models that looked like them, even through images and texts, increased sense of belonging. The authors theorize that when a group is underrepresented, positive representations can counter a lack of sense of belonging. Simultaneously, educators must be cautious of representation because presenting inaccurate depictions of 
African American history and culture can thwart sense of belonging (Gray, Hope, \& Matthews, 2018).

In addition to pedagogical and curricular practices, research shows that teacherstudent relationships are also integral in increasing student belonging. The length of time a teacher is with a student can increase sense of belonging because relationships can be strengthened over time. Furrer and Skinner (2003) note the decrease in student relatedness to teachers when students enter middle school. The authors posit that this may be attributed to middle school structure, where a student has more teachers in a typical day, leading to less time for personal relationship building. This finding is similar to Kester's (1994) research on ten African American middle school students, which shows they had a strong bond with their school when they stayed with the same teacher for three years. In addition to time spent with students, particular practices build relationships and foster sense of belonging. Osterman (2010) suggests empathizing with students, giving them autonomy, and getting to know them as people as ways to develop student-teacher relationships to increase sense of belonging. Similarly, Bouchard and Berg (2017) found student-teacher relationships are more integral than peer relationships and extracurricular opportunities in fostering positive student sense of belonging, specifically the practice of seeing students as individuals, defined as going beyond conventional teaching to support students' social and emotional development. In fact, Cemalcilar (2010) found that teacher-student relationships are more important for sense of belonging than relationships with school-based administrators. The data used in Cemalcilar's study was collected in Istanbul, Turkey and consisted of roughly 800 middle school students in both high and low socioeconomic status schools. Cemalcilar's (2010) study results show that while 
interactions with administrators influence students' feelings towards their school, teachers played a greater role in influencing school attachment. When reviewing these results, a consideration is the ethnically homogenous population and whether these results would be mirrored in American schools. Other research consistently shows the importance of teacher-student relationships in fostering student sense of school belonging. In a study of students with disabilities and sense of belonging, Crouch, Keys, and McMahon (2014) found that student-reported negative interactions with teachers and staff significantly predicted lower rates of sense of belonging, controlling for ethnicity and disability. Negative interactions included teacher criticism or disapproval, arguments or fights with students, getting on a student's nerves, and/or getting angry or expecting too much from students. Crouch et al. (2014) assert that negative teacher interactions and relationships with students are not the only factors contributing to a lower sense of belonging, and that positive and supportive relationships may lessen the effects. In these studies, diversity is considered regarding socioeconomic class, race, and disability; however, there is still a need for continued research on this topic and on African American female students. Research shows staff interactions, pedagogical practices, and curricular choices further sense of belonging or diminish sense of belonging. Practices like providing engaging instruction, curriculum that reflects the students, and seeing students as individuals all serve to foster sense of belonging. While this research examines, Native American, urban, rural, foreign, and diverse populations, the specific interactions that impact African American female students' sense of belonging still need to be explored.

\section{Peer Relationships}


School staff play a vital role in not only the overarching school environment, but also in fostering the necessary positive student-to-student relationships that would increase sense of belonging. Anderman (2003) asserts that schools have academic and social features and argues that teachers can ensure that students are treated respectfully by their peers. Additional research supports the importance of staff members in fostering peer relationships, and ultimately student sense of belonging. Bouchard and Berg (2017) found that peer relationships impact students' sense of belonging, but this relationship is not as linear as teacher-student relationships. Teacher relationships have a stronger correlation to student sense of belonging and Bouchard and Berg (2017) note that since friendships are usually created amongst people with similar attitudes and values, peer relationships may not correlate to school engagement or lack thereof, but may be attributed to factors outside the scope of the school setting. Similarly, Furrer and Skinner (2003) found that, first, the loss of peer relatedness or attachment did impact students' experiences in the classroom. At the same time, if students had low peer relatedness, it did not impact students academically when students had strong adult (parent and teacher) relationships. Additionally, there was no statistically significant difference between male and female students and their level of attachment to peer relationships in this research study.

Additional research shows that students who have positive peer relationships not only have a stronger sense of belonging, but greater academic achievement. Faust et al. (2014) state students with positive peer relationships enjoy school more and produce greater academic success. Nichols (2006) reports individual student voices that emphasized having friends, a peer group, and being included by student groups as factors 
to their sense of belonging. Vaquera's study (2009) examined just under 60,000 Latinx and White students using data collected from the National Longitudinal Study of Adolescent Health. The results of this study show that students who had school-based friends had lower engagement problems and a greater sense of belonging. At the same time, students who had their best friend out of the school building had a lower sense of belonging. Vaquera (2009) speculates that this could be because the students feel out of place at school, may have a stronger attachment to their community, are less likely to spend time at school-related activities or may have trouble making friends at school. Much of the research indicates the importance of positive peer relationships and the impact their relationships have on sense of belonging.

Schools can also facilitate peer relationships through programming, clubs, and activities. This is because school belonging is generated through the convergence of teacher and peer relationships. For example, Demanet and Van Houtte (2011) conducted research showing that teacher relationships do not work in isolation to generate a greater sense of belonging. In fact, they found that students who perceive they have high teacher support, peer attachment, and overall school belonging are less likely to engage in misconduct. Engaging in arts-based activities, for example, can foster a greater sense of belonging as was shown in Kreutzmann, Zander, and Webster (2016) where an additional semester of dance class led to greater sense of belonging, possibly due to peer relationships fostered within the program. In Nichols' (2006) work, students mentioned the school environment's lack of opportunities, such as soccer and band, when discussing why they did not feel a positive sense of belonging. On the other hand, Booker (2007) found that all African American participants emphasized their participation in the 
classroom setting rather than extracurricular activities. This echoes Brown's (2009) work, who cautions against relying solely on after-school programming to support African American female students. She writes, "experience has taught me that you cannot program Black girlhood celebration. More specifically, there is no magic after-school program, girl empowerment intervention, or some kind of gender-specific club that is capable of positively working for every girl involved" (p. 25). Because there is no universal programming that will capture each African American female student's needs, researchers must continue to question and explore how to support their belonging.

\section{Critique and Significance}

Researchers agree that there is a general lack of scholarly literature surrounding African American girls and their experiences. This assumption is supported by Chavous and Cogburn (2007). They note that there is minimal research on race and gender, specifically Black girls' academic socialization, experiences, and personal identities, and how those impact academics. Moreover, Chavous and Cogburn argue that Black girls and women are "superinvisible" (p.28), and their experiences are absent from gender, race, and education research literature. They argue Black female education research, "ignores the unique risks that they face in their educational development, minimizes their resilience in the face of risk, and homogenizes their experiences" (p.28). Finally, researchers assert that Black girls have been ignored in research and more attention has been given to Black males and White females (Butler, 2018; Evans-Winter \& Esposito 2010; Ricks, 2014). These critiques highlight a need for research that accounts for the intersectionality of race and gender. 
For practitioners, this lack of research results in an underserving of Black girls. Chavous and Cogburn (2007) contend that current research has been conducted in predominantly White, middle-class populations and may not fully express Black female experiences. This lack of literature has impacted practice. Black girls have developed coping and defense strategies to counter gendered racism, but these are misinterpreted by school staff as cultural characteristics and personality traits (Ricks, 2014). Ultimately, these factors, "push African American girls out of school" (NAACP \& NWLC, 2014, p.5).

With regard to sense of belonging research, there is still a need for research on students of color, gender differences, the interaction between students, peers, and teachers, and more qualitative research. Researchers agree on the need for future research on ethnicity-based differences and individual groups of color and sense of belonging (Capps, 2005; Singh et al., 2010). Furthermore, Boston and Warren (2017) explain that there are specific gaps in the research regarding African American students, academic achievement, and student sense of belonging. Other researchers argue that gender-based differences still need to be explored (Shochet et al., 2011) and gender differences in African American youth (Smalls, White, Chavous, \& Sellers, 2007). While their research focused on Latinx students, Sanchez et al. (2005) still note the need for future research to investigate the school experiences of male and female students of color.

Not only is there a need to expand who is researched, but there is also a need to expand upon how sense of belonging research is conducted. School sense of belonging research has been largely quantitative in nature. Particularly, the use of surveys and questionnaires have been the primary method for measuring sense of belonging. The 
majority of the studies within this literature review are quantitative studies. They provide an overview of sense of belonging and show general trends in the research. Yet, there is a need for varied insight on sense of belonging. For example, Gray et al. (2018) point out the self-report measures used in quantitative studies may not express instructional and institutional barriers that hinder positive sense of belonging. Faust et al. (2014) assert the need for more qualitative research to support quantitative data. Though, within qualitative research, few studies capture students' voices and perspectives, and even fewer gather African American female students' voices and perspectives. Doda and Knowles (2008) collected written responses from middle school students and coded the responses for emerging themes. The researchers indicated they solicited responses from students in 30 different urban, suburban, and rural schools, but the race or gender of the participants was not detailed. Johnson (2015) conducted an ethnographic case study, but the participants are all school staff members, not students. Bouchard and Berg (2017) adapted Goodenow's PSSM scale (1993b) to conduct semi-structured interviews with both students and school staff members. In this study, the gender of the participants was identified, but not race. Both Booker (2007) and Kester (1994) gathered African American student voices through interviewing. Still, African American female students were homogenized, with their gendered and racial experiences encapsulated within the umbrella of African American experiences. This dissertation study aims to fill this gap in the research through foregrounding the individual voices and the collective voice of African American female students that have been missing from previous research on sense of belonging. 


\section{Critical Race Theory, Black Feminist Thought, and Sense of Belonging}

The frameworks used when conducting research and whether overarching research agendas account for both gender and race within research on African American females must be examined (Evans-Winter \& Esposito, 2010). Specifically, understanding sense of belonging for African American students must utilize frameworks that exist outside of educational psychology, in that these frameworks are rooted in Whiteness (Gray et al., 2018). This dissertation study gathers insight into African American female students' sense of belonging and what practices can increase or diminish sense of belonging by utilizing the Critical Race Theory (CRT) and Black Feminist Thought (BFT). Both frameworks were selected because individual voices and experiences are honored. This is done through stories and dialogue, which give voice to people of color and center their experiences. Thus, in order to take into account both race and gender and to place African American female students in the center of research, this dissertation study uses CRT and BFT.

\section{Critical Race Theory}

According to Delgado and Stefancic (1995), CRT began within law in the mid1970s when the Civil Rights Movement's advances were being chipped away. CRT has four basic tenets. The first is that racism is standard and a permanent fixture in our society. The authors write, simply, "racism is ordinary" (p.7), thus making it challenging to eradicate. Second, those in power are not invested in eliminating racism because it benefits them. Third, race and racism were created by society; therefore, are not fixed concepts. The fourth tenet is that people of color have a unique voice because of oppressions they have experienced. White counterparts do not share these experiences. 
Stories give voice to people of color and center their experiences. Delgado and Stefancic (1995) explain that CRT utilizes storytelling to shed light on racism and to counter the notion that racism is normal. These stories, or counter-stories, contrast the constructed myths about people of color that are ingrained in society.

CRT has expanded beyond legal studies and is visible in education research. For example, education theorist Ladson-Billings (1998) applies CRT to the American education system. When examining instruction, there is a presumption in schools that African American students are deficient and need remediation. Assessment and testing serve as methods of substantiating this myth. Pedagogical practices use a one-size-fits-all model and when students do not achieve results, the students are deemed the reason why. In curricula, African American histories, stories, and experiences are rendered colorblind or eliminated when they counter dominant society and power. Finally, Ladson-Billings (1998) explains that we can begin to dismantle myths and racist practices through storytelling by which people of color can name their own reality.

Because this research spotlights African American female students, an emphasis must be placed on both their racial/cultural identity and gender. The examination of the multiple categories an individual embodies, be it race, gender, class, sex, sexual orientation, etc., is a core concept in CRT, called intersectionality (Delgado \& Stefancic, 1995). CRT scholar Kimberle Crenshaw (1991) argues against examining singular identity categories and suggests instead looking at the interactions between race and gender because, "women of color are marginalized within both" (p. 1244). Looking at one component of identity will not fully capture the full dimension of one's experiences.

\section{Black Feminist Thought}


In pursuit of capturing a holistic understanding of African American female students' sense of belonging, this dissertation study also utilizes BFT as a framework. Within BFT, Collins (2009) even references Crenshaw's scholarship on intersectionality. Collins noted the intersection of race and gender and the oppressions associated with these identities act jointly to create injustice. When she first entered academia in the 1980s, Collins noticed that African American women, their experiences, and their perspectives were missing (Collins, 2015). Collins explains that Black feminist thinking is not a novel concept and can be traced as far back as Sojourner Truth's “Aint I a Woman?" in 1851. BFT thinkers include but are not limited to academics, blues singers, poets, storytellers, and ordinary women (Collins, 2009). BFT was visible in the abolitionist, suffragist, civil rights, and Black power movements (Taylor, 1998). Yet the term was not coined as a framework until 1990 by Collins herself through her seminal text, Black Feminist Thought. There was and still is a need for BFT as a framework in that scholarly research has and continues to marginalize Black women and their experiences (Collins, 2015). This framework has been used in arts-education research, research on social work, rural women, and poverty, among other topics (Acuff, 2018; Bryson \& Lawrence-Webb, 2000; Norris, 2012).

Patricia Hill Collins' (2009) work on BFT captures race and gender's intersectionality. BFT has core themes of, "work, family, sexual politics, motherhood, and political activities [that] rely on paradigms that emphasize the importance of intersecting oppressions in shaping the U.S. matrix of domination" (Collins, 2009, p. 269). These themes can serve to conceptualize the relationship between African American female students and school sense of belonging. 
Within BFT, Collins (2009) has four main objectives. First, she wants to center the ideas of both ordinary Black women and intellectuals in her analysis. The second objective is acknowledging race, gender, class, etc. and the interconnectedness or intersectionality of these in shaping the experiences of Black women. Third, BFT has an epistemological framework for assessing if ideas are truly Black and feminist. The final objective of BFT is the empowerment of African American women.

Within Collin's (2009) theory of BFT, there is a particular epistemology used that consists of five key components. First, lived experiences are the criteria for making meaning. This means for Black women, credibility is rooted in actual experiences. Those who have actually gone through experiences are the experts. They are more trustworthy than those who may have simply studied experiences. Second is the use of dialogue in assessing knowledge claims. Knowledge is created in collaboration and dialogue with others who are within the community, not alone. This component is directly tied to oral traditions in Africa and the concept that people are more human when within a community. Third, there is an ethics of caring. This means the personal expression of emotions and empathy is a part of knowledge validation. Collins (2009) mentions, "talking with the heart" (p. 281), meaning showing expressions, emotions, and empathy are all part of knowledge validation. Fourth, there is an ethic of personal accountability. Someone's background, character, and values are integral to the validity of their claims. Collins (2009) provides an anecdote that elucidates this component. Her students wanted to know who an author was, his personal biography, and if he truly cared about the topic he wrote on before evaluating his writing. The last component is Black women are agents 
of knowledge. This component emphasizes that Black women should speak for themselves.

In this dissertation study's use of BFT, African American female voices are central to constructing knowledge on how sense of belonging is developed. Additionally, their lived experiences at school are considered vital to understanding sense of belonging. African American female students are treated as the primary voices of knowledge for how their belonging is fostered or diminished. Finally, the knowledge constructed within this research was constructed through collaboration and dialogue. Thus, to ensure the participants in this study are agents of knowledge, value the lived experiences of the participants, and to fill the gap around African American female voices within sense of belonging research, the research questions of this dissertation study are: 1) According to students, what contributes to a positive African American female sense of belonging in school? 2) According to students, what diminishes African American female sense of belonging in school?

\section{Summary}

In conclusion, the research indicates that academic achievement is positively correlated to sense of belonging across demographic groups (Boston \& Warren, 2017; Faircloth \& Hamm, 2005; Goodenow, 1993b, Singh et al., 2010). School sense of belonging can impact student well-being by decreasing the effects of stress, anxiety, and depression (Albanesi et al., 2018; Faust et al., 2014; Shochet et al., 2011; Watts et al., 2019). With regard to staff, positive teacher-student relationships and interactions can lead to stronger school sense of belonging (Bouchard \& Berg, 2017; Cemalcilar, 2010). Studies also show that peer relationships factor into sense of belonging in that students 
with a greater number of school-based friends have a greater belonging (Nichols, 2006; Vaquera 2009).

Despite the research on sense of belonging, there are still clear gaps in the research. Students of color and their sense of belonging needs to be expanded upon (Capps, 2004; Sanchez et al. 2005). There is also minimal research on African American students' sense of belonging (Boston \& Warren, 2017) and particularly research around African American females in school (Chavous \& Cogburn, 2007; Evans-Winter \& Esposito 2010; Ricks, 2014). Finally, gender differences are areas that were noted as an additional gap (Smalls et al., 2007; Singh et al., 2010).

The main research methodology has been quantitative in nature and, in particular, the use of Goodenow's (1993b) PSSM tool. This survey has high reliability and quantitative methods drawn from large sample sizes, leading to increased generalizability. Yet, quantitative research cannot elucidate experiences and perspectives. Within the research analyzed in this literature review, few studies utilize direct student voice to understand belonging. Within those research studies, there is lack of African American female voices. This dissertation study and research questions serve to fill this gap within the scholarly research. This dissertation will also provide practitioners with tools and tangible practices they can incorporate in their schools and classrooms to help foster African American female student sense of belonging. 


\section{CHAPTER III}

\section{METHODS}

\section{Introduction}

Collins (2009) writes, “There is no essential or archetypal Black woman whose experiences stand as normal, normative, and thereby authentic" (p. 32). Instead, the author argues that within Black women's collective standpoint there are different responses to the same challenges Black women experience. Black Feminist Thought (BFT) focuses on understanding the collective experience of Black women, but also the different and individual experiences within the collective. This study's essence is to hear and learn from individual African American female student voices on what fosters their sense of belonging to gather insight on the collective sense of belonging for African American females in schools. To guide this study, I have sought to answer the following two research questions: 1) What contributes to a positive African American female sense of belonging in school? 2) What diminishes African American female sense of belonging? In this chapter, I provide a rationale for selecting a Participatory Action Research (PAR) design and particularly an arts-based approach. I will also explain the site selection process, identify data sources, data collection process, data analysis procedures, amendments that were made to the study due to a global pandemic (coronavirus), limitations, and discuss researcher positionality. 


\section{Research Design}

\section{Participatory Action Research}

The way we conduct research and gain knowledge about African American females should be radical and creative so that researchers do not continue to study them in passing (Butler, 2018). Butler (2018) provides ways to shift how research is conducted. Her suggestions are, "we can seek, find, listen to, work alongside, and learn from Black girls across the field of education." (p. 40). In order to make meaning in collaboration with African American females students, emphasize voice and action, this dissertation utilizes a Participatory Action Research (PAR) design. This research design combines research with education and action (Hall, 1992). According to Hall (1992), PAR became known in the 1970s when work was conducted in Tanzania, where participants and their experiences were placed in the center of the research. He notes that PAR is biased in favor of marginalized and dominated groups. In PAR, knowledge is socially constructed and allows for group discourse of experiences (Hall, 1992). According to Brydon-Miller (1997), PAR does not have a quintessential methodology. While usual qualitative methods can be used, the participants guide the choice of methods. PAR moves away from doing research on people, and instead, research is conducted with people (McTaggart, 1997). McTaggart explains that participants are encouraged to work together as agents of change. Likewise, within this dissertation study, the aim is to couple findings with actions so that sense of belonging for African American female students can be increased in schools.

PAR is the appropriate research design for this dissertation study due to the clear connections to Black feminist epistemology. Within PAR, McTaggart explained how 
participants are agents in the production of knowledge (1997). According to Collins (2009), Black women's ideas and thoughts are suppressed within institutions. Using PAR addresses this and the BFT tenet of Black women as agents of knowledge. PAR can create space for participants to speak for themselves. Moreover, within PAR individuals work together to make changes (McTaggart, 1997). Both PAR and BFT emphasize that people exist within communities and one of the tenets of BFT emphasizes the use of dialogue to construct knowledge (Collins, 2009). Finally, similarly to BFT, PAR emphasizes accountability in that action research aims to change society and take theory and apply it to practice.

\section{Digital Storytelling}

The arts-based research approach used in this study is digital storytelling. According to Rossiter and Garcia (2010), digital stories are vignettes that merge multimedia components like images, audio, and video with stories. However, the researchers note that a digital story does not need to have all these elements. Digital storytelling emerged in the 1980s with Dana Atchley, who coined the term when experimenting with multimedia in storytelling. Digital storytelling then took root in 1994 when Atchley, Joe Lambert, and Nina Mullen launched the Center for Digital Storytelling, offered workshops, and developed digital storytelling into what it is today. This center's vision was to be a space of empowerment, education, advocacy, and community mobilization (Stewart \& Ivala, 2017).

Digital stories do not have prescribed specifications on what components are necessary and how digital stories should be created. For example, in Steward and Ivala's (2017) study, conducted in a South African university, the focus was on silence and 
voice. In this study, the digital story's overarching audio was the author's voice. Steward and Ivala suggest that stories are not linear or one dimensional. This proposes that digital stories do not necessarily have a particular or prescribed format; rather digital stories should produce dialogue. Another example is Eglinton, Gubrium, and Wexler's (2017) work with indigenous Alaskan adolescents and using digital stories for identity-making, creativity, and voice. In this study, digital storytelling is a learning by doing process. Eglinton et al. (2017) explain that the process commonly has a set of two phases of writing or crafting, followed by editing and screening. Sadik (2008), in a study conducted with teachers and students, discusses student choice where the student may choose to talk about an image for as long or as little as they like and the process as a whole must take into account the students' technological skill level. These studies show that digital stories do not have a prescribed format, but rather emphasize voice. Emphasizing voice, rather than format, is visible in this dissertation study as well.

Voice, either through authorship or the actual creator's voice, is a facet of digital storytelling. Through the use of voice, digital storytelling parallels the major components of BFT and Critical Race Theory (CRT). Rossiter and Garcia (2010) suggest that this can be achieved through the actual use of the creator's voice with voiceover narration. Digital stories may also communicate the creator's personal experiences. At the same time, digital storytelling also creates a space for a discussion on the collective experience of a group (Benmayor, 2012). As digital storytelling lends itself to learn more about a group's collective experience, it can serve to counter the myths and dominant narratives that have been foregrounded in society. This notion that digital stories can create a space for a collective experience harkens to the collective standpoint Collins (2009) discusses in 
BFT. Rolon-Dow (2011) explains that by creating counterstories, they capture resistance to racism and challenge dominant discussions that do not delve into the experiences of students of color. The notion that digital stories are counter-stories is reiterated in other research studies as well (de Jager, Fogarty, Tewson, Lennette, \& Boydell, 2017; Rossiter \& Garcia, 2010). This allows for a connection to CRT in that voice is a key component of CRT. Ladson-Billings (1998) writes:

The use of voice or "naming your reality" is a way that CRT links form and substance to scholarship. CRT scholars use parables, chronicles, stories, counterstories, poetry, fiction, and revisionist histories to illustrate the false necessity and irony of much of current civil rights doctrine. (p. 13)

Likewise, digital storytelling supports CRT because it can create a space where storytellers can name their reality, present their stories, and counter the dominant narrative.

Similar to CRT, voice is an element in BFT. Digital storytelling can serve to capture the collective voice and experience of African American women and provide a space for individual voices. Collins (2009) argues that Black women have been described as outspoken and assertive speakers, yet there is an, "overarching theme of finding a voice to express a collective, self-defined Black women's standpoint remains a core theme in Black feminist thought" (p. 110). In BFT, discovering the collective voice is vital to understanding African American female experiences. Harris-Perry (2011) adds to the idea of Black female voice when she states, "Even if there is no single, universal black female experience, there are enough shared identities, beliefs, and experiences to offer insight into African American women as a group.” (p. 47). The author explains that 
Black female experiences are varied and cannot be placed under a single narrative. This need to discover the collective and honor the individual is why digital storytelling was selected for this research study.

Workshop Sessions. This study consisted of five workshop sessions (outlined in Appendix F) occurring over the course of five days. This study's model is similar to Rolon-Dow's (2011) testimonio, where the researcher organized the day to day activities, started group discussion, provided mini-tutorials, and provided individuals assistance or feedback as needed. In Rolon-Dow's (2011) format, the participants also collaborated with each other on all phases of the digital story creation process from idea formation to technological needs. Additionally, the workshop sessions were emergent in design. According to Creswell (2014), an emergent design means, "that the initial plan for research cannot be tightly prescribed, and some or all phases of the process may change or shift after the researcher enters the field and begins to collect data" (p. 186). An emergent design was selected to allow for adjustment and changes based on the participants' various desires, needs, and skills. PAR is also congruent to emergent design in that in PAR, there is "no cookbook approaches to follow" (Hall, 1992, p.20).

In this study, the workshop sessions were conducted via Google Classroom and group sessions were conducted using Google Meets. All sessions were recorded using the record feature on Google Meets. Additionally, Goodenow's (1993b) Psychological Sense of School Membership Scale (Appendix G) was adapted and used to begin the conversation with participants on their sense of belonging and to gauge participants' sense of belonging. Semi-structured reflective writing prompts were designed to discover specific details about participants' sense of belonging. These semi-structured reflective 
questions, similar to semi-structured interview questions, were open-ended and at times needed probes (Merriam \& Tisdell, 2016). The semi-structured reflective questions also served as a launchpad for discussions during workshop sessions.

The workshop sessions included time to plan, develop, collaborate, and view digital stories. Participants used the drafting document (Appendix H) to sketch their ideas on what the audience would see and hear as they view their stories. Next, participants determined what platform best suited their preference, skill level, and technological capabilities to complete their digital stories. Participants were introduced to WeVideo through a brief tutorial and I asked what other platforms would be best. The participants unanimously choose to use Google Slides. Participants then developed their digital stories while meeting in the sessions to allow for collaboration on ideas and technological expertise. During the last workshop session, participants viewed each others' completed digital stories and discussed what stood out in the stories.

\section{Data Collection and Instrumentation Procedures}

\section{Site Selection}

The study was conducted virtually, and participants were recruited from Georgia Davis Powers Middle School (GDPMS), a magnet school in Jefferson County Public Schools. Magnet schools arose post-desegregation to further school choice and counter White flight to the suburban areas (Garland, 2013). All students in this magnet school applied to be in the school and there is a heavy emphasis on parent/guardian commitment to the program. Additionally, this site was selected because of the large African American population. I desired a site with a large African American population because previous research (Booker, 2007; Nichols, 2006) shows students feel an increased sense 
of belonging when around similar racial groups. In 2019-2020, 51.9\% of the student body at GDPMS were identified as Black (JCPS, 2018b). In this same year, the overall Black population of students in the district was about half this number, $30.6 \%$, indicating the large African American student body population at this site. Secondly, this site was selected because of the ease of access to the field to conduct research. I currently serve as the assistant principal at GDPMS, which allowed me to reach potential participants. This became pivotal in recruiting study participants because in-person schooling was halted for the remainder of the year and the upcoming calendar year due to the novel coronavirus (COVID-19) pandemic. I believe students were more inclined to participate in the study because the study was conducted by a familiar face. I believe parents and families were also more willing to consent because it was someone they knew they could trust their child with. Moreover, as the assistant principal, I can put the findings into practice to better support African American female students' sense of belonging.

\section{Recruitment}

Participants were selected using convenience sampling. According to Saumure and Given (2008), convenience sampling is when research participants are selected for ease of availability. The authors describe participants within studies that use convenience sampling as ready, have a desire to participate, and are able to participate. Often, those recruited to participate with this sampling method are individuals who are the most invested in the topic and desire to share their stories (Saumure \& Given, 2008). For this research study, the participants were sixth-grade African American female students at GDPMS. One reason for selecting sixth-grade students is because I currently serve as the assistant principal for this grade level. Again, this allows ease of access to participants. 
Additionally, research shows that sense of belonging decreases as students matriculate through school (Anderman; 2003; Gillen-O’Neel \& Fuligni, 2013). This is supported by Jefferson County Public School (JCPS) data, which shows that sense of belonging decreases as students transition from elementary to middle school (JCPS, 2018b). Thus, hearing student perspectives at this grade level may provide further insight into why a decrease in sense of belonging occurs. At the sixth-grade level as well, students are transitioning from elementary into middle school. Within JCPS, this transition usually includes adjusting to a new school building with a greater population of students, along with schedule structures that may alter the time a student spends with each particular teacher. These changes may impact sense of belonging in that greater time with a teacher increases belonging (Kester, 1994). Moreover, I will be remaining with this same group of students during their time at GDPMS by serving as their assistant principal in the seventh and eighth grades. At present, I have begun to develop relationships with both the students and their families. I hope the data from the study and findings will allow me to serve my students better this year and in the years to come. I also intend to use the findings in this study to provide staff with professional development training. Additionally, the study participants were asked what they believe should be the next steps with the study's findings

Before the Institutional Review Board (IRB) approval, I received permission from both the school building principal and assistant superintendent to conduct this research study. Prior to conducting the research, I received provisional approval from the districtlevel IRB and then received approval from the University of Louisville IRB. Afterwards, I sent a formal site selection letter that was signed by the school building principal. I had 
to submit amendments to my study to both district and university IRBs so that it could be conducted virtually because with the COVID-19 pandemic, all research in JCPS was halted. Upon receiving approval, I spoke with the school building principal to determine when it was best to begin recruitment and to conduct the workshop sessions. The principal indicated to start as soon as possible and before school ended. This was also an opportune time because teachers had stopped assigning new assignments for their classes, but students were still engaged with the Non-Traditional Learning platform.

All African American female sixth-grade students were given the opportunity to participate in this study; 93 students fit the selection criteria. To ensure that no potential participants were excluded, Black female students who were identified as African American, multiracial, first-generation American, and second-generation American were also invited to attend. Students who fit the selection criteria were emailed an invitation for participation flyer (Appendix E) and email accompaniment (Appendix D- For Research Participants). In the accompaniment, I noted that potential participants could respond directly to me via email if they wished to participate. Parents and guardians of potential participants received the flyer and an altered version of this email accompaniment (Appendix D- For Parents and Guardians) as well. Parents and guardians were allowed to respond via email if they wanted their child to participate. Additionally, students who fit the criteria were also invited to attend through Google Classroom and potential participants could indicate if they wanted to participate through this platform as well. The same flyer (Appendix E) and student accompaniment message (Appendix DFor Research Participants) were attached to a Google Classroom post. This was provided as another way to recruit participants to the study in addition to email correspondence. 
Based on my experience as an assistant principal, many students do not check their email but will check their Google Classroom accounts. Those potential participants who did not respond and those who indicated that they did not want to participate were removed from the Google Classroom.

I reached out via phone or email to the parents or guardians of the students who indicated they were interested in participating in the study. I explained the study's general purpose, the voluntary nature of the study, the timeline, and how they could reach me with additional questions. I sent the consent (Appendix B) and assent forms (Appendix C) to parents or guardians and students, respectively, via the EverSign eSignature platform. I followed up with a phone call or email if potential participants or their parents or guardians had not signed the forms. In these follow-up conversations, I reiterated that participation was voluntary and that participants could choose not to participate. I followed up with potential participants who had either an assent or consent form on how to access the EverSign platform or to gauge if they were still interested. Once both consent and assent forms were received, I narrowed the Google Classroom enrollment to only include participants who had turned in both consent and assent forms. There was a total of eight participants who returned both consent and assent forms. Of the eight participants, six actively participated in the study.

\section{Data Sources}

There are six data sources in this study: recorded Google Meets sessions, the Psychological Sense of School Membership Among Adolescents (PSSM) survey (Appendix G), semi-structured reflective questions (Appendix I), digital story drafts (Appendix H), the digital stories, and field notes. Each Google Meet was recorded using 
the record feature. This allowed me to facilitate the workshop sessions and assist with participants' technology needs. Each session lasted about an hour, but we continued longer if students joined the Google Meets later. Google Meets session recordings were transcribed verbatim, analyzed, and coded into themes. If a participant did not attend the Google Meets session, some participated asynchronously, outside of sessions.

The Google Classroom platform allowed students to complete parts of the survey when they could best engage. For example, some participants completed the PSSM survey early on. Others completed the survey later in the study, according to their preference. I had intended to gather pre and post-workshop session survey responses to see if inherent in their nature, the workshops were an intervention for sense of belonging. But because participants completed this in a non-linear fashion, I only asked the participants for one set of PSSM responses to gather an understanding of the participants' overall sense of belonging.

The semi-structured reflective questions were posted onto Google Slides. If needed, questions were altered for clarity. There was a total of six questions asked throughout the sessions (Appendix I). As a way to honor each participants' voice, initials were on each slide. This gave participants their own response space to respond with words, phrases, or pictures. Participants could also respond to one another similarly. There was a question a day and participant responses served as launch boards for discussion during meets. Using Google Slides allowed participants to share their unique perspectives and those who could not join Google Meet sessions could then still engage with the other participants by responding to the semi-reflective questions on Google 
Slides. Questions that were not in the Google Slides were woven into the discussion. Semi-structured reflective question responses were also analyzed and coded into themes.

Digital stories were drafted using the "What I see, What I hear" document (Appendix H). This document was designed for participants to consider what visual images they would incorporate into their digital story alongside what sounds, voiceover, or music they would include. There is a timestamp included to take pacing into account. Some participants opted not to use this planning document. Instead, some participants revisited and changed their digital story as they felt necessary or discussed their story out loud during the Google Meets session as part of their drafting. The "What I see, What I hear" (Appendix H) drafting sheet responses were also analyzed and coded into themes. Similar to the PSSM survey and semi-structured reflective questions, some participants chose to complete this document outside of the Google Meets session.

Completed digital stories were another data source. Participants' narration was transcribed, analyzed, and coded into themes as well. Images the participants used were also coded into themes. In the event the participant did not record their digital story, the Google Slide they completed and accompanying text/images that the participant included was coded and analyzed. I also took field notes throughout the sessions. These notes were included to provide an understanding of the individual participants and provide context for the workshop sessions.

\section{Data Analysis}

According to Merriam and Tisdell (2016), data analysis is the process of making meaning of the collected data. The authors explain that data analysis includes, "consolidating, reducing, and interpreting what people have said and what the researcher 
has seen and read" (p. 202). It is a negotiation between the concrete and abstract ideas found in the data. To negotiate the concrete and abstract ideas within this study, I transcribed data collected in this study myself. While it is common for researchers to submit data to a transcription service, I found that transcribing data myself increased my familiarity with the data. This is reiterated by Merriam and Tisdell (2016) when the authors suggest novice researchers should transcribe the first few interviews to increase familiarity with data and allow for simultaneous writing of analytic memos. Creswell (2014) notes that transcripts must be checked to ensure no obvious mistakes were made. Thus, I revisited recordings and reread participant responses of semi-structured reflective questions, drafting sheets, and digital stories.

After transcription, I "winnowed" the data. Creswell (2014) explains that when the researcher winnows data, they focus on some parts of the data and disregard other parts. Specifically, with this research study, the parts where the participants worked on their digital stories and where technology was explained were not included in the themes. These segments did not address sense of belonging directly, instead focused on the technological aspects of creating a digital story. To ensure that winnowed data was not preemptively disregarded, I reviewed all transcriptions that were not analyzed after coding again.

I used In Vivo coding next to initially code data. According to Saldaña (2016), initial codes are usually provisional and provide the researcher with a base for further exploration. The author describes In Vivo coding as coding that uses actual words and phrases from the participants. This method is used in studies, similar to this one, that wish to honor participants' voices and is common with studies with youth participants (Stewart 
\& Ivala, 2017). This coding procedure was selected because In Vivo coding honors the participants' voices, a key component of BFT and CRT. I bolded repeat words, phrases, or topics that were mentioned frequently by participants. I also bolded synonyms and antonyms to the words, phrases, or topics. This was done to honor similarities, but also differences in each participant's experience.

After In Vivo coding, I analyzed the data using focused coding. Saldaña (2016) describes focused coding as a coding method that takes the most frequent or notable codes to develop categories or themes. The purpose of the focused coding is to develop themes from the In Vivo codes. My intention was for the themes to encompass the entirety of In Vivo codes and capture both similarities and differences within participants' responses. With this method, participants did not necessarily agree with one another for the codes to fall under a particular theme. After generating themes, I asked participants to review the themes for accuracy through a Google Form.

\section{Research Validity}

Within PAR, validation is done through many methods, including but not limited to triangulation, interpretations, and participant confirmation (McTaggart, 1997). Through validation, researchers review the accuracy of the findings (Creswell, 2014). In this study, triangulation and member checking were the procedures conducted to increase validity. According to Creswell (2014), triangulation is the examination of information gathered from different data sources. In this research study, data was gathered from workshop sessions, participant responses to semi-structured reflective questions, digital story drafts, and digital stories. The data gathered from these sources was analyzed and coded. The other validity strategy used was member checking, or participant 
confirmation. Creswell (2014) defines member checking as a method to determine the accuracy of qualitative findings. Creswell (2014) explains that the researcher may take back the semi-complete product, findings, themes, etc. to the participants to determine their accuracy. In this research study, member checking was done through a Google Form (Appendix J). The themes were listed, and participants were asked if they agreed with the themes, whether they had noticed other themes in our sessions, and if they had other thoughts. The form was open-ended so that participants can express their responses in detail. Any theme that was not agreed upon by participants was revisited. Of the six participants, three completed the Google Form.

To ensure reliability, Creswell (2014) suggests strategies including checking transcripts and making sure there is no drift or shift in meaning in codes' definition. This was especially important for this dissertation study because I wanted to honor the African American female participants as agents of knowledge on sense of belonging. Therefore, I checked transcripts to make sure there were no obvious errors. I also compared the data to the codes regularly to see if there were no shifts in the definition of codes. For this dissertation study and for maintaining my personal accountability to the participants, reliability was of particular importance.

\section{Ethical Considerations}

I maintained the ethical standards prescribed to me through district and university IRBs while conducting this study. One potential ethical issue is with my role as the assistant principal of the school participants attend. I sought to clearly communicate that involvement in the study would not impact the participants' standing at the school. Within the consent form (Appendix B- Potential Risks), there is a disclaimer on my role 
if participants share information that would expose them to risks, I would investigate concerns further. I believe that since the study occurred virtually and outside of the school year, this allowed for a further separation and minimal overlap between my roles of researcher and assistant principal. For example, I did not have to enforce disciplinary measures or have critical conversations about grades as the study was conducted. I think this allowed the students to feel more comfortable and open in their responses. I reiterated this in the first workshop and as needed in subsequent workshops. There were no other foreseeable risks except possible discomfort in answering some questions. Steward and Ivala (2017) note that there are questions around practitioners pushing students to express emotional life experiences in digital stories. I was intentional about not pressing topics and conversations the participants did not want to have. Moreover, participants were given the choice not to answer any questions that made them uncomfortable.

Additionally, the virtual nature of this study allowed for participants' confidentiality to be maintained. The Google Classroom was only open to participants in the study who had turned in both consent and assent forms. The use of a virtual platform allowed for increased participant confidentiality in that there was no possibility that staff members would be privy to the participants' identities or our sessions as they may have in a school setting.

\section{Covid-19 Amendments}

During the 2020 year, a global pandemic erupted and altered our routines and the basic way we conducted daily life. According to the Center for Disease Control (CDC, 2020), COVID-19 spread from person-to-person through respiratory droplets and the 
number of cases was increasing each day. The virus was more likely to spread when people are in close contact. To limit human contact and weaken the spread of COVID-19, school buildings were closed, and students participated in non-traditional instruction (NTI) online throughout the state beginning April 7th. This plan was put in place to limit the spread of the virus while allowing education to continue.

Initially, this research study was designed to be conducted in person and over a month. There were going to be weekly sessions conducted after school and in Georgia Davis Powers Middle School's computer lab. During these sessions, there would be icebreakers taken from Games for Actors and Non-Actors by Augusto Boal (2002). Semistructured reflective questions were going to be completed in a graffiti style format where students would walk to others' responses and add images, words, or phrases. Digital stories would be completed in the lab space.

This research study had received both district and university-level IRB approval the same week schools were closed to in-person instruction. However, due to the COVID-19 virus, the district-level IRB limited research as more information about the virus was made known. Initially, with no certain return date to in-person school, it was uncertain if approved research could be conducted at all (L.Taylor, personal communication, March 19, 2020). When it was announced that school would not resume in-person for the remainder of the school year, all in-person research within the school district was indefinitely suspended for the 2020-2021 school year. Researchers were informed to pursue virtual options (L.Taylor, personal communication, May 21, 2020).

I brainstormed with my dissertation chair to convert this study to a virtual platform and submitted an amendment to my study. One of the concerns presented by the 
district-level IRB was honoring instructional time. I collaborated with the site principal on when it would be best to start recruitment and begin this study. The site principal noted that before the school year's official end would be best and suggested waiting for NTI assignments to be completed. Thus, recruitment for the study began in the last week of school. Because person-to-person contact spreads the virus, I researched and tried various e-signature platforms to determine which one would be the most user-friendly for consent and assent paperwork. I found that EverSign was the easiest to use on various devices. I also questioned what would be the best platform to allow participants to engage in workshops. Because potential participants used Google Classroom and Google Meets with their teachers for NTI, I chose these platforms.

\section{Limitations}

There were limitations to this research study. When the study began, the participants in this study had physically been out of their school building for about two months. For the participants, this meant they had not seen their teachers, peers, and other school staff in person for quite some time. Since the district had closed schools abruptly, some students were not even able to clear out their lockers, grab their textbooks and materials for non-traditional instruction. Schools are more than just places of learning and serve as centers for communities, sites for physical safety, mental health, emotional wellbeing, nutrition sources, and relationships (Dorn, Panier, Probst, \& Sarakatsannis, 2020). Students may not have received the same physical and emotional support they would have if in-person school were still in session. The participants mentioned missing their friends and socializing. Thus, I believe the pandemic may have created a sense of nostalgia in participants for teachers and peers. In addition to nostalgia, participants may 
not have had the same negative experiences, as well. With the shift to non-traditional instruction, the possible experiences of frustrations with staff or peers may have been muted within the study results. Negative experiences such as hearing behavior corrections from a teacher, feeling left out by a peer group, or seeing a low score on an assessment, may have been in the participants' periphery. While these examples may not reflect the participants' actual in-school experiences, the lack of negative interactions could possibly lead to greater positive reflections of in-person schooling.

Additionally, this research study was conducted during a time of civil unrest. Protests for justice for the police shootings of residents, Breonna Taylor and David McAtee, were ongoing during the research study and after (Kobin \& Loosemore, 2020). Protests and demonstrations were also, at times, violent with protesters hit with tear gas or arrested for peaceful demonstrations (Kobin \& Loosemore, 2020). These events, both tragic and traumatic, may affect African American female students' outlooks during this study and in years to come (Gray, Hope, \& Matthews, 2018). It is possible the civil unrest affected the study results by heightening a sense of critical consciousness regarding issues related to race, social injustice, and equity.

Lastly, this research study used convenience sampling to recruit participants. Because convenience sampling taps into a readily accessible and interested group of potential participants, it is difficult to determine whether a study's findings can be generalized to other groups of people (Samure \& Given, 2008). Convenience sampling may not be reflective of other African American female students and their sense of belonging. 


\section{Researcher Positionality}

When I consider my positionality, many factors of my identity come to mind. I am a woman of color, a first-generation Indian American, an educator, an assistant principal, and I am a researcher. Muhammad et al. (2015) describe identity as complex, multi-faceted, fluid, yet situational. This means that identity is not linear and given the situation, facets of one's identity are foregrounded over others. Simply stated, at times my identity as a woman takes center-stage rather than my Indian American identity, but at times, both are foregrounded. Most importantly, as an Indian American woman, I know that I may have some similarities in my lived experience with the participants, but there are many differences as well. I must always be open to listening.

Understanding, listening, and learning about the lived experiences of African American women will be ongoing. I understand that as an Indian American woman, the participants may have seen me as an outsider. Collins (2009) writes, "Historically, safe spaces were 'safe' because they represented places where Black women could freely examine issues that concerned us. By definition such spaces become less 'safe' if shared with those who were not Black and female" (p. 121). Interestingly, "safe" is an In Vivo code that emerged in the data. I acknowledge that as an Indian American researcher, the space created within this research study may not be entirely safe because I do not share the same racial and cultural identity as the research participants.

In being a researcher, I do not want to impose my identity on the research, but I understand that who I am will be evident in the research. Knowing this, I want to maintain the integrity of the participants' voices and experiences. My greatest fear as a researcher is encapsulated by bell hooks (1991):

'No need to hear your voice when I talk about you better than you can speak 
about yourself. No need to hear your voice. Only tell me about your pain. I want to know your story. And then I will tell it back to you in a new way. Tell it back to you in such a way that it has become mine, my own. Re-writing you, I write myself anew. I am still author, authority. I am still the colonizer, the speaking subject, and you are now the center of my talk.' Stop. (p. 241)

I read this as hooks (1991) assuming the voice of the researcher and imposing authority and meaning over the research participants and their experiences. hooks' (1991) researcher only wants to hear of the stories of pain, as if to sensationalize participants' lives and to tailor participants' experiences to meet the needs of the researcher. Fine (1994) counters this notion of the researcher making themselves the authority by listening to participants' voices and the plurality of voices. In my research analysis, I looked for commonalities and themes, but also sought to honor the unique voices through direct quotes and insertion of images used by the participants themselves. The themes also encompass both similarities in the participants' responses, but also differences.

Dwyer and Buckle (2009) argue that the researcher is not separate from the study and the researcher is uniquely connected to the participants. I found that being able to be a part of the group sessions and utilizing a workshop style allowed me to co-learn with the participants. I also believe that because the study was conducted online and after school ended, I could distance myself from my role as the assistant principal of GDPMS further. As an assistant principal, my responsibilities include assigning discipline to students not following district behavior guidelines. The role of disciplinarian has the potential to impact the participants either directly or indirectly. With a workshop style model, I participated in sessions, but remained neutral to avoid steering participants' 
responses. I participated in each icebreaker as an attempt to establish rapport and create a community amongst the participants. I did not participate in semi-structured reflective questions because I did not want to influence participant responses. The co-learning atmosphere in our workshops echoes Muhammad et al. (2015) who state that research should be a co-learning environment in which the research purpose is aligned while any variance is honored between the participants and the researcher.

\section{Summary}

In conclusion, Chapter 3 details the research design, site selection, recruitment, data sources and collection, data analysis, and research validity, ethical considerations, Covid-19 amendments to the study, limitations, and researcher positionality. Forthcoming chapters will include research findings, discussion, a summary, and the implications of the findings. This research study seeks to discover what increases or diminishes African American female sense of belonging in schools from African American female students' perspective. This is done by honoring individual voices and seeking to understand African American female students' collective experiences. This research can offer educators with tangible practices they can include in their pedagogy to support sense of belonging. 


\section{CHAPTER IV}

\section{FINDINGS}

\section{Introduction}

In this chapter, I will discuss the themes that emerged from the data collected. The research findings presented in this chapter will answer the overarching research questions: 1) According to students, what contributes to a positive African American female sense of belonging in schools? 2) According to students, what diminishes African American female students' sense of belonging in school? The organizational framing of Chapter 4 is designed to present the participants' collective experiences in the study while honoring individual voices. The chapter begins with the context of the study and details of the events in each session. Next, individual participant's profiles that include their method of participation within the study, unique contributions to the study, and an overview of their digital story are provided. There is also an overview of the Psychological Sense of School Membership (PSSM) survey and results. This is included to determine the participants' sense of belonging to their school at the time of the study. The major themes that emerged from the analysis of the data that was collected and triangulated are described. This chapter concludes with the participants' thoughts on the themes and how they believe the study results should be used. 


\section{Context of the Study}

Due to the coronavirus pandemic, this research study was conducted virtually over the course of five days. I doubt the participants anticipated their sixth-grade year ending this way. This study had a degree of sentimentality to it as this virtual space served to connect the participants to school and one another. This made the workshops a different experience for the participants and myself than what would have occurred inperson. I believe the participants were able to reflect on school candidly, but may have viewed school nostalgically. Interestingly, while this was a study on school sense of belonging, it was conducted in participants' homes. It was not uncommon to hear family members in the background or see relatives during our sessions. In our fourth session, you could see Rhea laugh as Athena's young cousin sang songs around her. This allowed us to see a different aspect of each other's lives. Still, sessions followed a similar format, beginning with an icebreaker, then delving into the semi-structured reflective questions, a discussion on responses, and finally working on digital stories.

\section{Session 1}

The first workshop included five participants and lasted 47 minutes. This session consisted of an icebreaker, reviewing consent and assent form information, a reflective question that defined sense of belonging, looking at digital storytelling software (WeVideo), and an overview of the PSSM survey. Session 1 began on the Tuesday after non-traditional education classes had finished. Of the six participants, Diana, Iris, Athena, Selene, and Rhea were present. The participants and I began the session with an icebreaker designed to allow for introductions. The participants searched for and shared an object in their house that started with the first letter of either their first or last name. 
The participants then shared their name, the object they gathered, and what interdisciplinary team they were on in their sixth grade year at Georgia Davis Powers Middle School (GDPMS). I, then, shared the purpose of the study. I explained that participation in the study was completely voluntary and that they could opt out of particular parts of the study if they felt uncomfortable. I provided an overview of the next four workshop sessions. Next, I discussed confidentiality which encompassed not only maintaining the confidentiality of the other participants of the study, but also refraining from using identifiers in digital stories. I asked participants what platform they would be interested in using for their digital stories. Three of the five participants stated they would like to use Google Slides. Afterwards, I walked the participants through getting to the semi-structured reflective questions on Google Classroom.

The first reflective question read: "When you think of belonging what comes to your mind? What do you think of when you think of belonging at school?" Participants responded to the question and one another within Google Slides, we then discussed what sense of belonging means. Next, I showed the participants WeVideo and conducted a brief tutorial on how to use the platform. The session ended with time to complete the PSSM survey. Some participants chose to complete the survey on their own after the session ended rather than during the session.

\section{Session 2}

Session 2 included five participants and was 50 minutes long. Session 2 began with a recap of the participants' definition of sense of belonging, digital storytelling ideas, moving to Google Slides, and selecting digital story templates. The second session 
initially began with just two participants, Athena and Minerva. Iris and Rhea joined about seven minutes into the session and Selene joined about 16 minutes into the session.

The participants introduced themselves directly to one another and afterward we answered the icebreaker on what they missed about school. Athena missed her friends and Minerva missed socializing. Afterward, the participants and I transitioned to recapping the definition of sense of belonging. I divided this into two sections. "Sense of belonging is:" and "At school that looks like:" and participants shared their ideas while I typed their responses. I believe recapping the definition of sense of belonging allowed Minerva, who was not present at the previous session, to familiarize herself with the previous session. The semi-structured reflective question for this day was, "What can the teacher or school staff say and do to make you feel like you belong? How do you know when your voice is honored or respected in a class?" During our discussion, I asked another semi-structured reflective question on what participants would change to foster sense of belonging (Appendix G- Question 4). Next, I conducted a brief tutorial on Screencastify because it would allow participants to turn a Google Slides presentation into a digital story. After the tutorial, I asked participants if they wanted to use Google Slides or WeVideo to create their digital stories, and the unanimous decision was to use Google Slides. We transitioned to what participants wanted to focus their digital stories on. Athena was the first to share her thoughts and participants used this to bring ideas together for their digital story "What I See, What I Hear" drafting sheet (Appendix F). Participants selected their Google Slides templates, but they could not download the templates because they had student access only with their accounts. I informed them that 
I would download the templates they selected and grant them access to edit the templates into their digital story.

\section{Session 3}

Session 3 was one hour and 24 minutes long. In this session, four participants were present. This session included an icebreaker, semi-structured reflective question and discussion, and ended with time to work on digital stories. Session 3 began with two participants, Selene and Athena. Iris joined about 17 minutes into the session and Rhea joined the Google Meet 55 minutes into the session. For the icebreaker, I asked participants, "We're going to share something that brings us joy or makes us happy. It can be a thing or a memory." Athena brought and shared her teddy bears on her camera screen, and Selene described a memory of a Disneyland trip. I shared a picture of my niece.

The semi-structured reflective question on a Google Slide presentation was: "How does your friend group add to your sense of belonging at GDPMS?" During the discussion, I decided to alter the pre-planning reflective question, "How can increasing your connectedness to students at the school make your time at GDPMS better?" because in the previous session, the participants indicated they would not change anything about school. I asked the altered version of the question out loud. Participants were asked, "What are the ways schools can get more kids connected to each other? What are some of the ways you all got connected with your friends and what can schools do to make sure kids get connected together?" The remainder of the session was spent with participants working on their digital stories. Participants collaborated with and asked questions of one 
another and me. During the session, I reminded participants about confidentiality as they worked on making their Google Slide templates into digital stories.

\section{Session 4}

Session 4 was one hour and ten minutes long with three participants. In this session, there was an icebreaker, a reflective question and discussion, time to develop, collaborate, record digital stories, and a reminder on completing the PSSM survey. Our fourth session included not only our participants, but also two toddler-aged relatives of Athena and Iris. This caused many laughs and adorable breaks from the workshop when the toddlers would talk to their relatives. The icebreaker for this session was, "Who inspires you and why?" All participants picked a parent or grandparent. Next, participants completed their reflective question, "Think about your day to day at school, from the time you come into the school building to the time you leave. Walk through the day in your mind. At what parts of the day do you feel the most connected to the school and others? Why?" In our subsequent discussion, we discussed the overall school environment, how the physical appearance or a school's activity offerings impact sense of belonging. Rhea was able to complete her digital story slides and I asked if she was ready to record the narration to her digital story. She began fixing her hair, using her image in the Google Meet as a mirror. I think this was because she thought her face would be in the story, so I reminded her and the participants in the session that the digital stories could not include identifiers. While Rhea was recording, the other two participants muted their microphones so background noise would not be heard and continued to work on their story. Rhea then completed the PSSM survey as Athena recorded. Iris stayed on with me to record her digital story narration after the other participants left. 


\section{Session 5}

The last session consisted of five participants and it was the shortest session, lasting 33 minutes. The session included a reflective question and discussion, recording and viewing finished videos, and a closing. This session began with a final reflective question, "What else do you want to share about school sense of belonging? Think about the classroom, with other students, and just the overall school" After a discussion on the responses to this question, I then asked participants out loud on when they felt disconnected from school (Appendix G- Question 6). All participants agreed that there was a time where they did not feel like they belonged at school, but were hesitant to respond with details. Then, Iris spoke on her experience, detailed later in this chapter (Theme 3). Afterward, Selene and Minvera recorded their digital stories. I showed the other pre-recorded digital stories to the participants. As participants' stories were played, participants identified what parts of the story touched on staff practices, peer relationships, and the overall school environment. We cheered and applauded after viewing each video.

\section{Participants}

Convenience sampling was used to invite potential participants to partake in this study. As outlined in Methods (Chapter 3), the convenience sampling inclusion criteria

were 1) enrolled at Georgia Davis Powers Middle School 2) listed as African American on their school enrollment information 3) listed as female on their school enrollment information 4) were sixth-graders at the time of the study. Eight students indicated they were interested in participating and completed consent and assent forms. Of the eight participants, six actively participated in the research study and workshop sessions. 
The participants in the study had varying levels of familiarity with one another. Some participants were on the same interdisciplinary team or shared classes, while others were on different interdisciplinary teams and only knew each other in passing. The participants varied in their participation in Google Meets sessions. Some opted to complete parts of the study in an asynchronous manner, choosing to reflect on questions and complete drafts outside of Google Meet sessions.

Diana. Diana attended only the first session. She mentioned technical difficulties in our Google Classroom with attending another one of our Google Meets sessions. Instead, she responded to semi-structured reflective questions, completed her drafting sheet, and her digital story asynchronously. Her digital story was not recorded because we completed the recordings during our Google Meets. In her drafting sheet, Diana focused specifically on African American female excellence and the positive comments others make about African American females. Her digital story slides included various definitions and ideas on sense of belonging. These definitions were retrieved from the internet. Her slide titles were "What is the definition of sense of belonging," "Why Pictures of people belonging
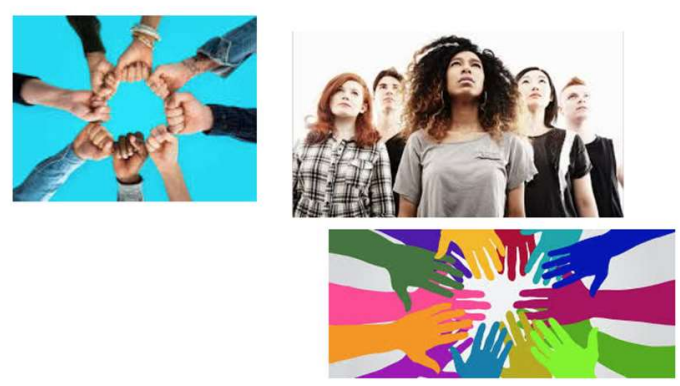
should people belong," "It is important to belong," "When is it important to make a person belong," "Reason to make someone belong," and "Pictures of people belonging." In her last slide, she included images that reflect inclusion and unity; two images were of hands together. In one image, the hands were diverse in skin tones and in the other image the hands were a variety of colors. One image, similar to her draft, which focused on 
African American females, had an African American female in the center of a group of men and women.

Iris. Iris was one of the first participants to submit the needed assent and consent forms to be a part of the study. She knew she wanted her voice heard. She even called me before the first session to ensure that it was still going on at the scheduled time and stayed on with me to talk about the Black Lives Matter protest after the first session. Iris would participate in sessions even when her friends and family were over. But one time, her chores did take precedence. She even attended a session, although her birthday party celebration was going on later in the afternoon. Iris has a cheerful

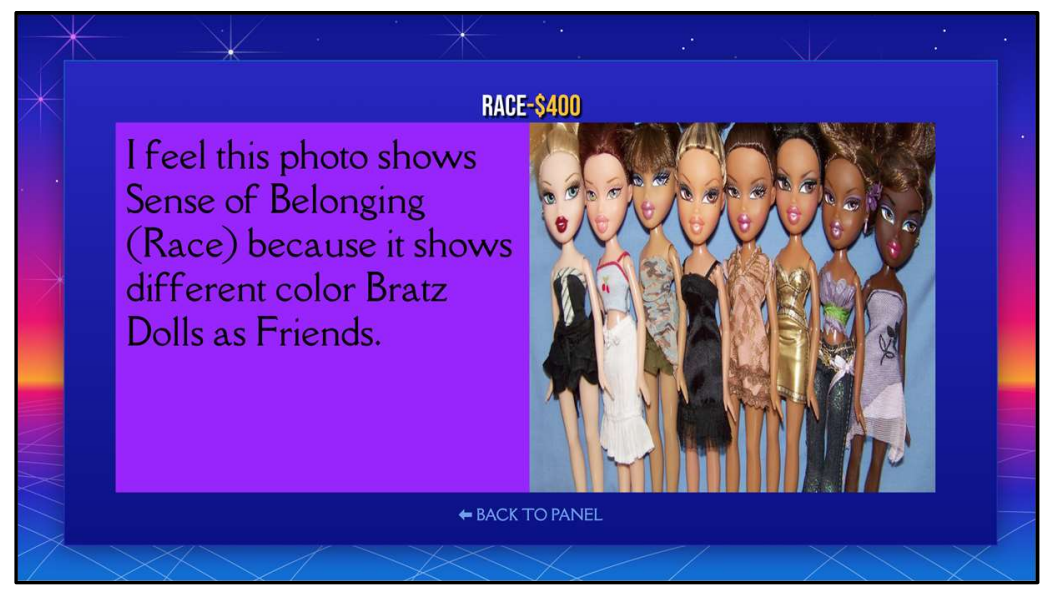
disposition, expressed through her open laughter and her pillow fight with her relative at the end of one session. Serious about her final product, Iris rehearsed her digital story's narration during our session before it was recorded. Iris also wanted to ensure that her digital story was clear to the viewer. In one session she asked me, "Can you look at my slides and make sure this is making sense? I don't think it does, but you never know." In another session, she asked, “Ms. Kaur, can you look at my slides to see if I'm doing this right?" Feedback was essential to Iris.

Iris's digital story did not focus directly on her experiences, but focused more on categories that enhance or diminish belonging. Iris broke her digital story down into 
several categories: race, similarity, socializing. In her race slides, she included a chart of different skin colors and Bratz dolls of various colors. In her similarity slides, she included an image of two African American sisters, what looks like protesters holding a sign stating, "You are not alone, we believe in you" and an image of people wearing masks, hinting at local civil unrest and the COVID-19 virus. For her similarity slides, she had a picture of two people hugging, a group laughing, and an African American family playing a board game. Again, there are no images of school or classrooms, but instead a general focus on sense of belonging. From my observations, family is foregrounded for Iris. She referenced family in two of her icebreaker responses. When I was providing a tutorial, love was the term she offered for me to search in the video-making platform. Then, she directed me to select the clip of a family.

Rhea. Rhea joined sessions frequently, and one time, Rhea even stayed on later with just me when she was late to a session. Rhea did not hesitate to ask clarifying questions when she did not understand a question or activity. She asked questions like how long the digital story should be and where she should put her ideas. Rhea also asked me for my input on what pictures to include in her digital story. Rhea was

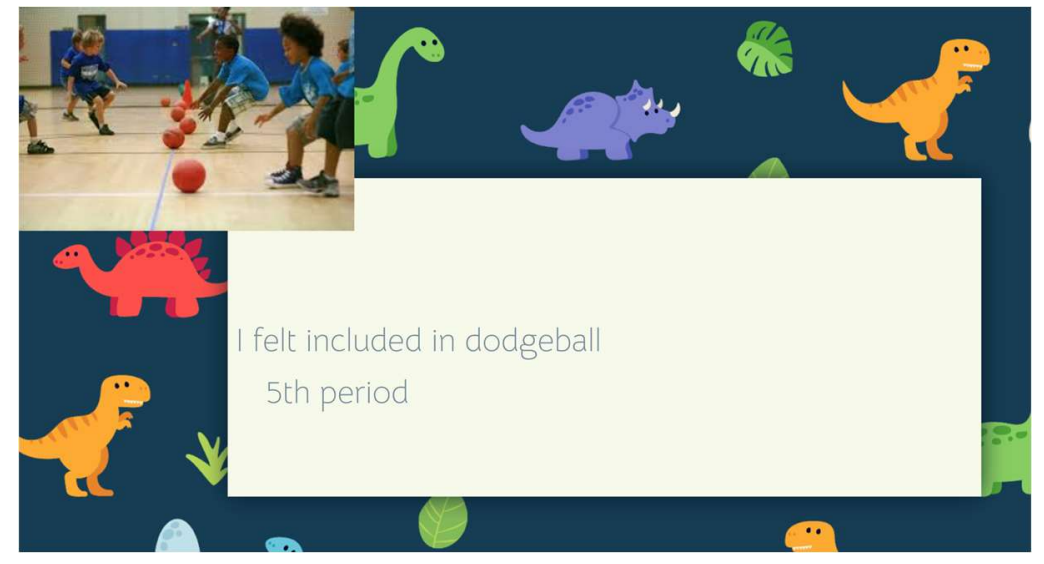
mindful of respecting others around her and would keep her earbuds plugged in on some sessions so her family would not hear our session. From my observations, Rhea was also task-oriented. Rhea was sure of her digital story and knew from the onset that it must 
include her gym class experiences and that she wanted to use the Google Slide platform. Her final video included two slides on her gym class, specifically when she played kickball and dodgeball. Her last slide included her experience in her third period class where she completed all tasks on a computer, but students still helped one another. In Rhea's digital story, she is unafraid to go off what was written on the slides and add her own unrehearsed words to her video.

Athena. Of the six participants in the study, Athena was consistent with attending Google Sessions on time at one p.m. each day. For one of the sessions, Athena took her Chromebook outdoors, had to fend off bugs, and compete with noise from the street. In one session, her baby cousin joined us, sang to us, and provided us with laughs. Athena was also most vocal about not only what made her feel like she belonged, but also when

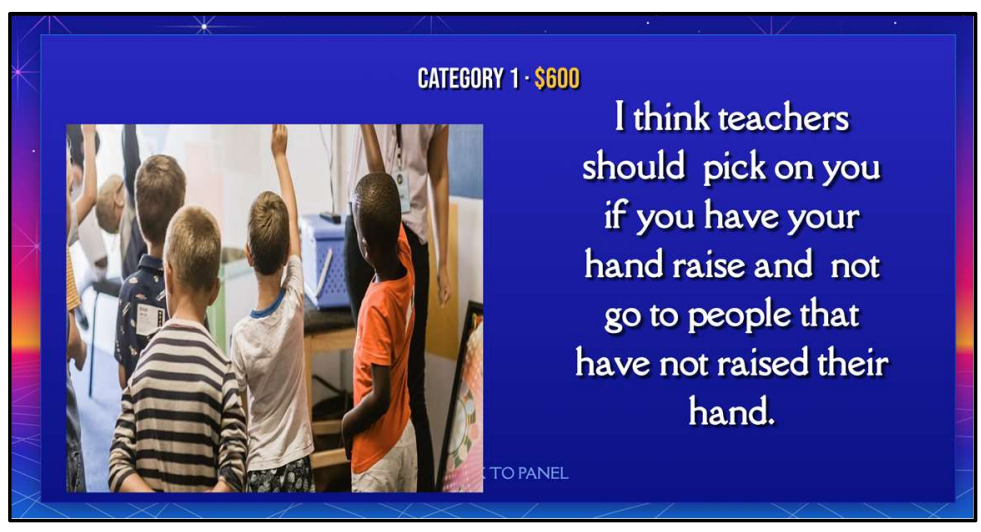
she did not feel like she had a sense of belonging. As we progressed through workshop sessions, her excitement for particular teachers and what she enjoyed in school was apparent, as well as what she did not enjoy. She almost cheered when hearing her favorite sixthgrade teacher would also be moving up to the seventh grade next year because this opened up the possibility that she may have this teacher again. Her original idea was to discuss a time when she felt misrepresented by a teacher. This incident is detailed in Theme 1, Honoring Lived Experiences. She picked a Jeopardy themed slide presentation and later began her video as a question and answer on school. This included when school 
was made. In the following session, she changed her idea into three slides. In the final version, her first slide included an introduction, her next slide discusses her friends and how they help her, and in her last slide, she tells us her thoughts on when hands are raised and how teachers should pick on those students who have their hand raised. She mentions having her raised hand but ignored in at least two other moments. In sessions, Athena made clear her African American identity. In our first session, I asked for a possible topic to search images for in WeVideo as I was providing an overview of the platform. Athena stated to search for "Black History." Of the prepopulated images that appeared, Athena suggested I select the one of Martin Luther King Jr.

Minerva. Minerva did not attend all sessions, but stayed in communication with me via text message. Like Diana, she chose to do a lot of the activities in the study asynchronously. Minerva was initially hesitant to have her image on camera, instead opting for an African American female cartoon avatar. I believe she opened up through the sessions, turning on her camera in our last session.

Although not the most vocal within the participant group, Minerva

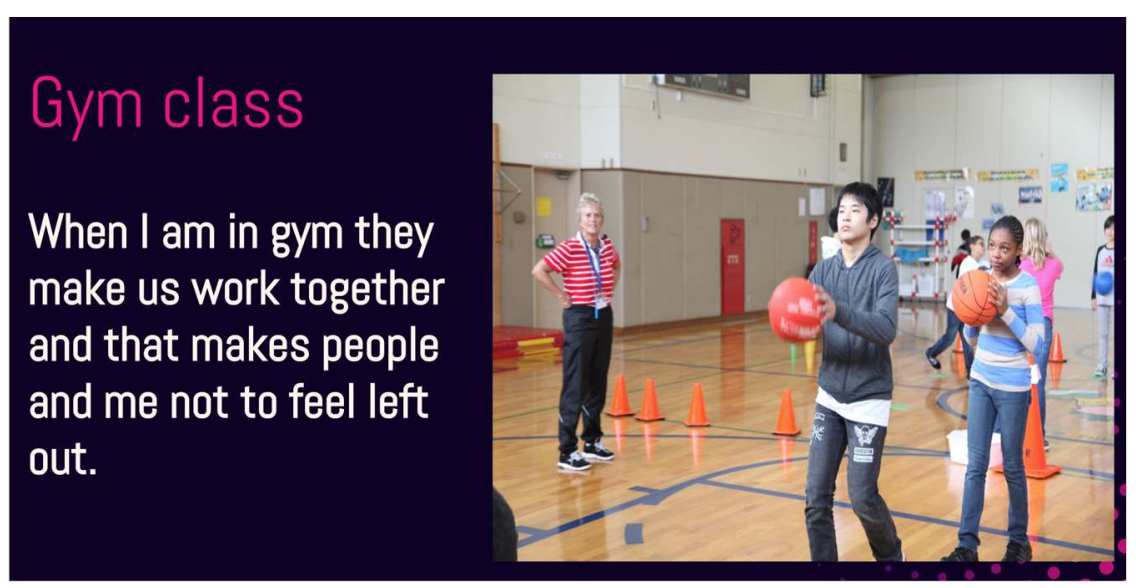
spoke with confidence and clarity. Minerva's digital story draft initially focused on her elementary school. She mentioned in a session too that she felt more included in elementary school than in middle school. She stated, "Yeah. I felt like that I belonged 
when I was in elementary, like in 5th grade" after probing she explains it was due to her enrollment in advanced placement classes in which, "Everybody was there to listen to what I had to say, was open to my ideas.” In her final digital story, like Athena, Minerva mentions her hand is ignored when she raises it. Her next slide focuses on friends and how they make her feel like she belongs. Her last slide, like Rhea, is on her gym class experiences where she was able to work with others and this allowed for her to feel included.

Selene. Selene joined the study from another state, at a family member's house. She mentioned in our third session that she enjoys traveling. She missed one session and noted that she would check her alarm to make sure it did not happen again. A planner, Selene wanted to know when seventh-grade orientation was even though, as she noted, summer had just started. It was not uncommon for Selene to ask questions of other participants and me during sessions. She, like Minerva, spoke with conviction and was always very polite. If Selene spoke over someone, she apologized and asked them to go

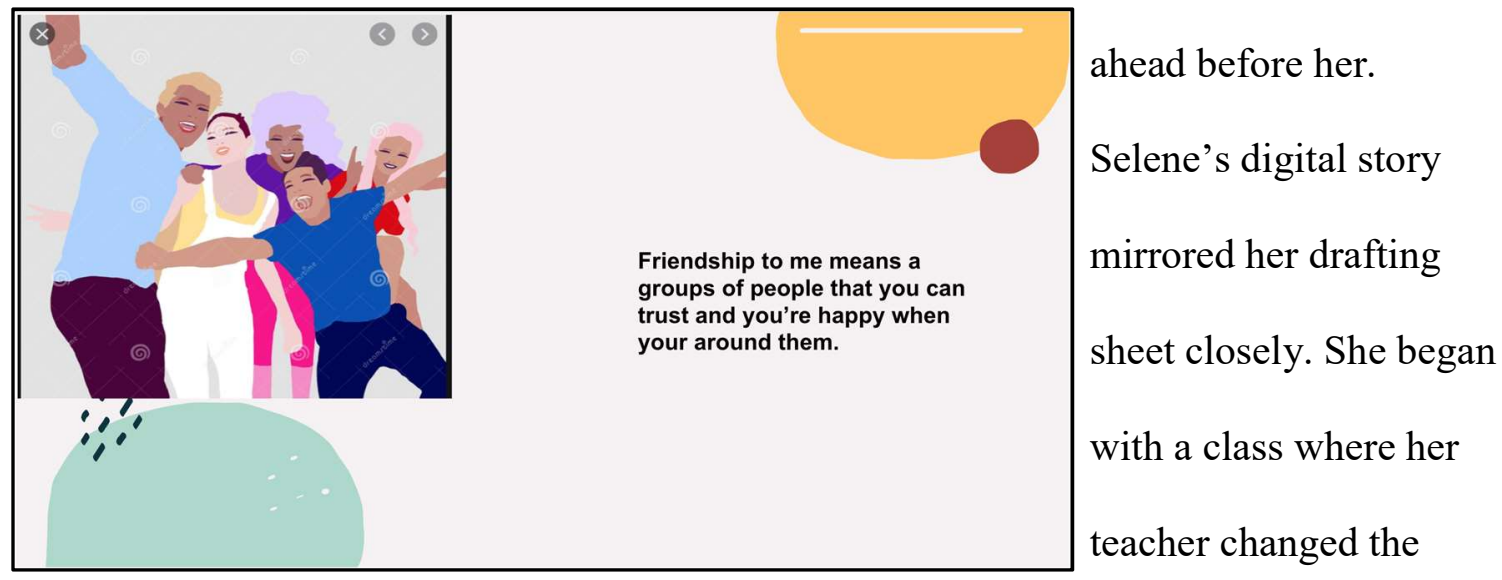

seating chart regularly, allowing her to talk to her friends about work, amongst other things. Selene discussed this class in workshop sessions as well. Her next slide, like others in the study, focused on gym. Next, she talked about her orchestra class and how 
everyone had to sound good for the whole orchestra to sound good. Her last slide was on friendship and its importance to her. The image she chose is of multiracial friends posing for a selfie. In the third workshop session, Selene says, "I miss my friends. I hope I'm on the same team with some of them "cause I really miss them." I believe friendship and peer relationships are integral to Selene's belonging to a school.

\section{Participant Sense of Belonging Ratings}

Of the six participants in the study, five completed the adapted PSSM survey. The survey was posted as a Google Classroom assignment, with no participant seeing the other participants' ratings. Participants completed the survey at different times, with some completing the survey within the first session and others completing the survey at later sessions. Overall, I believe the participants had a high sense of belonging at GDPMS. This is because all five participants marked "Never" for the statement, "Sometimes I feel as if I don't belong at GDPMS" and "Always" to the statement, "I feel proud of belonging to GDPMS.” These statements determine the participants' general sense of belonging at the school. All participants felt they had at least one staff member at the school they could talk to if they had a problem.

There are, however, other responses that indicate that facets of their sense of belonging may not be as high as their overall sense of belonging. For example, concerning staff interactions, two participants noted "Sometimes" to the statement, "Most teachers and staff at GDPMS are interested in me" and one selected sometimes to "The teachers and school staff at GDPMS respect me." With peer relationships, all participants indicated that they sometimes feel as though other students take their opinions seriously. The majority of the respondents sometimes felt a part of the school and not all felt people 
were always friendly. The most significant divergence in responses was with the statements on being included in activities and feeling different from others at school. The emphasis the participants have on peer relationships can account for these responses.

\section{Table 1}

Summary of PSSM Survey Results

\begin{tabular}{|c|c|c|c|}
\hline Indicator & Never & Sometimes & Always \\
\hline I feel like a real part of GDPMS. & - & 3 & 2 \\
\hline People at GDPMS notice when I'm good at something. & - & 1 & 4 \\
\hline It is hard for people like me to be accepted at GDPMS. & 4 & 1 & - \\
\hline Other students at GDPMS take my opinions seriously. & - & 5 & - \\
\hline Most teachers and staff at GDPMS are interested in me. & - & 1 & 4 \\
\hline Sometimes I feel as if I don't belong at GDPMS. & 5 & - & - \\
\hline $\begin{array}{l}\text { There's at least one teacher or staff member at GDPMS I can talk to if I } \\
\text { have a problem. }\end{array}$ & - & - & 5 \\
\hline People at GDPMS are friendly to me. & - & 2 & 3 \\
\hline Teachers and staff at GDPMS are not interested in students like me. & 3 & 2 & - \\
\hline I am included in lots of activities at GDPMS. & 2 & 2 & 1 \\
\hline I am treated with as much respect as other students. & - & 1 & 4 \\
\hline I feel very different from most other students at GDPMS. & 2 & 2 & 1 \\
\hline I can really be myself at GDPMS. & - & 2 & 3 \\
\hline The teachers and school staff at GDPMS respect me. & - & 1 & 4 \\
\hline People at GDPMS know I can do good work. & - & 2 & 3 \\
\hline I wish I were at a different school. & 4 & 1 & - \\
\hline I feel proud of belonging to GDPMS & - & - & 5 \\
\hline Other students here at GDPMS like me the way I am & - & 2 & 3 \\
\hline
\end{tabular}

Note. Adapted from "The Psychological Sense of School Membership Among Adolescents: Scale Development and Educational Correlates," by C. Goodenow, 1993, Psychology in the Schools, 30, p. 84. 


\section{Overview of Themes}

Four themes emerged from the data that was triangulated from workshop sessions, digital stories, semi-structured reflective question responses, and digital story drafting sheets. I triangulated the data gathered from these sources to develop themes. Afterward, I created a Google Form with the potential themes and asked the participants to provide their feedback on the themes. The themes were then further condensed with additional sub-themes added. The overarching themes are honoring lived experiences, peer relationships, fitting in but embracing differences, and being seen and heard by teachers. These themes reflect the participants' collective experience while individual participant voices are threaded into the analysis. I included individual voices in this analysis to honor where experiences were similar and respect where their experiences differed.

\section{Theme 1 Honoring Lived Experiences}

Honoring lived experiences emerged as a theme. I identified two sub-themes that were recurring in participant responses and discussions: 1) "Black pride" and 2) "The importance of family."

Black Pride. One sub-theme within the honoring students' lived experiences is having Black pride. In the first workshop, participants were asked what comes to mind when thinking about belonging or belonging at school. Athena responded with an image of a Black raised fist. This image is used to represent solidarity and support for Black Americans. According to den Berk and Visser-Maessen (2020) this is the Black Power salute, which garnered worldwide attention after the 1968 Olympics when medalists Tommie Smith and John Carlos each raised a black-gloved fist during the Star-Spangled Banner (Black power salute, 2016; Jorrit Van \& Visser-Maessen, 2020). Selene 
commented on this image, stating, "I agree with this because everyone should feel like they matter especially Black people and other minorities" and Iris stated, "\#BlackPride." Iris' use of the hashtag symbol can be seen as an allusion to Blacktags or hashtags associated with African American Twitter users who use the platform to share content expressing Black vernacular, social commentary, racialized issues, concerns, or humor (Sharma, 2013). In another session, Athena wrote, "I think that America is not a free country." As noted in Chapter 3, the workshop sessions occurred during the spread of COVID-19, but also during a time of civil unrest, specifically there were protests against police brutality towards African Americans in the United States and internationally. According to Chenowth (2020), antiracism protests were occurring throughout the United States as a response to the murders of Ahmaud Arbery, George Floyd, and Breonna Taylor. Taylor was a resident of the same city as the participants in this study. The participants' responses show that their present experiences and racial identity impact their sense of belonging. Iris stated in one session, "I think it means like when someone is like let's say a Black pride protester, feel like they're different, you should feel like they belong in the country, you shouldn't make them think that they don't belong in the country because of the fact that they're different." In Iris's statement, there is an overlap with the theme of "Fitting in, But Embracing Differences." She uses the events occurring in the city and throughout the country as her definition of sense of belonging. In her response, there is an emphasis on not only honoring Black experiences but acknowledging and accepting voices that may differ from one's own. Similarly, in Diana's digital storytelling draft her idea was to focus on Black female excellence. She wrote, "I see the people whispering good things on African American women," and "I 
hear the amazing things us Black females can do.” Here, acknowledging Black excellence is Diana's example of sense of belonging in school. She wants an environment that recognizes Black excellence, her excellence, out loud.

While acknowledging Black excellence increases sense of belonging, failure to foster relationships across race and When you think of belonging or belong what comes to your mind? What do you think of when you think of belonging at school?

misrepresentation of African American experiences can hinder sense of belonging. Iris brings up that race, specifically skin color, impacts sense of belonging at school. First, she includes a chart of different skin colors in her story and says, "I feel this chart shows Sense of Belonging because it shows different skin color which sometimes is why people don't feel like they belong." Then, she includes images of Bratz dolls of varying races and says, "I feel this photo shows Sense of Belonging (Race) because it shows different color Bratz Dolls as Friends." This can be a connection to her PSSM survey response; she noted only sometimes do other students like her the way she is. The order of Iris' images shows that while race can be a reason for diminished sense of belonging, friendship across racial lines can exist.

Athena brought up another hindrance to sense of belonging. She explains an experience she had in one of her classes where she describes feeling misrepresented:

I think we was in 4th period and we was talking about racism and the West End and it was like a graph and it was like how Black people in the West End don't 
have a lot of money... and a lot of people in my family live in the West End and I have a lot of money and I was like what?

Here, she explains how the representation of her community as impoverished did not include her and her family. During our session, I could not hear Athena's comments clearly, but could hear the recording during the transcription phase. Since during the session I could not make out her words, I ask for her to repeat her thoughts and Athena added, "Um, so like we was talking about Black history and the discrimination and like how a lot of people from like a long time were like the West End was for like White people and then like a whole bunch of Black people started moving in." In this addition, she explains her community's shifting demographics that she learned about in her fourthperiod class. This was her original idea she expressed for her digital story. While this was not the experience she chose to illuminate in her digital story, she is particularly concerned with herself and her family being labeled as low income because she is from the community discussed in the class. In her PSSM survey, Athena selected sometimes for being treated with as much respect as other students and for school staff respecting her. This experience can provide context for her selection in that her identity, in her eyes, was not faithfully represented, thus was not respected.

Family. In addition to Black pride, family recurred throughout the session and emerged as a sub-theme. In one session, I asked the participants to share who inspires them as our icebreaker. Three students participated in this icebreaker and each mentioned a family member. Iris mentioned her father, Athena wrote about her grandmother, and Rhea mentioned her mother. Iris even put a picture of herself and her father into the icebreaker slide to share with us. Rhea read the question aloud and responded immediately and 
without hesitation, "My mom inspires me because she's a leader.” In another session, the icebreaker was to share something that brings joy. Athena shared two stuffed animals, one given to her by her father and another by her uncle. Selene discussed going to Disney World with her family and reminisced on a particular incident where her father jumped into a picture she was taking of her "mawmaw," or grandmother. While these icebreakers were not directly related to sense of belonging, the participants' responses show the importance of family. When asked how parents can impact school sense of belonging, Selene wrote, "Well I think that having your parents

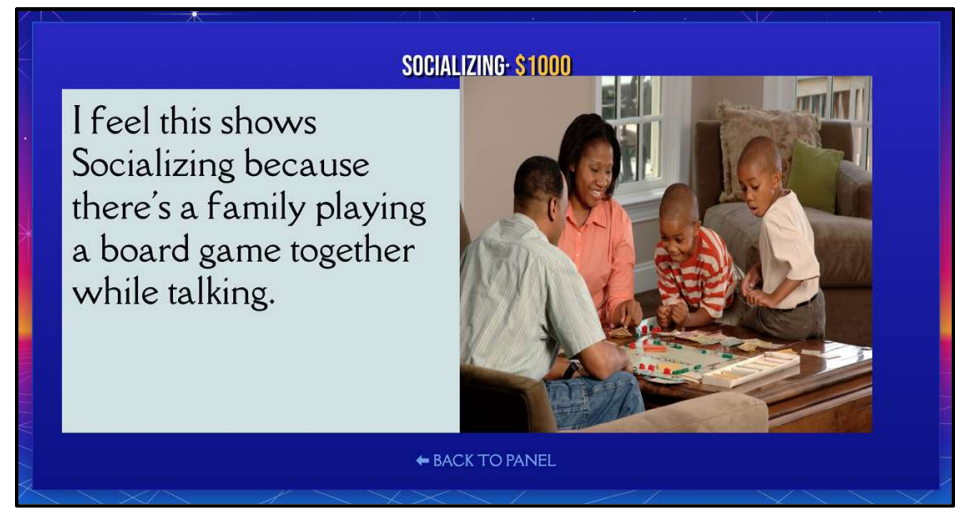
involved with school can make you feel better about talking to staff about your problems because you've been able to connect with them when your parents are there." Selene tells us that parents and family can serve as an advocate for students in schools.

The participants' responses on Black pride and family were labelled under the theme of honoring students' lived experiences because participants' lived experiences emerged in their responses on sense of belonging. This shows that sense of belonging in school is connected to acknowledging, understanding, and honoring racial identity and students' family bonds.

\section{Theme 2 Peer Relationships}

Peer relationships was another theme that appeared in the data. Within this theme, two subthemes emerged: peer collaboration and having fun. The in vivo codes "friends," 
"friendships," "help," "help[ing] each other," "working together," "fun" "having fun," "laugh" and "laughing" frequently appeared in the digital stories, sessions, and within participant responses. Participants mentioned having their friends as a support system and classroom practices that allow for friendship and peer collaboration to thrive, as well as, enjoyment with friends.

Peer Collaboration. Within the classroom, friends furthered sense of belonging through helping one another with assignments and classwork. In her digital story Selene said, "I felt like I belonged when I was in the classroom with my friends and we used to talk about stuff and help each other with our work and we could talk to each other about stuff that we related to and that's it." In her digital story, Selene shares on her orchestra class. In this class, students helped one another so that the individual was just as successful as the collective by making sure, "we could all sound good and not just one of us." Athena explains how her classmates supported her when staff would not. Athena says, "also like I did feel included, but I felt included by the students, like but not by the teachers." Upon probing she adds, "She would tell me like the reason like I didn't understand it was because I was talking or something but like I still like didn't understand and I was still trynna ask her for help but then that's when I stopped and started asking my friends for help." Athena explains her being misrepresented by her teacher, assuming Athena did not understand the content due to her talking, leading her to no longer seek the teacher's help altogether. Similar to the misrepresentation of her community, this teacher's interaction with Athena diminished her sense of belonging. Rhea explains working together with her peers in her gym and computer class. She says, "I felt included in third period because everybody was helping each other on the computer helping them do their work most of 
the time and doing everything like getting the like one that we needed, the stuff that we needed." Minerva echoes this in her digital story and mentions laughter; she states, "With friends: We can we will talk and they would help you learn sometimes and make you

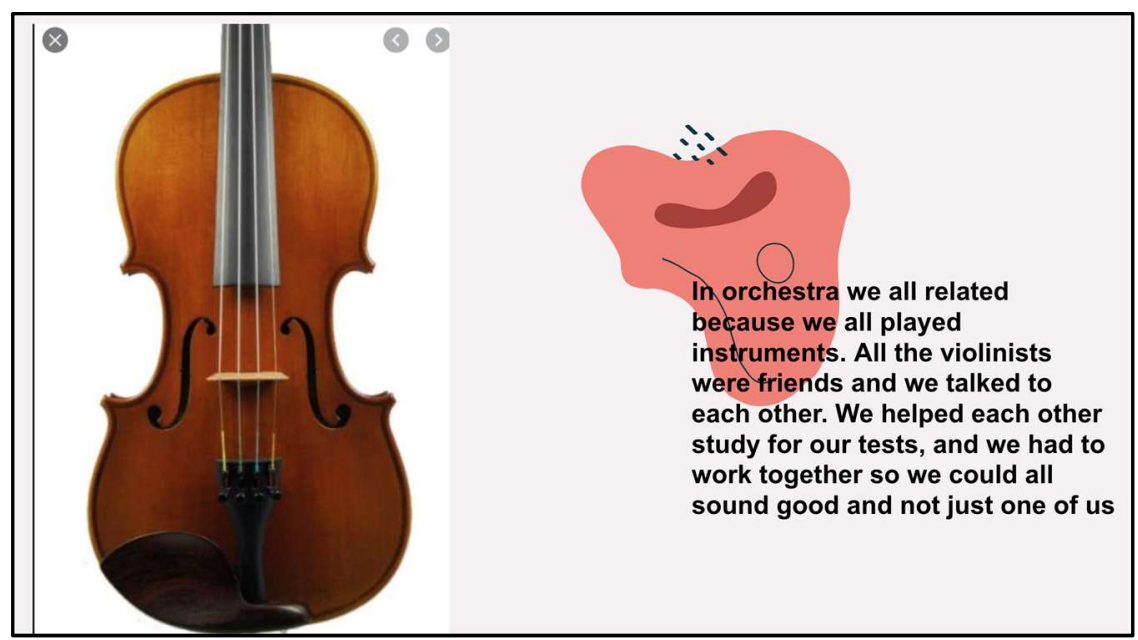

laugh which makes

you feel like you

belong there."

These examples

show how peer

collaboration and

learning with peers

are ways to increase

sense of belonging.

Still, within a peer support system, there can be difficulties in strengthening sense of belonging. Athena explains that if her friends talked to one another in her class and not her, she did not feel included. In our last session, she said, "I was in classes with most of my friends but like but like even the classes that I was in the classroom with my friends it still kind of didn't feel, it didn't feel like I belonged because like my friends they would go and talk to their other friends." To mitigate isolation, peer collaboration and mutual support can be facilitated by teachers as well. Selene stated,

Okay so Ms. Smith, she changed our seats so much and we really didn't like it, but changing our seats gives us different ways we can talk to different people you don't have the same group of friends all the time and you can try to branch out but like I think our school has a lot of clubs and stuff so yeah you can join that 
especially in like gym class because we worked on teamwork and it was just really fun

Selene explains that by changing students' seats regularly, despite student disapproval, her teacher facilitated peer support and collaboration.

Having fun. Having fun with friends and peers is a way to increase sense of belonging at schools. According to the participants, gym class, in particular, was a space for them to have fun. Selene engages in a conversation with Athena about gym class and her fourthperiod class, English. She says, "Ah Athena, you remember gym class? That's so fun and fourth.” Athena, agrees with Selene on how fun gym class was but with a caveat. She stated, "Fourth period was fun. It was only fun when I got to sit next to y'all." In the earlier example about changing seats, Selene mentions gym class and

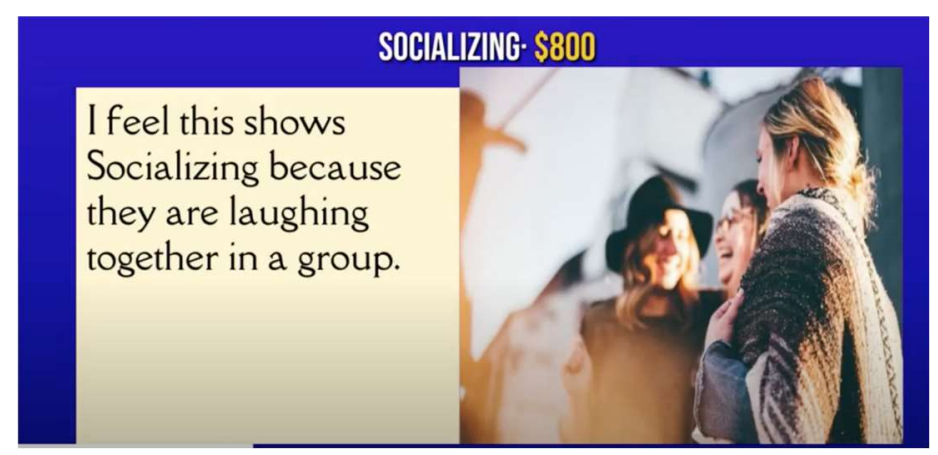
how it allowed for teamwork and fun. For Iris, sense of belonging is linked to fun and laughter. Iris states, "My classmates they help me have fun and laugh and sometimes help me learn too."

Events and clubs can provide opportunities for fun. Athena mentions having fun at a pep rally, "I do because I think that when we had the pep rally when we had the pep rally we had more fun like we wasn't like in the classroom all day doing work so like we had fun." Here, including supplemental activities outside of the regular classroom routine can increase student sense of belonging by adding fun. When asked about clubs or activities and how these can impact sense of belonging, Rhea said, "Like it just depends 
on what type of club it is like if it's cheerleading I like it because that's my favorite club basically. Cheerleading or dance and other clubs like I also like track and girl's on the run those are my top clubs but the other clubs I'm not so good about." If those clubs did not exist, this would not impact Rhea's sense of belonging; she adds, "No. No, because I still got friends in my classes throughout my first and seventh." While beneficial for Rhea's sense of belonging, extracurricular programming cannot overpower the sense of belonging attained from peer support and community in the classroom.

According to the participants in this study, peer relationships and creating opportunities for peer collaboration is linked to sense of belonging. They mention having friends as their support system in classrooms with content and understanding. Participants also talk about having fun at school with their friends.

\section{Theme 3 Fitting In, But Embracing Differences}

The next theme that emerged from the data was fitting in, but embracing differences. Within this theme, two sub-themes emerged: being included and safety. In the study, participants mentioned how important it was for them to be included even when they are dissimilar to others and finding a space where they fit in. The in vivo codes are "wanted" "group," and "left out." I interpret these codes as the desire to be a part of an inclusive environment.

Being Included. Rhea mentions making sure to include others despite differences. In her PSSM survey, she indicated that only sometimes others like her the way she is. Likewise, the importance of fitting in is emphasized in her words. She says, "Like when you're at school you like help other people like don't just don't help them because they have like pink hair or something and help them like you help other people that doesn't have like 
different colors and stuff." She uses hair as an example here, but this shows a school level microcosm of Iris's comment in Theme 1 on making Black Lives Matter protestors feel as though they too are a part of the country. Selene describes sense of belonging as, "I think of people being together and everybody's happy and feels wanted and nobody feels left out or sad." Wanting to be included by friend groups and not isolated from peers is a way to increase sense of belonging. In one session, the conversation shifted to if there ever was a time where the participants did not feel included. Quiet took over the usually conversational sessions. After some time, Iris spoke up on the feeling of being left out and on not fitting in. Iris explained,

Like there's popular kids in the school. So it's like when let's say you are in a class with popular kids and you're not like popular so you're in class with popular kids and kids that are popular and most of your friends are not in that class and you're just there, you don't feel like you belong because you're not

Selene had a similar experience of being excluded to Iris's but in elementary school. She wrote, “One time where I felt like I didn't belong was in fourth grade when my so called friends left me out." Selene is now a rising seventh-grader, yet she still recalls this experience of being excluded from her elementary years, showing how necessary fitting in is to participants. Iris provides an example of not fitting in with popular students and feeling isolated from those around you. In our final session, Iris posted a picture of an upset child with fingers being pointed at him. Interestingly, while this study focuses on African American female students and their sense of belonging, the images here are of a young boy and an all-male group; it does not appear that any of those in the images are African American. Athena describes this picture, "I think the picture with the kid that's 
like not belonging, he doesn't have a lot of friends and like they're pointing fingers at him because he doesn't have a lot of friends."

Safety. Being included and accepted is also likened to feeling safe in some responses. In her answer to the question, "When you think of belonging or belong what comes to your

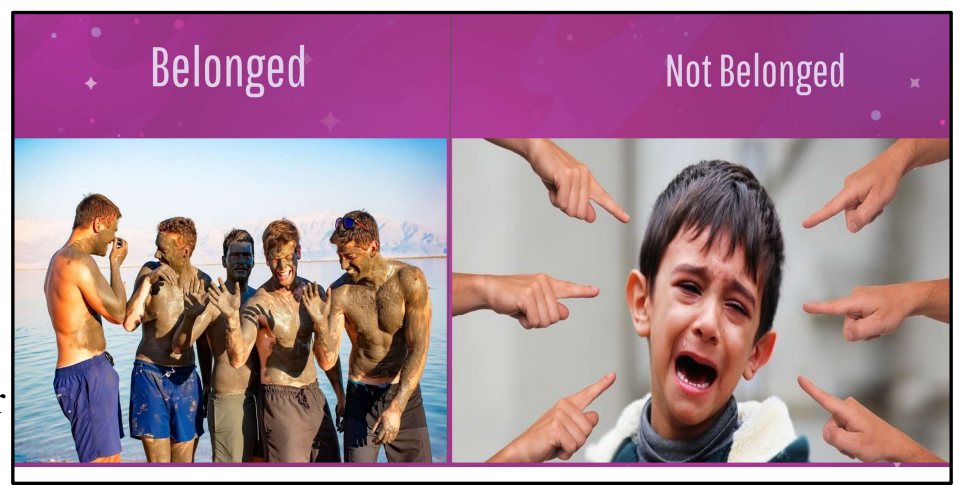
mind? What do you think of when you think of belonging at school?" The concept of safety is reiterated in Diana's comment slide and other participants' responses to her.

Diana: What I think of is that it would be like a safe place that you feel safe in. Athena: I agree

Selene: I agree because everybody should feel safe and wanted by a group of people

Iris: I agree with your answer because a lot of people don't have a safe place While it is ambiguous as to if the participants refer to physical safety or emotional safety, Selene's mention of being wanted makes the response thread one that focuses on emotional safety. Similarly, in an anonymous comment, one participant wrote, "I also agree because I mean it would not be fair if people are being left out when they do not feel safe in a place where they should be happy and feel wanted." Here, the comment also describes both how a school should be and how it should not. Happiness is closely related to safety for participants. Selene discusses happiness, fitting in and describes both her vision of what sense of belonging is and what it is not as well: "I think of people being 
together and everybody's happy and feels wanted and nobody feels left out or sad." One way to find a safe space and bolster happiness is to ensure that every student feels wanted. In one session, Iris posted an image she found from the internet that included a quote. The quote read, "What I hadn't forgotten was how I felt when I was in his class. How he encouraged me and how he tried to make a misfit feel that she did, in fact, belong." Here the term "misfit" reflects the idea of differences and the teacher makes sure that even this student feels accepted in the classroom despite differences. This type of classroom functions as an emotionally safe space for students.

\section{Theme 4 Being Seen and Heard by Teachers}

The final theme that emerged from the data was "Being seen and heard by teachers." In vivo codes in this theme include, "help," "raised my hand," as well as "chance." The participants in this study suggested practices that teachers can incorporate into their pedagogical approaches that would increase sense of belonging for African American female students. They offer providing everyone a chance or opportunity to speak or participate in the classroom community. Minerva said, "If my teachers sometimes let me speak my mind and let me tell others what I think. It would be better if teachers give everyone a chance to speak their mind." Minerva, the only participant to indicate wanting to be a different school on the PSSM survey, wants not only her voice to be heard but the voices of her peers as well. Her digital story also included a slide on her raised hand going unacknowledged by teachers. Selene provides a concrete method by which each students' voice can be heard and recognized by teachers. In one session, Selene suggests to teachers, "They can try and call on you so people can know how you feel. You know when your voice is respected because people will understand you." Here, 
Selene suggests calling on students to hear their voices. Upon calling on students, not only are they heard, but respected as well. In a session, Selene recalls a teacher's use of Class Dojo during in-person instruction. This web-based platform for educators allows for feedback points provided, goal-setting, instant communication of positive actions and goal-setting to parents and families who are linked to the platform, and a random name selector feature. Selene focuses on the last feature in particular. With random name selection, Selene states, "It makes you know everybody has a chance, everybody has a chance to answer the question." With this, students who are not called on frequently or who may be reluctant to raise their hands also can have their voices heard within the

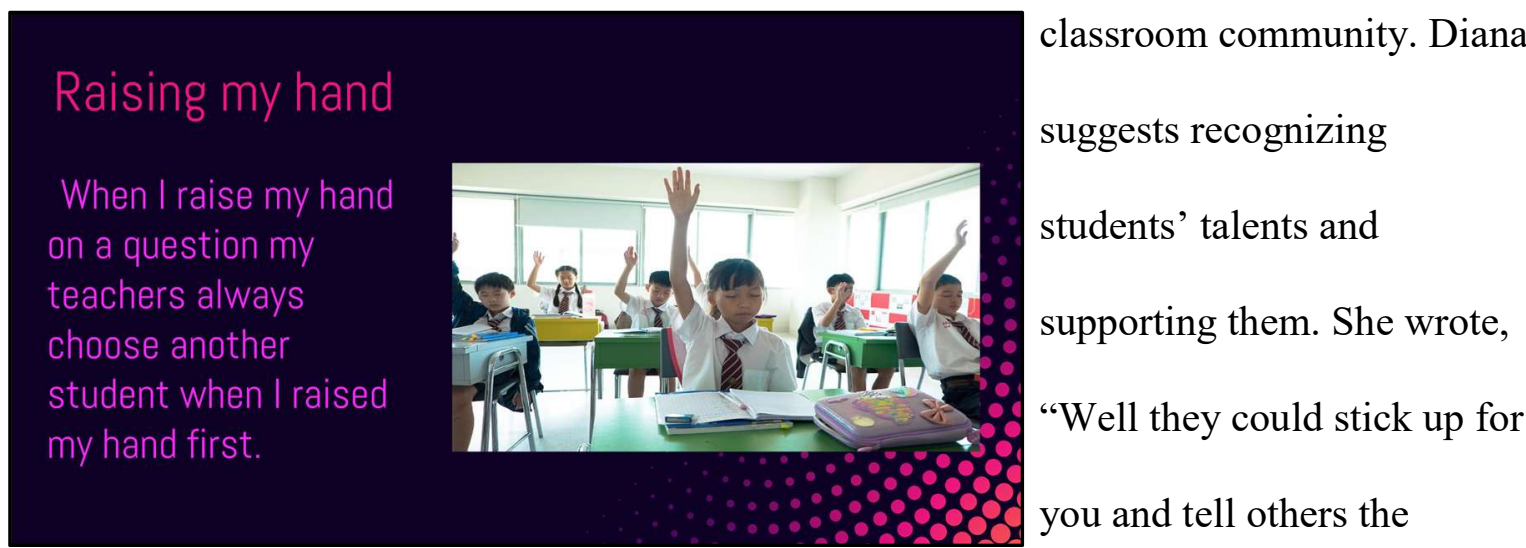

amazing things you can do on your own like your talents." Here, praise is another strategy for teachers to see and hear students.

The participants also mentioned their raised hand going unacknowledged by teachers. Athena wrote, "If I raised my hand, sometimes my teachers wouldn't pick me." Minerva also stated in her digital story, "Raising my hand: When I raise my hand on a question my teachers always choose another student when I raise my hand first." In a workshop session she stated, "Cause when people raise their hand, no one... well they choose the other people instead of choosing..." and her voice trailed off. Minerva does 
not tell us which group is not selected or if it is just her that is ignored. Nevertheless, it is clear others are chosen over her. In these quotes, all students are asking for help by raising their hand. Raising one's hand is a uniform practice in all classrooms. They are actively seeking teacher support by following the established norm in American classrooms of raising one's hand to gain attention. In one session, Rhea would raise her hand to be given a turn to speak even in a virtual setting. This may be because I am a member of the school's faculty and the workshops may mirror the synchronous lessons she had through non-traditional education. Regardless of the reasoning, Rhea was engaging in this ritual of hand-raising to be recognized when in a school setting. Minerva and Athena's ignored hands speak to their invisibility or lack of recognition in classrooms. This can be why both participants indicated they did not feel a part of the school in their survey. Iris, on the other hand, is recognized in classrooms. She provides us with a summation on sense of belonging for her, at her school. She explains, "When I feel like I belong at Georgia Davis Powers Middle School it's because of my classmates and my teachers. My teachers help me when I need help." Not only does she receive peer support (Theme 2), but her teachers provide her with help as well. She is acknowledged and seen by both groups.

Participants also discussed having all facets of their personality seen. Iris discusses being seen when she excels, but when she also does not excel. She said:

Yes because I feel like sometimes like my other icebreakers that we said I think it was like 2 days ago, like 3 days ago people will like slow down because some people may not understand you know as fast as others and I think that's like in STLP [Student Technology Leadership Team] like I, yeah I'm slower than others 
a little bit and faster than others a little bit sometimes I can be great and sometimes I can be not too great, you know?

She begins this statement with a generalization of recognizing people, with some being fast and others needing more time. She moves to a specific example of how she can be faster in some ways and slower in some ways than others in her student technology group. Similarly, Athena discusses the varying facets of her identity and when she is seen. Although she may not be discussing teachers in particular in her response, she is discussing being seen and where she feels the most seen. She describes having another side that is only for those closest to her: "So like I don't like how, people that know me like how Selene knows me, other people don't see me like that." Others see her as reserved, but her friends know that, "The other side of me is like I'm very goofy and extra, and I like to mess with people, I don't know why but I do. I like to have fun.” Again, while Athena's response is not directed exactly to teachers, it asks how we can create spaces for all students to be seen and acknowledged as multi-faceted.

\section{Participant Input on Themes}

To gather participant input on the themes that emerged, four questions were populated into Google Form (Appendix J) and participants were asked to respond to the questions. Of the six participants, Minerva, Selene, and Iris responded to the survey. The first question asked if the participants agreed on the themes. All three participants agreed on the themes. Iris responded, "Yes I agree and what do you mean by being seen by teachers?" I responded via text message explaining that this theme meant when a student's raised hand was acknowledged, or a student received help from a teacher. The second question asked participants if other themes should be added. One participant 
stated, "These are good topics. I can't think of any other topic," and the others did not think additional themes were needed. The third question in the Google Form was a general question on participants' thoughts on the themes. One participant wrote, "I love the Theme Fitting In, but accepting differences because it means that the fact that I'm Black you should still accept me for who I am but be my friend not because I'm Black."

The themes were slightly altered after this survey. Since this Google Form, I revisited the data and noticed that family was also a part of the participants' responses so family was added to the first theme. Additionally, "Having fun at school" was merged with "Classmate groupwork and support" because upon additional analysis of the data, fun was interconnected with peer relationships. Lastly, "Being seen by teachers" was amended to include being heard by teachers as well. Iris's question on the theme showed that additional clarifying language would be necessary to illuminate this theme further.

The final question asked participants how we should move forward with the results and information revealed from the study. The three respondents commented on the last question and suggested that we take this information outside of the research setting. The comments were:

- "We should do those topics and do maybe charts or projects with the topics we have"

- "We could try to be like this at school because I think a lot of people feel the way we do"

- "Use that information to accomplish other things" 


\section{Summary}

Chapter 4 began with an overview of each session, an introduction to each of the research participants, their level of participation in the study, and details on their digital story. Then, the results from the PSSM survey were discussed. An analysis of the data that was collected, analyzed, and triangulated was included. The data was organized along four themes. These themes were honoring lived experiences, peer relationships, fitting in but embracing differences, and being seen and heard by teachers. The chapter concludes with participant input on the themes that emerged from the research. Chapter 5 will provide a discussion of the major findings, implications for policymakers and practitioners, and recommendations for future research. 


\section{CHAPTER V}

\section{DISCUSSION AND CONCLUSION}

\section{Introduction}

This dissertation study intended to discover what fosters sense of belonging for African American female students through their voices and experiences. The overarching research questions of this study were 1) According to students, what contributes to a positive African American female sense of belonging in school? 2) According to students, what diminishes African American female sense of belonging in school? This dissertation study uses both Critical Race Theory (CRT) and Black Feminist Thought (BFT) to make African American female students' voices and experiences central. Their voices construct the understanding of sense of belonging. This final chapter of this dissertation will present a summary of the study, key findings drawn from the data presented previously in Chapter 4 and will describe the relevance of these findings to existing research literature. Recommendations for practice, policy, and future research will also be provided.

\section{Summary of the Study}

Researchers have explored sense of belonging through quantitative and qualitative measures. Within previous research, there are limited studies that use direct African American student voices on sense of belonging (Booker, 2007; Kester, 1994). Where student voices are included, African American female voices are not central to the 
research. Accordingly, this dissertation study used a Participatory Action Research approach to co-learn with participants what fosters or diminishes sense of belonging. In addition to constructing knowledge around sense of belonging through participants' voices, this study aims to change practices within schools and classrooms so that, indeed, all students feel as though they belong. As one participant wrote, we should, "Use that information to accomplish other things."

\section{Discussion of Findings}

Four themes emerged that show how sense of belonging is fostered or diminished for African American female students. The themes to emerge from the data were: 1) Honoring lived experiences: Black pride and family 2) Peer relationships: Peer collaboration and having fun 3) Fitting in, but embracing differences: Being included and safety 4) Being seen and heard by teachers

\section{Honoring lived experiences: Black pride and family}

Black pride. Affirming African American female students' racial identity is integral to fostering a positive sense of belonging. While Hernandez, Robins, Widaman, and Conger (2017) found greater ethnic pride amongst male students, participants in this study had a strong sense of pride. Diana wrote explicitly about hearing positive things African American women can do within a school as a way to foster belonging. Diana's response is similar to Dotterer, McHale, and Crouter's (2009) research, where high levels of ethnic identity, such as pride, show increased school belonging. Furthermore, Selene wrote about everyone feeling as though they matter in America, especially African American people. When asked about what sense of belonging means, Athena simply responded with a Black raised fist. The participants' responses mirror Boston and Warren's (2017) 
work on sense of belonging. Their study results suggest that African American students feel a sense of belonging when schools create a culture of acceptance for all races. Collins (2009) write in Black Feminist Thought, "On some level, people who are oppressed usually know it" (p. 11). The participants in this study were aware of the oppressions African American people endure and have experienced them in some capacity firsthand. In her digital story, Iris noted that skin color makes people feel like they don't belong. Athena also described her experience in class where she felt a teacher misrepresented her community and race. Inaccurate portrayal and historical inaccuracies when teaching students on African American history and culture diminish sense of belonging (Gray, Hope, \& Matthews, 2018). On the other hand, Gray et al. suggest to encourage African American students to explore their racial identity and heritage within school settings.

Family. In her section entitled "Safe Spaces and Coming to Voice," Collins (2009) explains that family networks and community institutions were essential to African American women to counter the controlling images of African American women perpetuated by the media and other institutions. Though not explicitly stated as impacting their school sense of belonging, for participants in this study, family was integral to their lives. Hence, family connection may be a way to foster sense of belonging. The participants noted family members as role models, and when discussing fond memories, they usually included family. Selene wrote on how parents can serve as advocates for students. Some researchers have examined family and parental connections in sense of belonging research. Similar to the findings in this study, Kester (1994) found that embedding students' lives outside of school into the classroom can increase belonging. 
Kester (1994) provides examples of achieving this such as including a students' commitments to their local community center as a part of their grade, recognizing their participation within community events, and overall, valuing their connections outside of school. Additionally, Furrer and Skinner (2003) found that students' connection to their parents can increase their academic motivation, engagement, and connection to school. Thus, family networks should permeate a school setting.

\section{Peer Relationships: Peer Collaboration and Having Fun}

Peer Collaboration. Opportunities for collaboration with peers in school foster sense of belonging for participants in this study. Collaboration can include helping peers with assignments or understanding content and working together towards a project or performance task. This finding confirms research where a positive correlation between sense of belonging and peer relationships exists at school (Bouchard \& Berg, 2017; Faircloth \& Hamm, 2011; Faust, Ennis, \& Hodge, 2014; Nichols, 2006; Vaquera, 2009). While Bouchard and Berg (2017) and Osterman (2010) found that teachers have a greater impact on belonging than peers, the participants in this study emphasized peer relationship and interactions. This emphasis may be because, as Uwah, McMahon, and Furlow (2008), argue females are interpersonally related. Participants discussed working through classwork with friends and receiving help from friends and classmates. This example reflects the second tenet of BFT, the use of dialogue. Collins (2009) explains that African American women see connectedness and dialogue as the main way of knowing. She writes, "new knowledge claims are rarely worked out in isolation from other individuals and are usually developed through dialogues with other members of a community" (p. 279). The participants in this study valued collaboration with their peers 
over isolation and saw collaboration as integral to their learning and, ultimately, belonging. The participants discussed informal opportunities to collaborate like talking with their peers on classwork and assignments and formal opportunities such as working together on a common goal.

Having Fun. For participants in this study, having fun is a part of their positive sense of belonging at school. The sense of belonging literature reviewed within this dissertation study does not address the relationship between sense of belonging and having fun or enjoyment at school. However, research conducted on middle school students by Hagenauer and Hascher (2013) shows that high school enjoyment is related to high academic achievement. Similar to research on sense of belonging where belonging decreases as students matriculate, Hagenauer and Hascher (2013) found that school enjoyment also decreases as students get older (Furrer \& Skinner, 2003). Enjoyment is one of the common emotions students feel in learning environments and occurs when students face different learning tasks at school, collaborative learning, and tasks based on competence levels. Hagenauer and Hascher (2013) suggest that fun is vital to a students' desire to engage in lifelong learning. They argue that to facilitate lifelong learning and enjoyment, both external rewards and intrinsic motivation should be included in a student's experience at school.

At the same time, extracurriculars were not as heavily emphasized by participants in this study as spaces for fun, peer collaboration, and belonging when compared to embedding these opportunities during the school day. In fact, one participant indicated she would be fine without afterschool programming because she had opportunities to be with her friends throughout the school day. This example reflects Booker (2007) and 
Brown (2009), the latter cautioned against relying solely on after-school programming. Instead, this study's responses show that collaboration and fun can and should be incorporated into events and into daily classroom practices to increase sense of belonging for African American female students.

\section{Fitting in, but embracing differences: Being included and safety}

Being included. Participants in the study emphasized being included within a peer group as a facet of a positive sense of belonging at school. On the other hand, participants spoke of experiences where they were left out and these experiences diminished their sense of belonging. They desired to be wanted by other students, even if there were differences amongst them. This desire is similar to research on peer relationships, peer group acceptance, and sense of belonging. Furrer and Skinner (2003) found the loss of peer relatedness can decrease belonging. Being included is also mentioned in Vaquera's (2009) work on school-based peer relationships. The author writes, "students may feel out of place in school and thus do not make friends, or students who have trouble making friends in school may then believe that they do not fit in their school " (p.502), both leading to decreased school belonging. Being excluded can lead to feeling out of place and feeling out of place can cause a student to be excluded from friend groups. On the other hand, being included is seen in Kester's (1994) results where peer acceptance is important to the participants in the study, in so much as success in the classroom was contingent on acceptance by peers instead of grades.

Safety. Feeling emotionally safe fosters sense of belonging for participants in this study. During workshop sessions, participants mentioned safety and feeling safe on a number of occasions. Safety is explicitly discussed within BFT, as well. Collins (2009) explains the 
importance of safe spaces and what constitutes a safe space: a space devoted solely to African American females, their empowerment, and free from surveillance from powerful entities. Developing safe spaces that honor differences is all the more vital given that, as Collins (2009) asserts, there is no uniformity of Black female experiences. Within the sense of belonging research reviewed for this dissertation study, safety is not mentioned. Routinely, staff members can facilitate a safe environment by protecting students and making sure others treat them kindly (Bouchard \& Berg, 2017). Safe spaces can be developed similar to Brown's (2013) Saving Our Lives Hear Our Truths (SOLHOT) program. This program centers on African American females through performance-based autoethnography, poetry slams, dance, hip-hop, dialogue, and including African American female voices. Embedded within the program is Black girls' celebration and allowing the girls to discuss the issues they find important.

\section{Being seen and heard by teachers}

Within this dissertation study, participants felt a sense of belonging when their voice was heard and they received opportunities to respond within a class. The concept of student voice is seen within Faust et al.'s (2014) research on sense of belonging. The researchers write:

Allowing students' voices in the classroom empowers students to advocate for themselves and for their peers. Student voice encourages academic and social growth in areas of cooperation, compromise, negotiation, and conflict resolution. Having their voices heard and establishing positive relationships with teachers and peers increases students' satisfaction levels within the learning environment. (p. 44) 
This shows the far-reaching effects of increasing student voice within the classroom, including fostering sense of belonging. This finding is visible in other sense of belonging research where allowing student voice in the classroom, active listening, and seeing students as individuals all increase sense of belonging (Bouchard \& Berg, 2017; StAmand, Girard, \& Smith, 2017).

At the same time, participants within the study felt as though their belonging diminished when teachers did not provide them opportunities to voice their thoughts or ignored them. Specifically, two participants in this study mentioned their raised hand going ignored by teachers. Within sense of belonging research, Murphy and Whitelegg (2006) found that male students had greater opportunities to participate in class than female students and teachers spent more time working with male students. While the participants in this study did not mention the gender of students given opportunities to speak or were acknowledged by teachers, this finding suggests that African American female students are not seen and heard as much as their peers. Although specific to schools, this finding reinforces previous studies on African American females that emphasize their invisibility in research (Chavous \& Cogburn, 2007; Smith, 2016). Chavous and Cogburn (2007) and Smith (2016) both discuss how research does not concentrate on African American female experiences. Regarding schools, Brown (2013) notes how normalized African American female invisibility has become. She states, "The more I work with Black girls, the more unsure I am about how to explain with any kind of absolute certainty what produces a Black girlhood so devastatingly devalued that, more often than not, invisibility becomes boring, a nonissue" (p. 100). 
These findings reflect the previous sense of belonging research but also add to our understanding of sense of belonging for African American female students. We learned the importance of racial identity, family, having fun, and feeling safe as components to fostering belonging. These components are in addition to peer relationships, being seen and heard, and peer acceptance, which was visible in the previous sense of belonging research. These findings can impact specific classroom practices so that African American female student belonging is fostered.

\section{Implications for Practice}

There are several implications for school-based practitioners, specifically teachers, that when practiced, foster sense of belonging. Additionally, some practices must be halted that diminish sense of belonging. These practices align to the themes that emerged from the data. Moreover, the research participants themselves provided some practices educators can utilize.

\section{Honoring Lived Experiences: Black Pride and Family}

Practitioners, specifically classroom teachers, can increase sense of belonging by creating a classroom community that honors students' lived experiences and racial identity. Teachers should mirror the practices Muhammad (2012) utilized during a fiveweek writing institute designed for African American females between the ages of 11 and 17. These practices included writing with students, allowing for writing that helps students self-define and counter misrepresentations, and incorporating texts that have social, political, spiritual, cultural, and economic foci. Furthermore, Muhammad (2012) cautions against using Black literature merely to showcase diversity. Instead, the curriculum should be responsive to students' multifaceted identities. Greene (2016) also 
explains that texts must affirm African American female students' race, gender, and cultural identities and their experiences outside and inside of school. Additionally, because this dissertation study occurred during a period of civil unrest, staff must be cognizant of how current events impact students, particularly students of color. Although the participants in this study were young, they were still aware of the protests, demonstrations, and the discourse around the killing of Breonna Taylor. Accordingly, school staff and practitioners must consider proactive methods of creating spaces of inclusion for students to present their thoughts and ideas, or as Morris (2016) suggests, "healing-informed learning spaces," (p.51). These spaces include mutual creation of norms, open and/or anonymous discourse between the teacher and students, and amongst students (Morris, 2016).

Furthermore, inaccurate and stereotypical portrayals of African American females in schools must be stopped (Morris, 2016; Muhammad 2012). Likewise, colorblind approaches should also be halted. Instead, more dynamic representations of African American females should be incorporated into curricular and pedagogical practices. Morris suggests, "imagine LaKeisha as a doctor in a math word problem and that they [students] understand the role of African American girls like Linda Brown and Claudette Colvin in shaping the nation's discourse on desegregation and equity in education" ( $\mathrm{p}$. 52). Furthermore, Ladson-Billings (1995) provides a classroom example where a student assumed a princess always had long blonde hair. The teacher counters this point by sharing an African folktale about a princess with the class. (Ladson-Billings, 1995). Because curricula are cultural, educators should allow for opportunities to legitimize African American culture, for students to see commonalities between themselves and the 
curricula, and to take pride in their connection to those who are similar to them (Gray et al., 2018).

Moreover, practitioners should develop connections with the families of the population they serve. Moving to a strength-based partnership that affirms African American values and cultural norms can help to solidify the connection between home and school (Thomas-Moore \& Day-Vines, 2010). Thomas-Moore and Day Vines (2010) describe a mutual relationship where African American families share their worldview and experiences with prejudice or oppression. Then, school staff affirm these experiences even if they are different from those of other students in the school and collaborate with families to support the student. According to Bryan and Henry (2008), school staff should shift from deficit to strength-based thinking and actions. Instead of assuming parents do not care when they are not involved in ways schools expect them to be, school staff can partner with local community-based organizations to create programs and resources for students and families. The authors suggest a Parent Involvement Committee, including both parents and staff to plan and implement programs. Finally, when programs and events are planned, parents and families should be invited to the school through direct and personal invitations.

\section{Peer Relationships: Peer Collaboration and Having Fun}

To foster sense of belonging for African American female students, educators should incorporate opportunities for collaborative learning into their pedagogical practice. Embedding collaborative learning into routine practices will allow for increased belonging. According to Ladson-Billings (1995), collaborative learning can be fostered informally when the teacher encourages students to teach one another and to be 
responsible for their academic success. She suggests formal collaborative learning can be created through a buddy system where students are paired together. A participant in this dissertation study offered a strategy for practitioners to increase peer relationships and collaboration. Collaborative learning is a facet of culturally relevant teaching (LadsonBillings, 1995). Selene recalled a teacher who regularly changed students' seats to allow students to work with different peers. This increased opportunities for students to "branch out" instead of staying with "the same group of friends all the time."

Finally, fun can be embedded throughout the school year through school-wide community-building events. The participants within the study noted the pep rally as a fun event. This event included an opportunity to showcase student performances, student versus student competitions, and student versus staff competitions. On a smaller scale, teachers can mirror these practices in their classrooms through embedding games and competitions into instruction. By infusing games into the classroom, fun can be increased, and as a result, sense of belonging. According to Koh, Kin, Wadhwa, and Lim (2012), games in the classroom can increase problem-solving skills and engagement, but games should be aligned with the content. Games can include digital games, boardgames, card games, simulation games, word-hunt games, or custom-created games made by the teacher. By infusing games into the classroom, fun can be increased, and as a result, sense of belonging.

\section{Fitting in, But Embracing Difference: Being Included and Safety}

Practitioners must be mindful of creating a safe and inclusive environment for students. School staff must not tolerate peer harassment (National Association of the Advancement of Colored People [NAACP] Legal Defense and Education Fund \& 
National Women's Law Center [NWLC], 2014). Instead, staff must ensure that students treat each other respectfully (Anderman, 2003). Anderman's study results found that, "students who reported that their teachers did promote mutual respect among students in their classes also reported less negative change in school belonging over time than did their peers" (p. 17). The survey items within this study indicate how to create an environment of inclusion. The items in the survey included not allowing students to make fun of others' ideas or laugh at someone if they gave the wrong answer. Also, teachers should not allow students to speak negatively about one another. Instead, teachers should encourage students to listen to their peers and respect each other's ideas.

Additionally, teachers should co-construct safe spaces for African American female students so that their voices are honored. Butler (2018) categorizes safe spaces for African American female students as those in which "Black girls can thrive, make meaning, care for one another, and negotiate" (p.39). When developing this space, Brown (2013) suggests explicitly developing spaces for African American female students and letting them know the space is for them. These spaces should allow students to openly express themselves and not have to guard who they are (Muhammad, 2012). Morris (2016) suggests that safe spaces must be co-constructed, free of prejudice, judgment, and instead focus on fostering positive relationships between students and teachers. Like the workshop sessions in this dissertation study, these spaces can also be digital and multimodal (Butler, 2018). Morris (2016) provides concrete ways to create spaces by establishing collective agreements and utilizing ways to engage students through anonymous feedback or one-on-one conversations. Schoolwide town hall meetings, community hearings, listening sessions with school administrators, teachers, community 
leaders, and families can increase African American female voice and safety (Crenshaw, Nanda, \& Ocen, 2015). The voices from these platforms can be incorporated into schoolbased practices so that whole schools can become safe spaces for African American female students.

\section{Being Seen and Heard by Teachers}

Finally, practitioners must increase student visibility and voice within the classroom and in school communities to foster sense of belonging for African American female students. Participants discussed school staff respecting their voices and letting them speak their mind. One method of achieving this can be through allowing students to act as teachers. Ladson-Billings (1995) highlights a practice conducted in one of the classrooms she observed. The teacher began the year by asking the students an area in which they had expertise. Then, she created a list of experts and shared this with the class and established a day for each expert to share their expertise with the entire class. Furthermore, staff can incorporate ways for students to voice their opinions and ideas privately as well.

The participants within this study offer strategies to increase student visibility and voice within classrooms. First, Athena and Minerva both shared experiences where their raised hand would go ignored. As Morris (2016) writes, "to be ignored is traumatic" (p. 39). Ignoring student participation within the classroom may be due to implicit biases, stereotypes, or a lack of relationships with students. Educators must continuously reflect on their biases and how biases may impact African American female students in classrooms and schools. Common stereotypes of African American girls and women are that they are angry, aggressive, or hyper-sexual and these may shape educators' 
perceptions of their students (NAACP \& NWLC, 2014). The continuation of this will only diminish belonging for African American female students further. Staff must be intentional about acknowledging raised hands and recognizing all students. One participant even offers a strategy to accomplish this. Selene suggests using random name selection tools so that all students have a chance to answer questions. This strategy may reduce bias by having an exact procedure for providing students opportunities to participate in class.

Ultimately, practitioners must reflect on their own biases as to why particular students within particular classrooms have voice and visibility while other students do not. For example, half the participants in this dissertation study mentioned gym class within their digital stories as a site of belonging. Practitioners must reflect if they are creating spaces to highlight, develop, and celebrate African American female intellectualism and other qualities as much as they do athleticism. Practitioners must consider how their biases impact student outcomes by examining their classroom-level data. This includes both failure and success data alongside behavior referral data. These data points must be aggregated by race and gender at frequent intervals. This examination must be coupled with next steps and changes in practices.

\section{Implications for Policy}

Butler (2018) writes, "seeing Black girls is the first required action in activism for and with Black girls, as it then pushes toward hearing girls, believing girls, understanding Black Girl matters, and articulating why Black girls matter” (p. 40). Accordingly, policies should be designed in such a way as to ensure African American female students are visible and heard. Based on this dissertation study's contributions to our understanding of 
sense of belonging, lawmakers and educational leaders should consider three policy implications. The first implication is that within racial equity policies, sense of belonging must be explicitly addressed with concrete steps to foster sense of belonging. Within the Jefferson County Public School Racial Equity Policy (JCPS, 2018b), there is a component for making students and families feel welcome and respected. This component must be expanded upon to address sense of belonging explicitly. Policymakers should replicate and fund approaches to sense of belonging similar to the CARE model (Ricks, 2014). According to Ricks (2014), CARE (connection, awareness, retraining, and encouragement) is a systematic approach to protecting and supporting African American female students. The first component is connection, where school staff members work actively to develop relationships with African American female students. In order to prioritize connection, teacher and administrator evaluations and incentives should include components to measure growth in connections to African American female students. Connection may be measured through sense of belonging indicators within the Comprehensive School Survey. For awareness, training and professional development should be provided to raise awareness of African American female students' experiences and issues. This includes not just training veteran staff members, but also pre-service teachers and those who are new to the profession so that they can place the needs, desires, and experiences of African American female students on the forefront as they develop in their practice. The third component is retraining. Practitioners are retrained on how they view African American female students, leaving behind a deficit lens or bias. The last component is encouragement. In this component, African American female students are matched with mentors to support their growth. In 
addition to outside mentors, mentorship should also exist at the school level with increasing the recruitment and retention of African American female teachers so that schools are representative of their populations. While teaching is a female-dominated profession, most female educators are currently White females (Farinde, Allen, \& Lewis, 2016). According to Farinde et al. (2016), Black female teachers are essential not just as practitioners but also as, "role models for students, cultural translators, counselors, parental figures, and mentors who advocated for their students and gave a voice to the voiceless" (p.117). Thus, increasing the prevalence of African American female teachers in schools is valuable to student sense of belonging. The CARE model is suited for fostering sense of belonging. This model honors African American female student identity and increases the practitioner's pedagogical toolkits so that students are seen dynamically and authentically.

Furthermore, policymakers must address the intersectionality of race and gender. This is a key component of Critical Race Theory and is vital to understanding how multiple identity categories impact individuals' lived experiences. The JCPS Racial Equity Policy (JCPS, 2018b) also mentions intersectionality concerning raising student achievement, but not for sense of belonging. To address intersectionality, school districtlevel policies must explicitly address African American female students' voices, needs, and experiences. Patton, Crenshaw, Haynes, and Watson (2016) echo this notion when they write, "oftentimes, the challenges facing Black people and Black men and boys are treated as one in the same. As a result, an asymmetrical solidarity is perpetuated among Black people, relegating the lived experiences of Black women and girls to the margins" (p.194). Addressing intersectionality is not a call for the removal of African American 
male voices and needs in policies, but a request to make the voices and needs of African American females salient in policy discourse as well. Foregrounding African American females in school district-level policies includes dismantling policies that may decrease physical and socioemotional safety for African American females in school. For example, dress code policies that prohibit hairstyles worn by girls and women within the African diaspora should be examined and reconceptualized (Morris, 2016). Furthermore, discipline policies that further negative and stereotypical perspectives of African American female students as confrontational, loud, or assertive, must be reviewed and revisited (NAACP \& NWLC, 2014). Policies created to meet the needs and desires of African American female students should include their voices. Above all, African American females are agents of knowledge and can speak for themselves (Collins, 2009). Policymakers should request participation through focus groups, community forums, and public meetings during the development phases of policies (NAACP \& NWLC, 2014). Surveys can also be implemented to garner voice from those who may wish to participate outside of group or public spaces. Moreover, African American female students' voices should be garnered beyond the development phases to instill an ethic of school and districtwide accountability to students. Reporting measures that allow for anonymity should exist within each school for students to express any experiences with bias, discrimination, or stereotyping. I recommend that these measures be uniform throughout the district and made accessible through print and digital platforms to ensure faithful and consistent implementation. Afterward, restorative conversations, corrective action, and appropriate professional development should be held with pertinent stakeholders. These 
policy implications seek to instill ongoing practices that support African American female students and their experiences and voices.

Finally, concrete initiatives should be created that target the needs of African American female students. Like Obama's “My Brother's Keeper" initiative, there should be a well-funded and strategically designed initiative solely devoted to African American female students, their needs and their outcomes. According to My Brother's Keeper Second Anniversary Fact Sheet (2016), this includes cradle to graduation action plans, mentorships, summer jobs for girls, and a task force to gather data and future recommendations. However, there should be strategies specific to the gendered needs of female students. These include, but are not limited to, resources to support pregnant or parenting students, culturally relevant teen pregnancy prevention programs that do not shame young mothers (NAACP \& NWLC, 2014).

\section{Recommendations for Future Research}

While this research begins to shed light on African American female student experiences, there is still a need to continue research with and about Black girls. There are a few areas of interest that need to be considered for future research. For example, while this study focused on the intersectionality between race and gender, there are other identities that should be considered when conducting research on and with African American female students and their sense of belonging. Stefanic and Delgado (1995) write, "many races are divided along socioeconomic, political, religious, sexual orientation, and national origin lines each of which generates intersectional individuals," (p. 55). Thus, researchers should examine socio-economic class and beauty standards, such as skin tone and hair texture, to increase our understanding of what fosters or 
diminishes sense of belonging for African American female students. I recommend examining varying socio-economic backgrounds because of the experience Athena illuminated in which she felt her community was misrepresented as lower class by a teacher. I also recommend investigating beauty standards and sense of belonging. A constructed social hierarchy positions African American females with darker skin against African American females with Eurocentric features (Robinson-Moore, 2008). Because of the prevalence of this constructed social hierarchy in our society, there may be an impact on African American female students and their sense of belonging.

Moreover, one limitation of this study was the time in which the research was conducted. As noted in previous chapters, participants' schooling was disrupted due to a pandemic. It is recommended that another study seeking to replicate the methods used in this study be conducted during a typical school year or immediately after the close of a typical school year. During this research study, there was a period of heightened civil unrest, as evidenced by police shooting and Black Lives Matter demonstrations.

Historical events such as these have the capacity to shape adolescent outlooks in the short and long term (Gray et al., 2018). In this regard, comparing the findings with this study and similar subsequent studies may allow practitioners and researchers to add to their understanding of individual and collective African American female student experiences and perspectives on sense of belonging. Lastly, research conducted on and with African American female students should continue to utilize frameworks that address both race and gender.

It is also recommended that other sampling methods be used when replicating the methods in this study. A limitation of this study was that convenience sampling was 
utilized. This sampling style allowed for an eager participant pool from one site but may have excluded diverse perspectives on African American female students' sense of belonging. I recommend maximum variation sampling where sites and participants that are diverse, but based on specific characteristics are selected (Creswell \& Poth, 2018). Additionally, same or similar research questions and methods should also be utilized with different age groups given that past research indicates sense of belonging decreases as students matriculate through school (Anderman, 2003; Gillen-O’Neel \& Fuligni, 2013).

This dissertation study advances prior research on African American female students and their sense of belonging in schools. This research seeks to address the fact that African American females are superinvisible in research (Chavous \& Cogburn, 2007). Additional research still needs to be conducted to nourish a rich research agenda so to address what Crenshaw et al. (2015) call a, "knowledge desert that exists around the lives and experiences of Black women and girls" (p. 6). Researchers must continue to see African American students as worthy of study while learning from and with African American students (Ladson-Billings, 2014). It is recommended that future research also use methods and research designs, like the current study, that create an environment of co-learning so that research is not done to African American females, but with them.

There are additional research topics that should be explored to understand African American female student sense of belonging. Within the literature reviewed, there was a gap in research on sense of belonging and fun. Additional research should examine the relationship between these concepts for African American female students. Because the need for fun may be specific to younger students, researchers should question if the same emphasis is placed on fun and enjoyment for older African American female students. 
Moreover, this research found that safety increases sense of belonging. Future research on safety and sense of belonging should be conducted in which researchers aim to discover how safety at school is defined by African American girls and what practices increase or diminish their sense of safety.

\section{Conclusion}

It was recently brought to my attention that Rhea wants to be a school principal when she grows up. She told her teacher she loves school. This dissertation officially began three years ago when I worked at the district-level as a resource teacher. When I saw the sense of belonging data presented in Chapter 1 and the gap between African American female students and their peers, to be honest, it made me angry. For me, the data was not just numbers, those were my students. Years later, and now as an assistant principal, the data still shows a gap. Those numbers are still my students. I want Rhea's future aspirations to become a reality and I want her to always love school. In addition to being a site of learning and achievement, school should be a place of belonging. School should be a place where Rhea and all students are valued, accepted, included, and encouraged.

To ensure that all our students have a sense of belonging and love school, we must begin by listening. Within this research, six African American female students' voices were presented to develop an understanding of sense of belonging. Four findings emerged from the data collected. Those findings were honoring lived experiences, peer relationships, fitting in, but accepting differences, and being seen and heard by teachers. These findings support previous sense of belonging research on ethnic identity (Dotterer et al., 2009), peer relationships (Bouchard \& Berg, 2017), peer acceptance (Vaquera, 
2009), and student voice (Bouchard \& Berg, 2017). Still, we cannot stop at six voices. As one participant wrote in her Google Form response, "We could try to be like this at school because I think a lot of people feel and way we do." We must continue to hear the voices of African American female students. It is imperative that we consider school practices and how we conduct research to better support and understand African American female students. This begins with no longer accepting African American female invisibility. 


\section{REFERENCES}

Abdollahi, A. \& Noltemeyer, A. (2018) Academic hardiness: Mediator between sense of belonging to school and academic achievement? The Journal of Educational Research, (111)3, 345-351.

Acuff, J.B. (2018). Black Feminist Theory in 21st-century art education research. Studies in Arts Education, 59(3), 201-214.

Albanesi, C., Cicognani, E., \& Prati, G. (2018). In influence of school sense of community on students' well-being: A multilevel analysis. Journal of Community Psychology, 46(7), 917-924.

Anderman, L.H. (2003). Academic and social perceptions as predictors of change in middle school students' sense of school belonging. The Journal of Experimental Education, 72(1), 5-22.

Andrews, D.J., Brown, T., Castro, E., \& Id-Deen, E. (2019). The impossibility of being “Perfect and White”: Black girls' racialized and gendered schooling experiences. Review of American Educational Research Journal, 56(6), 2531-2572.

Baumeister, R. F., \& Leary, M. R. (1995). The need to belong: Desire for interpersonal attachments as a fundamental human motivation. Psychological Bulletin, 117(3), $497-529$.

Benmayor, R. (2012). Digital Testimonio as a signature Pedagogy for Latin@ studies. Equity \& Excellence in Education, 45 (3), 507-524. 
Black power salute. (2016). Free Press Journal, Retrieved fromhttp://echo.louisville.edu/login?url=https://search-proquestcom.echo.louisville.edu/docview/2289821152?accountid=14665

Boal, A. (2002). Games for actors and non-actors (2nd ed.). New York, NY: Routledge. Booker, K. C. (2007). Likeness, comfort, and tolerance: Examining African American adolescents' sense of school belonging. The Urban Review, 39(3), 301-317.

Boston, C., Warren, S. R., (2017). The effects of belonging and racial identity on urban African American high school students' achievement. Journal of Urban Learning, Teaching, and Research, 12, 26-33.

Bottiani, J. H., Bradshaw, C.P., Mendelson, T., (2017). A multilevel examination of racial disparities in high school discipline: Black and White adolescents' perceived equity, school belonging, and adjustment problems. Journal of Educational Psychology, 109(4), 532-545.

Bouchard, K. L., \& Berg, D. H. (2017) Students' school belonging: Juxtaposing the perspectives of teachers and students in the late elementary school years. School Community Journal, 27(1), 107-136.

Brown, R.N (2009). Black Girlhood Celebration: Toward a hip hop feminist pedagogy (Vol 5.). New York, NY: Peter Lang Publishing Inc.

Brown, R. N. (2013). Hear our truths: The creative potential of black girlhood. Chicago: University of Illinois Press.

Bryan, J., \& Henry, L. (2008). Strengths-based partnerships: A school-family-community partnership approach to empowering students. Professional School Counseling, 12(2), 149-156. 
Brydon-Miller, M. (1997). Participatory action research: Psychology and social change. Journal of Social Issues, 53(4), 657-666.

Bryson, B.J., \& Lawerence-Webb, C. (2000). Social work practice and profession: The utility of Black Feminist Thought. Race, Gender \& Class, 7(4), 1-10.

Brown v. Board of Education, 350 U.S. 483 (1954).

Butler, T. (2018). Black girl cartography: Black girlhood and place-making in education research. Review of Research in Education, 42(1), 28-45.

Byrd, C.M., \& Chavous, T.(2011). Racial identity, school racial climate, and school intrinsic motivation among African American youth: The importance of personcontext congruence. Journal of Research on Adolescence, 21(4), 849-860.

Capps, M. A. (2004). Teacher perceptions of middle school students' sense of belonging in Southeast Texas. Journal of Educational Research \& Policy Studies, 4(2), 120.

Cemalcilar, Z. (2010). Schools as socialization contexts: Understanding the impact of school climate factors on students' sense of belonging. Applied Psychology, 59(2), 243-272.

Center for Disease Control (2020). Frequently Asked Questions. Retrieved from https://www.cdc.gov/coronavirus/2019-ncov/faq.html\#Basics

Chavous, T., \& Cogburn, C.D. (2007). Superinvisible women: Black girls and women in education. Black Women, Gender, and Families, 1(2), 24-51.

Chenoweth, E. (2020). The future of nonviolent resistance. Journal of Democracy. 31(3), 69-84.

Collins, P.H (2009). Black feminist thought (2nd ed.). New York, NY: Routledge. 
Collins, P.H. (2015). No guarantees: Symposium on Black Feminist Thought. Ethnic and Racial Studies, 38(13), 2349-2354.

Covarrubias, R., \& Fryberg, S.A. (2014). The impact of self-relevant representations on school belonging for Native American students. Cultural Diversity and Ethnic Minority Psychology, 21(1), 10-18.

Crenshaw, K. (2014, July 29). The Girls Obama Forgot. The New York Times. Retrieved from https://www.nytimes.com/2014/07/30/opinion/Kimberl-WilliamsCrenshaw-My-Brothers-Keeper-Ignores-Young-Black-Women.html

Crenshaw, K. (1991). Mapping the margins: Intersectionality, identity politics, and violence against women of color. Stanford Law Review, 43(6), 1241-1299.

Crenshaw, K. W., Nanda, J., \& Ocen, P. (2015). Black girls matter: Pushed out, overpoliced and underprotected. Retrieved from $\underline{\text { http://static1.squarespace.com/static/53f20d90e4b0b80451158d8c/t/54d2d22ae4b }}$ 00c506cffe978/1423102506084/BlackGirlsMatter_Report.pdf

Creswell, J.W (2014). Research Design: Qualitative, quantitative and mixed methods approaches (4th ed.). Los Angeles, CA: Sage.

Creswell, J. W. \& Poth, C. (2018). Qualitative inquiry \& research design: Choosing among five approaches (4th ed.). Thousand Oaks, CA: Sage Publications.

Crouch, R., Keys, C.B., \& McMahon. S. D. (2014). Student-teacher relationships matter for school inclusion: School belonging, disability, and school transitions. Journal of Prevention \& Intervention in the Community, 42(1), 20-30.

de Jager, A., Fogarty, A., Tewson, A., Lennette, C., Boydell, K., (2017). Digital 
storytelling in research: A systematic review. The Qualitative Report, 22(10), p. 2548-2582.

Delgado, R., \& Stefancic, J. (1995). Critical race theory: The cutting edge. Philadelphia: Temple University Press.

Demanet, J., \& Van Houtte, M. (2012). School belonging and school misconduct: The differing role of teacher and peer attachment. Journal of Youth and Adolescence, $41,499-514$.

Doda, N., \& Knowles, T. (2008). Listening to the voices of young adolescents. Middle School Journal, 39(3), 26-33.

Dorn, E., Panier, F., Probst, N., \& Sarakatsannis, J. (2020, August). Back to school: A framework for remote and hybrid learning amid COVID-19. McKinsey Insights. Retrieved from https://www.mckinsey.com/industries/public-and-socialsector/our-insights/back-to-school-a-framework-for-remote-and-hybrid-learningamid-covid-19

Dotterer, A.M., McHale, S.M., \& Crouter, A. C.(2009). Sociocultural factors and school engagement among African American youth: The roles of racial discrimination, racial socialization, and ethnic identity. Applied Developmental Science, 13(2), 61-73.

Dwyer, S.C., \& Buckle, J.L. (2009). The space between: On being an insider-outsider in qualitative research. International Journal of Qualitative Methods, 8(1), 54-63.

Eglinton, K.A., Gubrium, A., \& Wexler, L. (2017). Digital Storytelling as Arts-Inspired Inquiry for Engaging, Understanding, and Supporting Indigenous Youth. International Journal of Education \& the Arts, 18(5). 
Essed, P. (1991). Understanding everyday racism: An interdisciplinary theory. Newbury Park, CA: Sage Publications.

Evans-Winters, V, \& Esposito, J. (2010). Other people's daughters: Critical race feminism and Black girls' education. Educational Foundations, 24(1-2), 11-24.

Every Student Succeeds Act of 2015, Pub. L. No. 114-95

Epstein, R., Blake, J.J., González, T., (2017). Girlhood interrupted: The erasure of Black girls' childhood. Georgetown Law, Center on Poverty and Inequality. Retrieved from https://www.law.georgetown.edu/poverty-inequality-center/wpcontent/uploads/sites/14/2017/08/girlhood-interrupted.pdf

Exec. Order No. 13506, (March 11, 2009). Retrieved from https://obamawhitehouse.archives.gov/the-press-office/executive-order-creatingwhite-house-council-women-and-girls

Fact Sheet: My Brother's Keeper Second Anniversary. (2016). WH.gov/MBK. Retrieved From https://obamawhitehouse.archives.gov/sites/whitehouse.gov/files/images/Blog/M BK\%20Year\%20Two\%20Fact\%20Sheet_FINAL.pdf

Faircloth, B. S., \& Hamm, J.V. (2005). Sense of belonging among high school students representing 4 ethnic groups. Journal of Youth and Adolescence, 34(4), 293-309.

Faircloth, B. S., \& Hamm, J.V. (2011). The dynamic reality of adolescent peer networks and sense of belonging. New Directions for Child and Adolescent Development, $57(1), 61-78$.

Farinde, A. A., Allen, A., \& Lewis, C. W. (2016). Retaining Black teachers: An 
examination of Black female teachers' intentions to remain in K-12 classrooms. Equity \& Excellence in Education, 49(1), 115-127.

Faust, P. B., Ennis, L. S., \& Hodge, W. M. (2014). The relationship between middle grade student belonging and middle grade student performance. Alabama Journal of Educational Leadership, 1, 43-54.

Fine, M. (1994) Working the hyphens: reinventing self and other in qualitative research. In: Denzin NK and Lincoln YS, Handbook of Qualitative Research. Thousand Oaks, CA: SAGE, 70-82.

Fordham, S. (1993). Those loud black girls: (Black) women, silence, and gender "passing" in the academy. Anthropology and Education Quarterly, 24(1), 3-32.

Furrer, C., \& Skinner, E. (2003). Sense of relatedness as a factor in children's academic engagement and performance. The American Psychological Association, 95(1), 148-162.

Garland, S. (2013). Divided We Fail. New Haven: Yale University Press

Gillen-O’Neel, C. \& Fuligni, A. (2013). A longitudinal study of school belonging and academic motivation across high school. Child Development, 84(2), 678-692.

Gonzales, N. A., Germán, M., Kim, S. Y., George, P., Fabrett, F. C., Millsap, R., \& Dumka, L. E. (2008). Mexican American adolescents' cultural orientation, externalizing behavior and academic engagement: The role of traditional cultural values. American Journal of Community Psychology, 41, 151-164.

Goodenow, C. (1993a). Classroom belonging among early adolescent students: Relationships to motivation and achievement. Journal of Early Adolescence, 13(1), 21-43. 
Goodenow, C. (1993b). The Psychological sense of school membership among adolescents: Scale development and educational correlates. Psychology in the Schools, 30, 79-90.

Goodenow, C., \& Grady, K. E., (1993). The relationship of school belonging and friends' values to academic motivation among urban adolescent students. The Journal of Experimental Education, 62(1), 60-71.

Gray, D.L, Hope, E.C., \& Matthews, J.S. (2018) Black and belonging at school: A case for interpersonal, instructional, and institutional opportunities structures. Educational Psychologist, 53(2), 97-113.

Greene, D.T. (2016). "We need more 'us' in schools!": Centering Black adolescent girls' literacy and language practices in online school spaces. The Journal of Negro Education, 85(3), 274-289.

Green. E.L., Walker, M., \& Shapiro, E. (2020, October 1). A battle for the souls of Black girls'. New York Times. Retrieved from https://www.nytimes.com/2020/10/01/us/politics/black-girls-schooldiscipline.html $^{\circ}$

Hagborg, W. (1998). An investigation of a brief measure of school membership. Adolescence, 33(130), 461-468.

Hagenauer, G., \& Hascher, H. (2015). Early adolescents' enjoyment experienced in learning situations at school and its relation to student achievement. Journal of Education and Training Studies, 2(2), 2324-8068.

Hall, B. L. (1992). From margins to center? The development and purpose of participatory research.The American Sociologist, 23(4), 15-28. 
Harris-Perry, M.V. (2011). Sister citizen:Shame, stereotypes, and Black women in America. New Haven: Yale University Press.

Haynes, C., Stewart, S., \& Allen, E. (2016). Three paths one struggle: Black women and girls battling invisibility in US classrooms. The Journal of Negro Education, 85(3), 380-391.

Hernandez, M.M., Robins, R.W., Widaman, K.F., \& Conger, R.D. (2017). Ethnic pride, self-esteem, and school belonging: A reciprocal analysis over time. Developmental Psychology. 53(12), 2384-2396.

hooks, b. (1991). Yearning: Race, gender, and cultural politics. In M. Eagleton (3rd ed.), Feminist Literary Theory: A Reader (p. 239-242). Oxford, UK: Blackwell.

Huyge, E., Van Maele, D., \& Van Houtte, M. (2015). Clarifying the implications of traditional gender role ideology for school belonging. Gender and Education. 27(1), 1-18.

Huynh, V.W., \& Gillen-O'Neel, C. (2016). Discrimination and sleep: The protective role of school belonging. Youth \& Society. 48(5), 649-672.

Hussar, B., Zhang, J., Hein, S., Wang, K., Roberts, A., Cui, J., Smith, M., Mann, F. B., Barmer, A., Dilig, R., Nachael, T., Barnett, M., \& Purcell, S. (2020). The Condition of Education 2020. U.S. Department of Education, National Center for Education Statistics. Washington, D.C.

Jefferson County Public Schools (2018a). Comprehensive School Survey. Retrieved from https://www.jefferson.kyschools.us/departments/data-managementresearch/comprehensive 
Jefferson County Public Schools (2018b). Envision Equity Report. Retrieved from https: assessment.jefferson.kyschools.us/DMC/EE/eeHome

Jefferson County Public Schools (2018c). Racial Equity Policy. Retrieved from https:// drive.google.com/file/d/1IOPfUiJHcb03tfX8iaxmRcBZA1DND8Vg/view

Johnson, L.P., (2015) The writing on the wall: Enacting place pedagogies in order to reimagine schooling for Black male youth. Discourse: Studies in the Cultural Politics of Education, 36(6), 908-919.

Jorrit Van, d. B., \& Visser-Maessen, L. (2019). Race matters: 1968 as living history in the Black freedom struggle. European Journal of American Studies, 14(1).

Kester, V.M. (1994). Factors that affect African-American students' bonding to middle school. The University of Chicago Press, 95 (1), 63-73.

Kobin, B., \& Loosemore, B. (2020, June). 'We've had enough!' 1,000-plus rally for justice for Breonna Taylor on her 27th birthday. USA Today. Retrieved from http://echo.louisville.edu/login?url=https://www-proquest$\underline{\text { com.echo.louisville.edu/docview/2409849055?accountid }=14665}$

Koh, E., Kin, Y. G., Wadhwa, B., \& Lim, J. (2012). Teacher perceptions of games in Singapore schools. Simulation \& Gaming, 43(1), 51-66.

Kreutzmann, M., Zander, L., \& Webster, G. D. (2017). Dance is belonging! How social networks mediate the effect of a dance intervention on students' sense of belonging to their classroom. European Journal of Social Psychology, 48, 240254.

Ladson-Billings, G. (1995). Toward a theory of culturally relevant pedagogy. American Educational Research Journal, 32(3), 465-491. 
Ladson-Billings, G. (1998). Just what is critical race theory and what's it doing in a nice field like education? International Journal of Qualitative Studies in Education, 11(1), 7-24.

Ladson-Billings, G. (2009). The dreamkeepers: Successful teachers of African American children. San Francisco, CA.: Jossey-Bass Publishers.

McGraw, K., Moore, S., Fuller, A., \& Bates, G. (2008). Family, peer and school connectedness in final year secondary school students. Australian Psychologist. 43(1), 27-37.

McTaggart, R. (1997). Participatory Action Research : International Contexts and Consequences. Albany, NY: SUNY Press.

Merriam, S.B., \& Tisdell, E.J. (2016). Qualitative Research: A guide to design and implementation. (4th ed.). San Francisco, CA: Jossey-Bass.

Morris, M.W. (2016). Protecting Black girls. Educational Leadership, 74(3), 49-53.

Morris, M.W. (2016) Pushout: The criminalization of Black girls in schools. New York: The New York Press.

Muhammad, G.E. (2010). Creating spaces for Black adolescent girls to "write it out!" Journal of Adolescent \& Adult Literacy, 56(3), p. 203-211.

Muhammad, M., Wallerstein, N., Sussman, A.L., Avila, M., Belone, L., \& Duran, B. (2015). Reflections on researcher identity and power: The impact of positionality on community based participatory research (CBPR) process and outcomes. Critical Sociology. 41(7-8), 1045-1063.

Murphy, P., \& Whitelegg, E. (2006). Girls and physics: Continuing barriers to 
"Belonging." Curriculum Journal, 17(3), 281-305.

National Association of the Advancement of Colored People Legal Defense and

Educational Fund, Inc. \& National Women's Law Center. (2014). Unlocking opportunity for African American girls: A call to action for educational equity.

New York, NY. Retrieved from

https://www.nwlc.org/sites/default/files/pdfs/unlocking_opportunity_for_african american girls final.pdf

National Center for Education Statistics (2016). Status and trends in the education of racial and ethnic groups. United States Department of Education, 1-169.

Nichols, S.L. (2006). Teachers' and students' beliefs about student belonging in one middle school author(s). The University of Chicago Press, 106(3), 255-271.

The No Child Left Behind Act of 2001, PL 107-110, sec. 1001, available at http://www.ed.gov/legislation/ESEA02/

Norris, A.N. (2012). Rural women, anti-poverty strategies, and Black Feminist Thought. Sociological Spectrum, 32(5), 449-461.

Nunn, N.M. (2018). Super-Girl: Strength and sadness in Black girlhood. Gender and Education, 30(2), 239-295.

Ogbu, J.U. (2004). Collective identity and burden of "Acting White” in Black history, community, and education. Urban Review, 36(1), 1-35.

Osterman, K.F. (2010). Teacher practice and students' sense of belonging. In T. Lovat, R. Toomey, \& N. Clement (Eds.), International Research Handbook on Values Education and Student Wellbeing (p. 239-260). University of Oxford, UK: 
Springer.https://books.google.com/books?id=tl WyTNtsL4C\&printsec=frontcove $\underline{\mathrm{r} \# \mathrm{v}=\text { onepage } \& \mathrm{q}=\text { osterman } \& \mathrm{f}=\mathrm{false}}$

Patton, L.D., Crenshaw, K., Haynes,C., \& Watson, T.N. (2016). Why we can't wait: (Re)examining the opportunities and challenges for Black women and girls in education. Journal of Negro Education. 85(3), 194-198.

Ricks, S. A. (2014). Failing through the cracks: Black girls and education. Interdisciplinary Journal of Teaching and Learning. 4(1), 10-21.

Robinson-Moore, C. (2008). Beauty standards reflect Eurocentric paradigms-so what? Skin color, identity, and Black female beauty.The Journal of Race \& Policy. 4(1), 66-85.

Roche, C., \& Kuperminc, G.P., (2012). Acculturative stress and school belonging among Latino Youth. Hispanic Journal of Behavioral Sciences. 34(1), 61-76.

Rolon-Dow, R. (2011). Race(ing) stories: Digital storytelling as a tool for critical race scholarship. Race, Ethnicity and Education. 14(2), 159-173.

Rossiter, M., \& Garcia, P. (2010). Digital storytelling: A new player on the narrative field. New Directions for Adult and Continuing Education. 126, 37-48.

Sadik, A. (2008). Digital storytelling: A meaningful technology-integrated approach for engaged student learning. Education Tech Research and Development, 56, 487506.

Saumure, K., \& Given, L.M. (2008). Convenience Sampling. In Given, L.M. (Eds.). The sage encyclopedia of qualitative research methods. Los Angeles, CA: Sage Publications.

Saldaña, J. (2016). The Coding Manual for Qualitative Researchers (3 rd ed.). London: 
SAGE.

Sanchez, B., Colon, Y., \& Esparza, P. (2005). The role of sense of belonging and gender in the academic adjustment of Latino adolescents. Journal of Youth and Adolescence, 34(6), 619-628.

Sharma, S. (2013). Black Twitter? Racial hashtags, networks and contagion. New Formations, 78(1) 46-64.

Shochet, I.M., Smith, C.L, Furlong, M.J., \& Homel, R. (2018).A prospective study investigating the impact of school belonging factors on negative affect in adolescents. Journal of Clinical Child \& Adolescents, 40(4), 586-595.

Shi, Q., \& Goings, R. (2018). What do African American ninth graders discuss during individual school counseling sessions? A national study. Professional School Counseling, 21(1), 1-9.

Singh, K., Chang,M., \& Dika, S. (2010). Ethnicity, self-concept, and school belonging: Effects on school engagement. Educational Research for Policy and Practice, 9, $149-175$.

Smalls, C., White, R., Chavous, T., \& Sellers, R. (2007). Racial ideological beliefs and racial discrimination experiences as predictors of academic engagement among African American adolescents. Journal of Black Psychology, 33(3), 299-330.

Smerdon, B.A. (2002). Students' perceptions of membership in their high school. Sociology of Education, 75(4), 287-305.

Smith. A.L. (2016). \#BlackWomenMatter: Neo-capital punishment ideology in the wake of state violence. The Journal of Negro Education, 85(3), 261-273.

St-Amand, J., Girard, S., \& Smith, J. (2017). Sense of belonging at school: Defining 
attributes, determinants, and sustaining strategies. IAFOR Journal of Education. 5(2), 105-119.

Stearns, E. (2002). No child left behind and the education achievement gap. policy briefs: Education reform. 2(5),1-4. Retrieved from http://echo.louisville.edu/login?url=https://www-proquestcom.echo.louisville.edu/docview/61991828?accountid=14665

Steward, K.D., \& Ivala, E. (2017). Silence, voice, and “other languages": Digital storytelling as a site for resistance and restoration in a South African higher education classroom. British Journal of Educational Technology, 48(5), 11641175

Taylor, U.Y. (1998). The Historical Evolution of Black Feminist Theory and Praxis. Journal of Black Studies, 29(2), 234-253.

Thomas-Moore, C., \& Day-Vines, N. (2010). Culturally competent collaboration: School counselor collaboration with African American families and communities. Professional School Counseling, 14(1), 53-63.

Tyler, T. R., \& Degoey, P. (1995). Collective restraint in social dilemmas: Procedural justice and social identification effects on support for authorities. Journal of Personality and Social Psychology, 69, 482-497.

U.S. Department of Education, Office for Civil Rights. (2014). Civil Rights Data. Retrieved from https://ocrdata.ed.gov/Downloads/CRDC-School-Discipline-Snapshot.pdf Uwah, C., McMahon, H.G., \& Furlow, C.F. (2008). School belonging, Educational 
aspirations, and academic self-efficacy among African American male high school students: Implications for school counselors. Professional School Counseling, 11(5), 296-305.

Vaquera, E. (2009). Friendships, educational engagement, and school belonging: Comparing Hispanic and White adolescents. Hispanic Journal of Behavioral Science, 31(4), 492-514.

Voelkl, K.E. (1997). Identification with school. American Journal of Education, 105(3), 294-318.

Walton, G., \& Cohen, G. (2007). A question of belonging: Race, social fit, and achievement. Journal of Personality and Social Psychology, 92, 82-96.

Watts, S.J., Province, K., \& Toohy, K. (2019). The kids aren't alright: School attachment, depressive symptoms, and gun carrying at school. American Journal of Criminal Justice, 44, 146-165.

Wegmann, K.M. (2017). Measuring social support and school belonging in Black/African American and white children. Research on Social Work Practice, 27(5), 582-593. 


\section{APPENDICES}

\section{APPENDIX A}

\section{Site Selection Letter to Principal}

Dear Dr. April Brooks,

I would like to request permission to conduct a study at Georgia Davis Powers Middle School, entitled "What fosters a sense of belonging for African American female students?" The study's purpose is to obtain information on what increases sense of belonging for African American female students. This research is being done because currently, African American female students have a lower sense of belonging than other groups across the district. The goal of this research is to share what increases sense of belonging to better serve all our students.

The study will collect data via digital stories that will be created by participants over the course of five workshops. All 6th grade African American female students are invited to participate in this research study. Additional data sources will include surveys, semi-structured reflective questions, drafts, workshop recordings, field notes, etc.

Participant confidentiality will be safeguarded through the following measures:

- Digital stories are secured through password protected computers and WeVideo, the tool for creating digital stories, is also password protected.

- All print materials will be secured in locked cabinets and only accessible to the researcher.

- Each participant will be assigned a pseudonym to maintain confidentiality within the research study.

- During one of the workshop sessions, confidentiality will be reviewed so that digital stories also do not include participant identifiers.

Participation is voluntary and will be sanctioned by both the University of Louisville and Jefferson County Public Schools Institutional Review Boards before being conducted. Materials and activities used during the workshop sessions are attached for 
your review. After the study, I would be happy to share the results with you or any members of the faculty. If you have any questions or concerns about any of the materials or in general, please let me know. If you agree to allow me to conduct this study, please sign in the space provided below.

Sincerely,

Rajwinder Kaur

I grant permission for Rajwinder Kaur to conduct the following study:

Signature

Printed Name

Co-investigator signature

Date Signed 


\section{APPENDIX B}

\section{Consent Form}

\section{INFORMED CONSENT}

What fosters a sense of belonging for African American female students? An arts-based research Digital storytelling study.

\section{Summary Information}

This study seeks to discover what fosters a sense of belonging for African American
female students in K-12 settings. This study uses an emergent, arts-based methodology:
digital storytelling. Digital stories are created by the participants during five workshops.
The purpose of this study is to gather information on what increases sense of belonging
for African American female students. All 6th grade African American female students at
Georgia Davis Powers Middle School are invited to participate in this research study.
This study is workshop style; the students will learn how to develop digital stories and
share what increases their sense of belonging.
This research is being done because currently African American female students have
lower sense of belonging than other groups across the district. The goal of this research is
to share what increases sense of belonging to better serve our students. The approximate
number of subjects in this study is 12 participants. However, should more participants
seek to join, their participation is welcomed.
Participants in this study will attend five workshops. Each workshop will be held
throughout the spring semester at Georgia Davis Powers Middle School or virtually
through Google Classroom. The study may continue beyond the end of school date of
May 27 th, with a possibility of concluding in mid-June.
Workshop dates are subject to change depending on the weather and participants' needs.
The public viewing session will be off-site. More information will be provided once a
final location has been confirmed. Participants are not required to attend the public
viewing.


There are risks to this study that are described in this document. There are minimal risks and discomforts involved in this study. However, these include:

* Arranging transportation to and from the site on workshop days (for in person meetings)

* Participants may feel some discomfort answering reflective questions and during activities about their sense of belonging to school.

* Furthermore, Rajwinder Kaur, the co-investigator conducting this study, also serves as the assistant principal at Georgia Davis Powers Middle School. Your child's participation in this study will not have any changes in standing, grades, discipline, etc. at Georgia Davis Powers Middle School for participating in this study. Ms. Kaur will function solely as a researcher during workshop sessions. However, if your child reveals information that has potential risks (i.e. bullying), Ms. Kaur will investigate with due diligence.

* While every attempt will be made to minimize risks, unforeseeable risks may arise.

This research is emergent in design, alternatives to procedures are welcomed. Participants can provide alternatives and present their perspective throughout workshops. Again, participation is voluntary and can be discontinued at any time during the study.

\section{Introduction and Background Information}

Your child is invited to take part in a research study because your child's perspective will help us understand what furthers sense of belonging for African American female students in K-12 settings. The study is being conducted under the direction of Dr. Mary Brydon Miller Ph.D. and Ms. Rajwinder Kaur at the University of Louisville. This study aims to answer the following research questions:

1. According to students, what contributes to a positive African American female sense of belonging in school?

What staff interactions and practices contribute to a positive sense of belonging? How can peer relationships be harnessed or developed to increase sense of belonging? What elements of the school environment increase a positive sense of belonging?

2. According to students, what diminishes African American female sense of belonging in school?

What staff interactions and practices diminish sense of belonging?

To what extent do peer relationships in school impact sense of belonging?

What elements of the school environment diminish sense of belonging?

Taking part in this study is entirely voluntary. That means that your child is not obligated to participate in this research. We urge you to discuss any questions you may 
have about this study with our staff members before agreeing to participate. Take your time to make your decision. If you decide to allow your child to participate, you and your child must sign this form to show that your child can participate.

\section{Purpose}

The purpose of this study is to gather information on what increases sense of belonging for African American female students. All 6th grade African American female students at Georgia Davis Powers Middle School. School are invited to participate in this research study. This study is workshop style; the students will learn how to develop digital stories and share what increases their sense of belonging. Jefferson County Public School data shows that African American female students have one of the lowest sense of belonging rates at the elementary, middle, and high school levels. Sense of belonging also decreases as students move from elementary through high school. This study hopes to find ways to increase sense of belonging for African American female students by listening and learning from their perspective and experiences. The approximate number of subjects in this study is 12 participants. However, should more participants seek to join, their participation is welcomed.

\section{Procedures}

This research study will be workshop style with a total of 5 workshop sessions, sessions may be virtual or in person. Virtual Sessions will be conducted through Google Classroom and Google Meets in a closed classroom where only participants of the study will be included. Any in person sessions will be conducted at Georgia Davis Powers Middle School. In each session, participants will work towards developing their digital story. Workshops will also include icebreakers and other activities. Workshops follow an emergent design so activities can change based on participant interests and needs. In these workshops, participants will also learn how to use WeVideo, a web-based platform for creating short videos. WeVideo will also keep drafts of the digital stories and other pictures, clips, or sounds needed to make the stories. The researcher will be facilitating this training, as well as other brief tutorials on acceptable use images, confidentiality, etc. Additionally, workshops will include icebreakers, reflective writings, surveys, and activities surrounding sense of belonging. Participants can decline to participate in activities that may make them uncomfortable. Participants may use other video creating technologies as well. The reflective writings will be used to have participants think about their sense of belonging at school. The surveys will give pre and post information on the participants sense of belonging to see any change in sense of belonging due to the study. Icebreakers will create a sense of community among the participants who can choose to collaborate on their digital stories. 
The participants will also have the option of having their digital story viewed by a public audience consisting of JCPS staff, students, and families. The purpose for this public viewing is for JCPS staff to gain strategies to increase African American female student sense of belonging.

The research results will be shared with you through a public viewing session. Results of the overall research study will be shared with you at this session. This session is open to Jefferson County families and staff so that results can impact current practices, but also to maintain the confidentiality of the participants. The digital stories will be shared at an off-site location at the start of the 2020-2021 school year. This will be revealed as we get closer to the date and a location and time is finalized.

Your child's data will not be stored and shared for future research even if identifiable private information, such as their name is removed. Data will be destroyed at the three year mark, according to IRB stipulations. The consent, assent, forms, and other documents related to the research study will be shredded. Recordings of workshop sessions will be deleted from devices and Google Drive. Finally, the WeVideo account used to create digital stories will be permanently deleted, thus deleting the stories and all other data on the account.

Timeline of the Study

If you agree to allow your child to take part in this study, their involvement will last approximately one week . Each workshop will be no more than 1 hour long hours long. Workshops sessions will take place at Georgia Davis Powers Middle School or virtually through Google Classroom and Google Meets. Workshops may continue after May 27th, but no later than mid-June.

Each workshop will be no more than an hour long. The surveys may take upwards of 10 minutes and individual activities may take upwards to half an hour, with most of the time devoted to draft, creating, finalizing, and coding digital stories. After a viewing of all the completed digital stories, participants will also code digital stories into themes. All sessions will be audio and video recorded; these recordings will only be viewed by the researcher.

It is not anticipated that the research study will be terminated, but in the event that unforeseen circumstances arise, participants and families will be made aware in writing of the termination of the study.

\section{Potential Risks}

The potential risk for participants is minimal. The participants are not mandated to participate in this study. They may feel some discomfort answering reflective questions about their sense of belonging to school. However, the process is confidential 
and participants are advised that they can stop the participation at any time. During the initial session, the co-investigator will also review maintaining the confidentiality of the other participants in the study and later, in the sessions, there will be information on how to maintain confidentiality in Digital stories. The public viewing is an open event to JCPS staff, students, and families; therefore, again protecting participant confidentiality. There are no foreseeable risks other than possible discomfort in answering questions. However, there may also be unforeseen risks.

- Furthermore, Rajwinder Kaur, the co-investigator conducting this study, also serves as the assistant principal at Georgia Davis Powers Middle School. Your child's participation in this study will not have any changes in standing, grades, discipline, etc. at Georgia Davis Powers Middle School for participating in this study. Ms. Kaur will function solely as a researcher during workshop sessions. However, if your child reveals information that has potential risks (i.e. bullying), Ms. Kaur will investigate with due diligence.

- While every attempt will be made to minimize risks, unforeseeable risks may arise.

Benefits

The potential benefits outweigh the potential risks in that participants will have an opportunity to gain a new skill: learning how to use WeVideo and how to create digital stories. In addition, participants may be better equipped to work collaboratively and develop relationships with one another during this process. These relationships may extend beyond the workshop sessions and may then positively impact their sense of belonging to school. Also, your child may not benefit personally by participating in this study. The information collected may not benefit your child directly; however, the information may be helpful to others.

The results of this research may guide future programs and practices in JCPS. The public viewing will allow for JCPS staff to view the digital stories. From the digital stories, the audience will gain insight into what fosters sense of belonging for African American female students. Then, these strategies can be implemented into the classroom and at schools. Additionally, direct results of the research study will be disclosed to participants and their families through the public viewing session and through written communication (as needed).

\section{Alternatives}

Taking part in this research study is voluntary. If your child chooses to take part in this research, their major responsibilities will include:

- Attending workshop sessions

- Maintaining confidentiality of the other participants 
This research is emergent in design, alternatives to procedures are welcomed. Participants can provide alternatives and present their perspective throughout workshops. The alternative to participating is that you can choose not to participate

Payment

You or your child will not be paid for your/their time, inconvenience, or expenses while your child is in this study.

Confidentiality

Total privacy cannot be guaranteed. We will protect your privacy to the extent permitted by law. If the results from this study are published, your child's name will not be made public. Once your child's information leaves our institution, we cannot promise that others will keep it private.

Your child's information may be shared with the following:

- Organizations that provide funding at any time for the conduct of the research.

- The University of Louisville Institutional Review Board, Human Subjects Protection Program Office, Privacy Office, others involved in research administration and research and legal compliance at the University, and others contracted by the University for ensuring human participants safety or research and legal compliance

- The local research team

- People responsible for billing, sending and receiving payments related to your participation in the study

- Applicable government agencies, such as:

- Office for Human Research Protections

- The JCPS Institutional Review Board.

Some of these records could contain information that personally identifies your

child. Reasonable efforts will be made to keep the personal information in the research record private and confidential but absolute confidentiality cannot be guaranteed.

If during the course of the study, your child discloses allegations of abuse or neglect, the researchers are legally obligated by Kentucky law to report those allegations to the Kentucky Cabinet for Health and Family Services

\section{Security}

The research records that are reviewed, stored, and analyzed Georgia Davis Powers Middle School and will be kept in a secured area or on secure virtual platforms, like Google Drive. Digital stories are secured through password protected computers and WeVideo, the tool for creating digital stories, is also password protected. All print materials will be secured in locked cabinets and only accessible to the researcher. Additionally, each participant will be assigned a pseudonym to maintain confidentiality within the research study. During one of the workshop sessions, confidentiality will be 
reviewed so that digital stories also do not include participant identifiers. The list that matches your child's name to their pseudonym will be kept in a locked file cabinet in the researcher's office.

Recordings of the workshop sessions will be kept on a password protected iPad and on Google Drive, which is also password protected. These recordings will only be reviewed by the researcher. The researcher will use the recordings to supplement notes on sense of belonging and as an additional source of data.

In the event of any publication resulting from the research, no personally identifiable information will be shared. At the public viewing of the digital stories, no personally identifiable information will be shared.

\section{Voluntary Participation}

Taking part in this study is completely voluntary. Your child may choose not to take part at all. If your child decides not to be in this study, you or your child won't be penalized or lose any benefits for which you or your child may qualify. If you and your child decide to be in this study, you or your child may change your mind and stop taking part at any time. For example, you and your child may withdraw from the study if you choose to after the close of the school year, May 27th. If you choose to withdraw, you may decide and confirm with the co-investigator if you allow your child's work to be included in the study. If you or your child decide to stop taking part, you and your child won't be penalized or lose any benefits for which you qualify. You and your child will be told about any new information learned during the study that could affect your decision or your child's decision to continue in the study. The activities, workshops, and digital stories produced in this study are not required a part of Jefferson County Public Schools Non-Traditional Instruction and is not required.

\section{Research Participant's Rights}

If you have any questions about your rights as a research participant, you may call the Human Subjects Protection Program Office at (502) 852-5188. You may discuss any questions about your rights as a research participant, in private, with a member of the Institutional Review Board (IRB). You may also call this number if you have other questions about the research, and you cannot reach the study doctor, or want to talk to someone else. The IRB is an independent committee made up of people from the University community, staff of the institutions, as well as people from the community not connected with these institutions. The IRB has approved the participation of human participants in this research study.

Costs For Participation 
There are no expected costs for participation in this research in addition to transportation to the Georgia Davis Powers Middle School on workshop dates. You will not lose any legal rights by signing this form.

Compensation for Participation

Your child will not receive any compensation for being in this research study.

Research Funding

There are no grants associated to this research.

Questions, Concerns and Complaints

If you have any questions about the research study, please contact mary.brydonmiller@louisville.edu or by phone at (502) 852-6887. If you have questions, complaints, or concerns or believe you may have developed an issue related to this research, contact Rajwinder Kaur at rajwinder.kaur@jefferson.kyschools.us.

If you have concerns or complaints about the research or research staff and you do not wish to give your name, you may call the toll free number 1-877-852-1167. This is a 24 hour hot line answered by people who do not work at the University of Louisville.

This research study has been approved by JCPS and University of Louisville Institutional Review Board. If you have questions regarding your child's rights as a research participant or you have concerns or general questions about the research, you may also call the JCPS IRB Chairperson at (502) 485-3036 if you cannot reach the research team or wish to talk to someone else. For more information about participation in a research study and about your institutional review board (IRB), which is a group of people who review the research to protect your rights, please visit the JCPS IRB's website. You can access more information about your rights as a participant and the protection of human research participants here. If you do not have access to the Internet, copies of these Federal regulations are available by calling JCPS at 502-485-3036.

\section{Acknowledgment and Signatures}

This document tells you what will happen during the study if you choose to take part. Your signature and date indicates that this study has been explained to you, that your questions have been answered, and that you agree to take part in the study. You are not giving up any legal rights to which you are entitled by signing this informed consent document though you are providing your authorization as outlined in this informed consent document. You will be given a copy of this consent form to keep for your records.

Participant Name (Please Print)

Signature of Participant 
Date Signed

Printed Name of Legally

Authorized Representative (if applicable)

Signature of Legally

Authorized Representative

Date Signed

Authority of Legally Authorized Representative to act on behalf of Participant*

*Authority to act on behalf of another includes, but is not limited to parent, guardian, or durable power of attorney for health care.

Printed Name of Investigator (PI, Sub-I, or Co-I)

Signature of Investigator (PI, Sub-I, or Co-I)

Date Signed

Phone number for participants to call for questions:

Primary Investigator: Dr. Mary Brydon-Miller Ph.D.

Department of Educational Leadership, Evaluation and Organizational Development

Room 314 - College of Education

1905 S 1st St, Louisville, KY 40208

502-852-6887 mary.brydon-miller@louisville.edu

Co-Investigator: Rajwinder Kaur

Assistant Principal

502-485-8277x2681 rajwinder.kaur@jefferson.kyschools.us

Site(s) where study is to be conducted: Jefferson County Public Schools, 3332 Newburg Road Louisville, KY 40218 


\title{
APPENDIX C
}

\begin{abstract}
Assent Form
What fosters a sense of belonging for African American female students? An arts-based research Digital storytelling study.

I am invited to be in a research study being done by Professor Mary Brydon-Miller and Rajwinder Kaur. When a person is in a research study, they are called a "subject". I am invited because I am an African American female student. This study wants to learn more about what makes me feel like I belong in school.
\end{abstract}

This means that I will attend five workshops and in those workshops I will be creating and coding digital stories. These digital stories tell the viewer what makes me feel like I belong at school. There may be some risks with this study. These risks are: I may feel uncomfortable answering some of the questions or in some of the activities.

This study will last about a week and will meet five times. If you agree to take part in this research, you will come to Georgia Davis Powers Middle School or workshops will be held on Google Classroom during the spring semester. Workshops may take place after May 27th. The benefit to me for participating in this study is learning a new skill and getting to know others who are also in the study.

My family, the professor, and Ms. Kaur (my assistant principal), and other participants will know that I'm in the study. If anyone else is given information about me, they will not know my name. A number, pseudonym, or initials will be used instead of my name.

I have been told about this study and know why it is being done and what I have to do. My parent(s) have agreed to let me be in the study. If I have any questions I can ask Professor Mary Brydon-Miller and Rajwinder Kaur. They will answer my questions. If I do not want to be in this study or I want to quit after I am already in this study, I can tell the researcher and she will discuss this with my parents.

Printed Name of Subject

Signature of Subject

Date Signed 
Printed Name of Parent/Guardian

Printed Name of Investigator

Signature of Investigator

Date Signed 


\section{APPENDIX D}

\section{Accompaniment}

\section{For Research Participants}

Dear $6^{\text {th }}$ Grade students,

This is Ms. Kaur. As you know I am the $6^{\text {th }}$ grade Assistant Principal at Georgia Davis Powers Middle School. I am also working on my doctorate at the University of Louisville. I am writing to invite you to participate in my research study on African American female student belonging (feeling respected, valued, and listened to in school). In this study you will be making a digital story. A digital story is a short video those in the study would create that tells a story on your school belonging. I want to learn from you and hear what you have to say on this topic.

If you decide to take part in this study, you will join the study's Google Classroom. On this Google Classroom you will work towards creating a digital story with others who are in the study. We will have icebreakers and also look into school belonging in other ways.

This is completely voluntary so you can choose to be in the study or not. I have attached a flyer to this email with more information. If you'd like to participate, just email me back or call me at 502-966-7428. If you have any questions about the study, please email or contact me at 502-966-7428. I

Thank you very much.

Best,

Ms. Kaur

\section{For Parents and Guardians}

Dear Georgia Davis Powers Middle School Parents and Guardians,

This is Ms. Kaur. As you know I am the $6^{\text {th }}$ grade Assistant Principal at Georgia Davis Powers Middle School. I am also working on my doctorate at the University of Louisville. I am writing to invite your child to participate in a research study on African American female student belonging (feeling respected, valued, and listened to in school). In this study they will be making a digital story. A digital story is a short video those in the study would create that tells a story on their school belonging. I want to learn from them and hear what they have to say on this topic. 
If you decide to allow your child to part in this study, you will join the study's Google Classroom. On this Google Classroom they will work towards creating a digital story with others who are in the study. We will have icebreakers and also look into school belonging in other ways.

This is completely voluntary so you can choose to have your child be in the study or not. I have attached a flyer to this email with more information. If you would like your child to participate or if you have any questions about the study, please email or contact me at 502-966-7428.

Thank you very much.

Best,

Ms. Kaur 


\section{APPENDIX E}

\section{Recruitment Flyer}

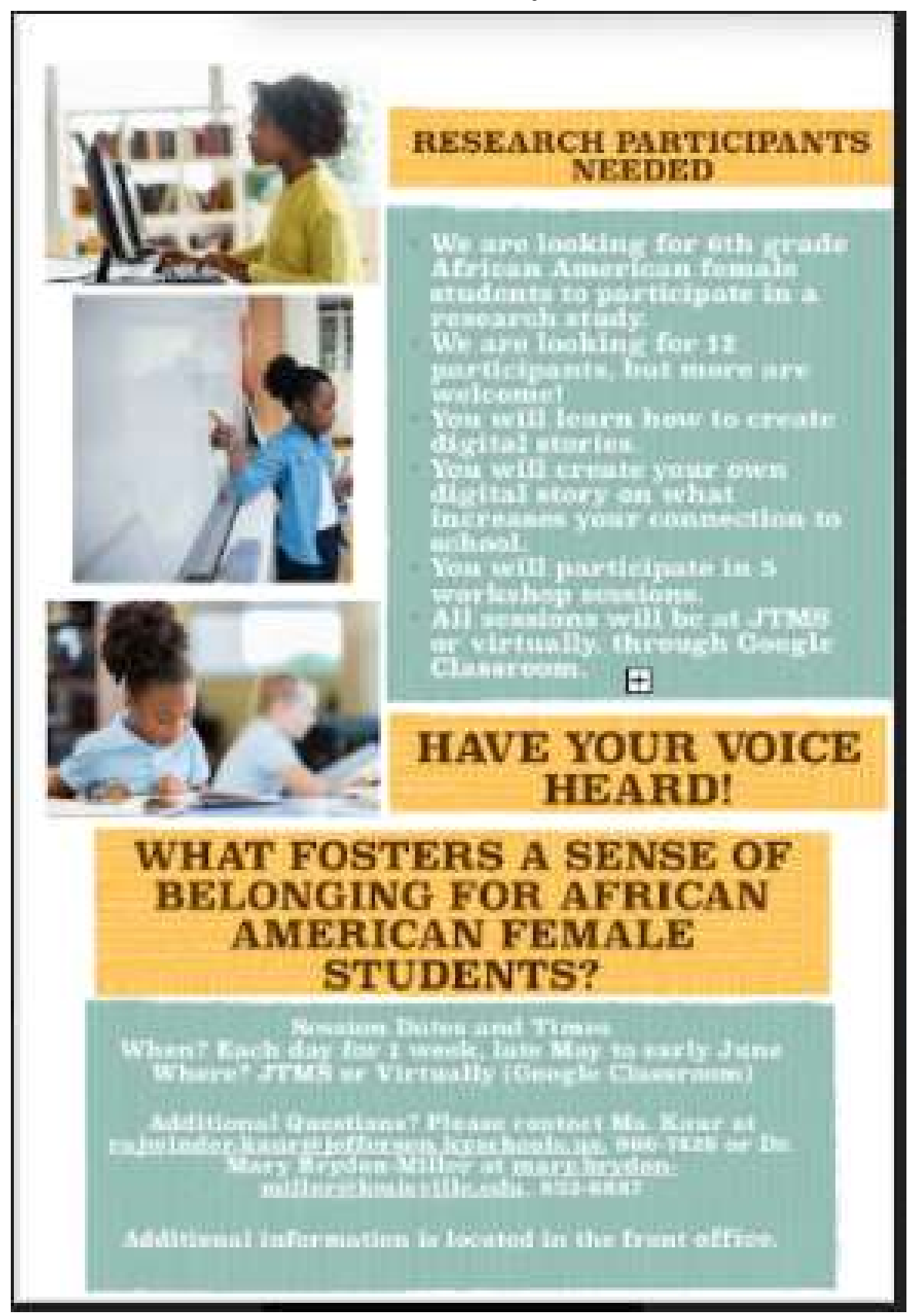




\section{APPENDIX F}

Workshop Session Breakdown

Workshop 1: Discussion of paperwork, explanation of workshops, Consent and assent paperwork, icebreakers and sense of belonging introduction.

Workshop 2: Digital stories draft, reflective writing, and icebreakers.

Workshop 3: Icebreakers, using WeVideo and starting Digital Stories

Workshop 4: Icebreakers, creating and reflecting on digital stories. Finishing digital stores, coding with participants.

Workshop 5: Finishing up, debrief with students, reflection, and next steps for public viewing.

*Activities are subject to change depending on participant's skill level and need.

** Dates are subject to change due to any inclement weather. 


\section{APPENDIX G \\ PSSM Adapted Sense of School Membership Scale}

For each of the following statements, circle whether you feel like this is "Never,"

"Sometimes," or "Always" true for you. This is adapted from Goodenow's (1993) PSSM

survey.

\begin{tabular}{|c|l|l|l|l|}
\hline 1. I feel like a real part of GDPMS. & Never & Sometimes & Always \\
\hline 2. People at GDPMS notice when I'm good at something. & Never & Sometimes & Always \\
\hline 3. It is hard for people like me to be accepted at GDPMS. & Never & Sometimes & Always \\
\hline 4. Other students at GDPMS take my opinions seriously. & Never & Sometimes & Always \\
\hline $\begin{array}{l}\text { 5. } \text { Most teachers and staff at GDPMS are interested in } \\
\text { me. }\end{array}$ & Never & Sometimes & Always \\
\hline 6. Sometimes I feel as if I don't belong at GDPMS. & Never & Sometimes & Always \\
\hline 7. There's at least one teacher or staff member at GDPMS & Never & Sometimes & Always \\
\hline 8. $\quad$ People at GDPMS are friendly to me. & Never & Sometimes & Always \\
\hline 9. Teachers and staff at GDPMS are not interested in & Never & Sometimes & Always \\
\hline students like me. & I am included in lots of activities at GDPMS. & Never & Sometimes & Always \\
\hline 11. I am treated with as much respect as other students. & Never & Sometimes & Always \\
\hline 12. I feel very different from most other students at & Never & Sometimes & Always \\
\hline GDPMS. & 13. I can really be myself at GDPMS. & Never & Sometimes & Always \\
\hline 14. The teachers and school staff at GDPMS respect me. & Never & Sometimes & Always \\
\hline 15. People at GDPMS know I can do good work. & Sometimes & Always \\
\hline 16. I wish I were at a different school. & Never & Sometimes & Always \\
\hline 17. I feel proud of belonging to GDPMS. & Other students here at GDPMS like me the way I am. & Never & Sometimes & Always \\
\hline 18. & Always \\
\hline
\end{tabular}




\section{APPENDIX H}

What I see, What I hear

Draft your digital story. Think about the images and sounds you will hear and see during your digital story and jot down your ideas below.

\begin{tabular}{|l|l|l|}
\hline Time & What I See & What I Hear \\
\hline 10 seconds & & \\
30 seconds & & \\
40 seconds & & \\
50 seconds & & \\
1 minute, 10 seconds & & \\
1 minute, 20 seconds & & \\
1 minute, 50 seconds & & \\
\end{tabular}




\section{APPENDIX I}

\section{Semi-Structured Reflective Questions}

- Describe a time you felt at home at GDPMS.

- How do you know when your voice is honored or respected in a class?

$\circ$ What can the teacher or school staff say and do to make you feel more honored or respected?

- How does your friend group add to your sense of belonging here at GDPMS?

- How can increasing your connectedness to students at the school make your time at GDPMS better?

- If you could change one thing about school to make you feel more like you belong, what would you change and why?

- Think about your day to day at school, from the time you come into the school building to the time you leave. Walk through the day in your mind. At what parts of the day do you feel the most connected to the school and others? Why?

- Think about your day to day at school, from the time you come into the school building to the time you leave. Walk through the day in your mind. At what parts of the day do you feel the most disconnected? Why? 


\section{APPENDIX J}

\section{Google Form}

Other Thoughts on the Study and Sense of Belonging

Here are the big themes (topics that came up a lot) that I noticed from our sessions, your videos, reflective questions, etc.) that are important to knowing more about African American female students sense of belonging.

I am still in the process of writing things, but I also wanted your thoughts on what I have and next steps.

1. Do you agree with these themes? 1. Honoring students' experiences (Black Pride) 2) Classmate groupwork and support 3) Having fun at school 4) Fitting in, but accepting differences 5) Being seen by teachers

2. Is there another theme we may need to add to better understand African American female sense of belonging at school? 1. Honoring students' experiences (Black Pride) 2) Classmate groupwork and support 3) Having fun at school 4) Fitting in, but accepting differences 5) Being seen by teachers

3. Other thoughts on these themes? 1. Honoring students' experiences (Black Pride) 2) Classmate groupwork and support 3) Having fun at school 4) Fitting in, but accepting differences 5) Being seen by teachers

4. How do you think we should move forward with once we have the results and with the information learned from this study? 


\section{CURRICULUM VITAE}

Rajwinder Kaur

rajwinder.kaur@jefferson.kyschools.us

(502) 966-7428

\section{EDUCATION}

Doctorate, Education Leadership and Organizational Development

August 2017 - Present University of Louisville

Educational Specialist Degree in Instructional Leadership

May 2014 - July 2015

Bellarmine University

Master of Arts in Teaching: English Language Arts

June 2011 - May $2013 \quad$ University of Louisville

Bachelor of Arts in Film \& Media Culture and Political Science

September 2007 - May $2011 \quad$ Middlebury College

\section{PROFESSIONAL EXPERIENCE}

Assistant Principal

October 2018 - Present Johnson Middle Traditional School

Evaluate teachers/classified staff, and developing instructional programs

Developing physically and socioemotionally safe structures for learners

Analyzing data and using feedback to support present and future initiatives

Equity Committee Co-Chair

Chair Team Leader, Department Chair, and other meetings as needed

Develop teacher training programs and professional development

Recruiting new staff members

Resource Teacher

May 2018 - October 2018 Diversity, Equity, Poverty Programs

Assisting school administrators with developing Racial Equity Plans

Providing and designing professional development on Cultural Proficiency

Analyzing data to support school building leaders

English Language Arts Teacher

June 2013 - May $2018 \quad$ Ramsey Middle School

Differentiated instruction for diverse learners using data

Kentucky Teacher Internship Program Resource Teacher

Interdisciplinary Team Leader and Professional Learning Community Lead 
School-Based Decision Making council member English Language Arts Teacher June 2011 - June 2013 T.T. Knight Middle School

Attended PEAK (Performance Excellence for All Kids) training

Cultural Competence Committee member

\section{OTHER}

2019 Presenter at the JCPS Equity Institute on Anti-Bias Pedagogy

2018 Educators of Color Outstanding Middle School Educator

2017 Presenter at the JCPS Equity Institute on Storytelling in the Classroom

2017 Attended Middlebury College Breadloaf School of English

2015 Completed Action Research Project on the Effectiveness of Intervention Classes

2011 Teach Kentucky Fellow 